\title{
In Silico Analysis of Bioactive Peptides in Invasive Sea Grass Halophila stipulacea
}

\author{
Cagin Kandemir-Cavas ${ }^{1}$, Horacio Pérez-Sanchez ${ }^{2, *(\mathbb{D},}$, Nazli Mert-Ozupek ${ }^{3}$ and \\ Levent Cavas ${ }^{4, *}$ (D)
}

1 Department of Computer Science, Faculty of Science, Dokuz Eylül University, İzmir 35390, Turkey; cagin.kandemir@deu.edu.tr

2 Bioinformatics and High Performance Computing Research Group (BIO-HPC), Computer Engineering Department, Universidad Católica de Murcia (UCAM), 30107 Murcia, Spain

3 Institute of Oncology, Dokuz Eylül University, İzmir 35320, Turkey; nazlimert@hotmail.com.tr

4 Department of Chemistry, Faculty of Science, Dokuz Eylül University, İzmir 35390, Turkey

* Correspondence: hperez@ucam.edu (H.P.-S.); levent.cavas@deu.edu.tr (L.C.); Tel.: +34-968-278-819 (H.P.-S.); +90-232-301-8701 (L.C.)

Academic Editor: Ka-Chun Wong

Received: 4 April 2019; Accepted: 30 May 2019; Published: 7 June 2019

\begin{abstract}
Halophila stipulacea is a well-known invasive marine sea grass in the Mediterranean Sea. Having been introduced into the Mediterranean Sea via the Suez Channel, it is considered a Lessepsian migrant. Although, unlike other invasive marine seaweeds, it has not demonstrated serious negative impacts on indigenous species, it does have remarkable invasive properties. The present in-silico study reveals the biotechnological features of $H$. stipulacea by showing bioactive peptides from its rubisc/o protein. These are features such as antioxidant and hypolipideamic activities, dipeptidyl peptidase-IV and angiotensin converting enzyme inhibitions. The reported data open up new applications for such bioactive peptides in the field of pharmacy, medicine and also the food industry.
\end{abstract}

Keywords: bioactive peptides; Halophila stipulacea; in silico analysis; DPP-IV; angiotensin converting enzyme inhibitors

\section{Introduction}

Invasive species are becoming an important problem in the Mediterranean Sea where many vectors exist, including inflowing water from the Suez Channel and ships' ballast waters. One of the best-known invasive sea grasses is Halophila stipulacea (Forsskål) Ascherson [1], which was first reported in the Mediterranean Sea by Friscth [2]. This sea grass is abundant in the eastern Mediterranean Basin and very common along the Turkish coastline [3]. No validated eradication method for this invasive species is described in the scientific literature. A few reports mention the negative impacts of H.stipulacea on indigenous species [4], although Willette and Ambrose [5] mention that little is known of $H$. stipulacea's effects in its recently discovered Caribbean locations, while Van Tussenbroek et al. [6] report that H.stipulacea may be harmful for native species. Although most efforts so far have been devoted to finding alternative ways of evaluating non-indigenous species [7,8], invasive species secrete interesting secondary metabolites that can be exploited economically under the title of blue biotechnology. Indeed, recent years have seen growing interest in blue biotechnology-based products [9]. For example, bioactive peptides are one of the candidate targets that can be isolated from invasive species. However, to the best of our knowledge, the bioactive peptides from invasive H. stipulacea have not been assessed, and the aim of the present contribution is to fill in this gap in the literature.

Bioactive peptides (hereafter BPs) comprise 3-20 free amino acid food protein fragments [10] composed of covalently bonded (amide/peptide bonds) amino acids [11]. According to the BP database 
called BIOPEP [12], there are more than 3500 different BPs. The sources of natural BPs can be land-, marine- or food-derived, and include seaweeds [13,14] tropical amphibians [15], cyanobacterium [16], fermented soybean meal [17], sea cucumber [18], cereal crops [19] and milk [20]. BPs are of great importance because of their positive impact on human health. Daliry et al. [21] classified food-derived BPs as anti-cancer, antidiabetic, antihypertensive, antimicrobial, cholesterol-lowering peptides, and multifunctional peptides [21]. Since they help prevent the oxidation and microbial degradation of foods, BPs could be defined as a "new generation" of bioactive regulators [11]. Although BPs are generally coded in the parent protein structure, some BPs are found free in natural sources [11]. Due to their biological and pharmaceutical properties, the production of BPs is of great importance, whether it be by enzymatic hydrolysis [22], chemical synthesis [23] or microbial fermentation [24]. Other production processes include separation and purification techniques such as gel filtration, ultrafiltration $[25,26]$, reverse phase ultra-flow liquid chromatography (RP-UFLC) [25], and reverse phase high performance liquid chromatography (RP-HPLC) and characterization methods such as ultra-performance liquid chromatography tandem mass spectrometry (UPLC-MS/MS) [27]. Since these production, isolation, purification and characterization protocols are time- and solvent-consuming, bioinformatics tools are increasingly used $[13,16]$. The role of database-aided bioinformatics tools is to quantitatively predict the structure-activity relationship. Many tools have been developed such as BIOPEP [12], Antimicrobial Peptide Database (APD) [28] and PepBank [29]. Ribulose-1,5-bisphosphate carboxylase/oxygenase (RubisCO, E.C. 4.1.1.39) is an important photosynthetic enzyme and the most abundant protein in the world $[14,30]$. RubisCO is a bifunctional multimeric enzyme and it plays a role in photorespiration and carbon fixation in the Calvin cycle $[19,30]$. Thirty to fifty percent of RubisCO is soluble and contains eight large ( $56 \mathrm{kDa})$ and eight small $(14 \mathrm{kDa})$ subunits [31]. The small subunits of RubisCO contain high amounts of cationic and hydrophobic amino acids [31], while a bioactive dipeptide (Phe-Cys), which suppresses oxidative stress, has been obtained from the large subunit of RubisCO by in-silico thermolysin hydrolysis [32]. Some RubisCO derived peptides have revealed opioid activity, and some are G-protein coupled receptor ligands which constitute the most important class of drug targets [30]. Although there have been attempts at the chemical analysis of $H$. stipulacea [33], its detailed chemical composition is still not known in full.

This contribution presents an alternative and sustainable method for evaluating the invasive sea grass $H$. stipulacea by using in silico analysis of BPs in the large chain of RubisCO. Bioactive peptides are of great importance for the preparation of functional foods because of their excellent health-related effects. Many bioactivities, including antioxidant, antihypertensive and enzyme inhibitory properties have been associated with bioactive peptides from RubisCO of plants $[13,19]$.

\section{Materials and Methods}

\subsection{Sequence of H. stipulacea Rubisc/o}

Ribulose bisphosphate carboxylase large chain of H. stipulacea (H6TQS9) was retrieved from the UniProtKB/Swiss-Prot database at the ExPASy Bioinformatics Resource Portal [34]. According to the portal, the sequence provided is a fragment and consists of 200 amino acids.

\subsection{In silico BIOPEP Parameters}

All in-silico calculations were performed using the codes implemented in the BIOPEP webserver [12]. One of the main theoretical parameters $(A)$ is defined as the frequency of occurrence of bioactive fragments in the protein chain $A[12,35,36]$, which can be calculated by using Equation (1):

$$
A=a / N
$$

where $a$ is the number of fragments with given activity in a protein sequence and $N$ is the number of amino acid residues in the protein chain $[12,35,36]$. 
The frequency with which fragments with given activity were released by enzymes $\left(A_{E}\right)$ and the relative frequency of release of fragments with given activity by enzymes $(W)$ were calculated based on Equations (2) and (3), respectively.

$$
A_{E}=d / N
$$

where $d$ is the number of fragments with given activity in the protein sequence that could be released by enzymes, and $N$ is the number of amino acid residues in the protein chain. The relative frequency of release of fragments with given activity by selected enzymes $(W)$ is given by:

$$
W=A_{E} / A
$$

The values of $A_{E}$ and $A$ are defined according to Equations (1) and (2), respectively. Potential biological activity of protein $(B)\left[\mu \mathrm{M}^{-1}\right]$ :

$$
B=\frac{\sum_{i=1}^{k} \frac{a_{i}}{E C_{50 i}}}{N}
$$

In Equation (4), $a_{i}$ is the number of repetitions of the $i$-th bioactive fragment in protein sequence, $E C_{50 i}$ is the concentration of the $i$-th bioactive peptide corresponding to its half-maximal activity $[\mu \mathrm{M}], k$ is the number of different fragments with given activity and $N$ is the number of amino acid residues [35].

The theoretical degree of hydrolysis $\left(\mathrm{DH}_{t}\right)$ was also calculated using the following Equation (5):

$$
D H_{t}=\frac{d}{D} \times 100 \%
$$

In Equation (5), $d$ is number of hydrolyzed peptide bonds and $D$ is total number of peptide bonds in a protein chain.

The relative activity of fragments with given activity released by selected enzymes $(V)$ is:

$$
V=\frac{B_{E}}{B}
$$

In Equation (6), $B_{E}$ is the activity of fragments potentially released by proteolytic enzyme (enzymes) and $B$ is the potential biological activity of the protein.

The amino acid composition of protein was determined based on protein sequences, using the ProtParam program [37] available at [38].

\section{Results}

H. stipulacea large chain RubisCO was retrieved from expasy.org. After in silico proteolytic fragmentation of the RubisCO by BIOPEP tools, bioactive peptides were obtained. The raw data can be found in Appendix A (Tables A1-A56). BIOPEP parameters $\left(A, A_{E}, W, B H_{t}\right.$ and $\left.V\right)$ were extracted from the raw data and the results are presented in the Tables $1-10$.

The angiotensin-converting enzyme (ACE) inhibitor properties of bioactive peptides from RubisCO of $H$. stipulacea were given in Table 1 . The values were not calculated for prolyl endopeptidase, clostripain, thrombin, glutamyl endopeptidase II, Xaa-dipeptidase, chymosin, ginger protease (zingipain). From this table, maximum and minimum $A$ values were found to be 0.5833 and 0.5808 , respectively. The highest values were observed in V-protease, endopeptidase, V-8 protease (Glutamyl endopeptidase), and the minimum values were found in trypsin, plasmin and oligopeptidase B. The maximum $A_{E}$ value was found to be 0.0874 (calpain 2) and the minimum $A_{E}$ values were found to be 0.0097 (plasmin, oligopeptidase $B$, tripsin). The maximum and minimum relative frequency of release of fragments $(\mathrm{W})$ were found if RubisCO is cleaved by calpain $2(0.1500)$ and V-protease, glycyl endopeptidase, V8-protease (glutamyl endopeptidase) (0.0084). 
Table 1. The values of the parameters describing the predicted efficiency of bioactive Angiotensin Converting Enzyme (ACE) inhibitor fragment release from Halophila stipulacea-RubisCO by proteases.

\begin{tabular}{cccccc}
\hline Proteases & $A$ & $A_{E}$ & $W$ & $B$ & $V$ \\
\hline Chymotrypsin A & 0.5822 & 0.0485 & 0.0833 & 0.0017 & 0.0645 \\
Trypsin & 0.5808 & 0.0097 & 0.0167 & 0.0000 & 0.0004 \\
Pepsin & 0.5826 & 0.0194 & 0.0333 & 0.0000 & 0.0009 \\
Proteinase K & 0.5825 & 0.0777 & 0.1334 & 0.0033 & 0.1240 \\
Pancreatic elestase & 0.5827 & 0.0437 & 0.0750 & 0.0007 & 0.0256 \\
V-protease & 0.5833 & 0.0049 & 0.0084 & 0.0000 & 0.0003 \\
Thermolysin & 0.5825 & 0.0777 & 0.1334 & 0.0052 & 0.1932 \\
Chymotrypsin C & 0.5826 & 0.0631 & 0.1083 & 0.0018 & 0.0671 \\
Plasmin & 0.5808 & 0.0097 & 0.0167 & 0.0000 & 0.0004 \\
Cathepsin G & 0.5826 & 0.0388 & 0.0666 & 0.0008 & 0.0308 \\
Chymase & 0.5826 & 0.0388 & 0.0666 & 0.0008 & 0.0308 \\
Papain & 0.5826 & 0.0631 & 0.1083 & 0.0019 & 0.0718 \\
Ficin & 0.5827 & 0.0680 & 0.1167 & 0.0016 & 0.0592 \\
Leukocyte elastase & 0.5822 & 0.0485 & 0.0833 & 0.0025 & 0.0916 \\
Metridin & 0.5826 & 0.0388 & 0.0666 & 0.0008 & 0.0308 \\
Pancreatic elastase II & 0.5826 & 0.0194 & 0.0333 & 0.0000 & 0.0009 \\
Bromelain & 0.5822 & 0.0340 & 0.0584 & 0.0007 & 0.0276 \\
Oligopeptidase B & 0.5808 & 0.0097 & 0.0167 & 0.0000 & 0.0004 \\
Calpain 2 & 0.5827 & 0.0874 & 0.1500 & 0.0034 & 0.1285 \\
Glycyl endopeptidase & 0.5833 & 0.0049 & 0.0084 & 0.0000 & 0.0002 \\
Oligopeptidase F & 0.5826 & 0.0194 & 0.0333 & 0.0000 & 0.0009 \\
Proteinase P1 (lactocepin) & 0.5827 & 0.0243 & 0.0417 & 0.0005 & 0.0198 \\
Pepsin (pH > 2) & 0.5825 & 0.0777 & 0.1334 & 0.0022 & 0.0828 \\
Coccolysin & 0.5827 & 0.0680 & 0.1167 & 0.0021 & 0.0800 \\
Subtilisin & 0.5823 & 0.0534 & 0.0917 & 0.0055 & 0.2057 \\
V-8 protease (Glutamyl endopeptidase, pH:7.8) & 0.5833 & 0.0049 & 0.0084 & 0.0000 & 0.0003 \\
\hline
\end{tabular}

Table 2. The values of parameters describing the predicted efficiency of release of the bioactive antioxidative fragment from Halophila stipulacea-RubisCO by proteases.

\begin{tabular}{cccccc}
\hline Proteases & $\boldsymbol{A}$ & $\boldsymbol{A}_{\boldsymbol{E}}$ & $\boldsymbol{W}$ & $\boldsymbol{B}$ & $\boldsymbol{V}$ \\
\hline Chymotrypsin A & 0.0728 & 0.0049 & 0.0673 & 0 & 0 \\
Proteinase K & 0.0728 & 0.0243 & 0.3338 & 0 & 0 \\
Chymotrypsin C & 0.0728 & 0.0097 & 0.1332 & 0 & 0 \\
Cathepsin & 0.0728 & 0.0049 & 0.0673 & 0 & 0 \\
Chymase & 0.0728 & 0.0049 & 0.0673 & 0 & 0 \\
Papain & 0.0728 & 0.0049 & 0.0673 & 0 & 0 \\
Ficin & 0.0728 & 0.0049 & 0.0673 & 0 & 0 \\
Leukocyte elastase & 0.0728 & 0.0049 & 0.0673 & 0 & 0 \\
Metridin & 0.0728 & 0.0049 & 0.0673 & 0 & 0 \\
Bromelain & 0.0728 & 0.0049 & 0.0673 & 0 & 0 \\
Calpain 2 & 0.0728 & 0.0097 & 0.1332 & 0 & 0 \\
Proteinase P1 (lactocepin) & 0.0728 & 0.0097 & 0.1332 & 0 & 0 \\
Pepsin (pH > 2) & 0.0728 & 0.0049 & 0.0673 & 0 & 0 \\
Pubtilisin & 0.0728 & 0.0146 & 0.2005 & 0 & 0 \\
\hline
\end{tabular}


Table 3. The values of parameters describing the predicted efficiency of release of bioactive dipeptidyl peptidase IV inhibitor fragment from Halophila stipulacea-RubisCO by proteases.

\begin{tabular}{|c|c|c|c|c|c|}
\hline Proteases & $A$ & $A_{E}$ & $W$ & $B$ & $V$ \\
\hline Chymotrypsin A & 0.6501 & 0.0340 & 0.0523 & 0.0000 & 0.0086 \\
\hline Trypsin & 0.6518 & 0.0146 & 0.0224 & 0.0000 & 0.0000 \\
\hline Pepsin & 0.6518 & 0.0146 & 0.0224 & 0.0000 & 0.0086 \\
\hline Proteinase K & 0.6507 & 0.0922 & 0.1417 & 0.0000 & 0.0345 \\
\hline Pancreatic elestase & 0.6508 & 0.0777 & 0.1194 & 0.0000 & 0.0969 \\
\hline Prolyl oligopeptidase & 0.6533 & 0.0049 & 0.0075 & 0.0000 & 0.0000 \\
\hline V-protease & 0.6533 & 0.0049 & 0.0075 & 0.0000 & 0.0000 \\
\hline Thermolysin & 0.6504 & 0.0534 & 0.0821 & 0.0000 & 0.0071 \\
\hline Chymotrypsin C & 0.6501 & 0.0485 & 0.0746 & 0.0000 & 0.0242 \\
\hline Plasmin & 0.6518 & 0.0146 & 0.0224 & 0.0000 & 0.0000 \\
\hline Cathepsin & 0.6497 & 0.0243 & 0.0374 & 0.0000 & 0.0086 \\
\hline Clostripain & 0.6533 & 0.0049 & 0.0075 & 0.0000 & 0.0000 \\
\hline Chymase & 0.6497 & 0.0243 & 0.0374 & 0.0000 & 0.0086 \\
\hline Papain & 0.6506 & 0.0825 & 0.1268 & 0.0000 & 0.1066 \\
\hline Ficin & 0.6503 & 0.0874 & 0.1344 & 0.0000 & 0.0510 \\
\hline Leukocyte elastase & 0.6506 & 0.0728 & 0.1119 & 0.0000 & 0.1056 \\
\hline Metridin & 0.6497 & 0.0243 & 0.0374 & 0.0000 & 0.0086 \\
\hline Pancreatic elastase II & 0.6518 & 0.0146 & 0.0224 & 0.0000 & 0.0086 \\
\hline Bromelain & 0.6507 & 0.0680 & 0.1045 & 0.0000 & 0.1005 \\
\hline Oligopeptidase B & 0.6518 & 0.0146 & 0.0224 & 0.0000 & 0.0000 \\
\hline Calpain 2 & 0.6506 & 0.1214 & 0.1866 & 0.0000 & 0.1066 \\
\hline Glycyl endopeptidase & 0.6533 & 0.0049 & 0.0075 & 0.0000 & 0.0000 \\
\hline Oligopeptidase F & 0.6518 & 0.0146 & 0.0224 & 0.0000 & 0.0086 \\
\hline Proteinase P1 (lactocepin) & 0.6501 & 0.0340 & 0.0523 & 0.0000 & 0.0000 \\
\hline Pepsin $(\mathrm{pH}>2)$ & 0.6505 & 0.1165 & 0.1791 & 0.0001 & 0.4569 \\
\hline Cocolysin & 0.6503 & 0.0437 & 0.0672 & 0.0000 & 0.0071 \\
\hline Subtilisin & 0.6507 & 0.0583 & 0.0896 & 0.0000 & 0.0086 \\
\hline V-8 protease (Glutamyl endopeptidase) & 0.6510 & 0.0097 & 0.0149 & 0.0000 & 0.0000 \\
\hline
\end{tabular}

Table 4. The values of parameters describing the predicted efficiency of release of bioactive activating ubiquitin-mediated proteolysis fragment from Halophila stipulacea-RubisCO by proteases.

\begin{tabular}{cccccc}
\hline Proteases & $\boldsymbol{A}$ & $\boldsymbol{A}_{\boldsymbol{E}}$ & $\boldsymbol{W}$ & $\boldsymbol{B}$ & $\boldsymbol{V}$ \\
\hline Pancreatic elastase & 0.0146 & 0.0097 & 0.6644 & 0 & - \\
Leukocyte elastase & 0.0146 & 0.0049 & 0.3356 & 0 & - \\
Proteinase P1 (lactocepin) & 0.0146 & 0.0049 & 0.3356 & 0 & - \\
Pepsin $(\mathrm{pH}>2)$ & 0.0146 & 0.0097 & 0.6644 & 0 & - \\
\hline
\end{tabular}

Table 5. The values of parameters describing the predicted efficiency of the release of bioactive regulating fragment from Halophila stipulacea-RubisCO by proteases.

\begin{tabular}{cccccc}
\hline Proteases & $\boldsymbol{A}$ & $\boldsymbol{A}_{\boldsymbol{E}}$ & $\boldsymbol{W}$ & $\boldsymbol{B}$ & $\boldsymbol{V}$ \\
\hline Chymotrypsin C & 0.0146 & 0.0049 & 0.3356 & 0 & - \\
Ficin & 0.0146 & 0.0049 & 0.3356 & 0 & - \\
Calpain 2 & 0.0146 & 0.0049 & 0.3356 & 0 & - \\
Pepsin $(\mathrm{pH}>2)$ & 0.0146 & 0.0049 & 0.3356 & 0 & - \\
\hline
\end{tabular}

Table 6. The values of parameters describing the predicted efficiency of release of bioactive antithrombotic fragment from Halophila stipulacea-RubisCO by proteases.

\begin{tabular}{cccccc}
\hline Proteases & $A$ & $A_{E}$ & $W$ & $B$ & $\boldsymbol{V}$ \\
\hline Chymotrypsin C & 0.0097 & 0.0049 & 0.5052 & 0 & - \\
Calpain 2 & 0.0097 & 0.0049 & 0.5052 & 0 & - \\
Pepsin $(\mathrm{pH}>2)$ & 0.0097 & 0.0049 & 0.5052 & 0 & - \\
\hline
\end{tabular}


Table 7. The values of parameters describing the predicted efficiency of release of bioactive antiamnestic fragment from Halophila stipulacea-RubisCO by proteases.

\begin{tabular}{cccccc}
\hline Proteases & $A$ & $A_{E}$ & $W$ & $B$ & $\boldsymbol{V}$ \\
\hline Chymotrypsin C & 0.0097 & 0.0049 & 0.5052 & 0 & - \\
Calpain 2 & 0.0097 & 0.0049 & 0.5052 & 0 & - \\
Pepsin $(\mathrm{pH}>2)$ & 0.0097 & 0.0049 & 0.5052 & 0 & - \\
\hline
\end{tabular}

Table 8. The values of parameters describing the predicted efficiency of release of bioactive stimulating fragment from Halophila stipulacea-RubisCO by proteases.

\begin{tabular}{cccccc}
\hline Proteases & $\boldsymbol{A}$ & $\boldsymbol{A}_{\boldsymbol{E}}$ & $\boldsymbol{W}$ & $\boldsymbol{B}$ & $\boldsymbol{V}$ \\
\hline Papain & 0.0340 & 0.0049 & 0.1441 & 0 & - \\
Pepsin $(\mathrm{pH}>2)$ & 0.0340 & 0.0049 & 0.1441 & 0 & - \\
\hline
\end{tabular}

Table 9. The values of parameters describing the predicted efficiency of release of bioactive immunomodulating fragment from Halophila stipulacea-RubisCO by proteases.

\begin{tabular}{cccccc}
\hline Proteases & $A$ & $A_{E}$ & $\boldsymbol{W}$ & $\boldsymbol{B}$ & $\boldsymbol{V}$ \\
\hline Calpain 2 & 0.0097 & 0.0049 & 0.5052 & 0 & 0 \\
\hline
\end{tabular}

Table 10. Theoretical degree of hydrolysis $\left(D H_{t}\right)$ values for the following enzymes.

\begin{tabular}{|c|c|}
\hline Proteases & $D H_{t}$ \\
\hline Chymotrypsin A & 23.4146 \\
\hline Trypsin & 10.7317 \\
\hline Pepsin & 12.1951 \\
\hline Proteinase K & 37.0732 \\
\hline Pancreatic elastase & 54.6341 \\
\hline Prolyl oligopeptidase & 6.8293 \\
\hline V-protease & 7.3171 \\
\hline Thermolysin & 36.5854 \\
\hline Chymotrypsin C & 35.6098 \\
\hline Plasmin & 10.7317 \\
\hline Cathepsin & 20.4878 \\
\hline Clostripain & 5.3659 \\
\hline Chymase & 19.5122 \\
\hline Papain & 43.4146 \\
\hline Ficin & 44.3902 \\
\hline Leukocyte elastase & 38.5366 \\
\hline Metridin & 19.5122 \\
\hline Thrombin & 0 \\
\hline Pancreatic elastase II & 13.1707 \\
\hline Bromelain & 54.1463 \\
\hline Endopeptidase II & 0 \\
\hline Oligopeptidase B & 10.7317 \\
\hline Calpain 2 & 47.3171 \\
\hline Glycyl endopeptidase & 9.7561 \\
\hline Oligopeptidase F & 12.1951 \\
\hline Proteinase P1 (lactocepin) & 41.4634 \\
\hline Xaa-Pro dipeptidase & 0 \\
\hline Pepsin $(\mathrm{pH}>2)$ & 70.7317 \\
\hline Cocolysin & 30.2439 \\
\hline Subtilisin & 29.2683 \\
\hline Chymosin & 0 \\
\hline Ginger protease (zingipain) & 0 \\
\hline V-8 protease (Glutamyl endopeptidase) & 11.7073 \\
\hline
\end{tabular}


The highest $B$ value was found to be 0.0055 (subtilisin) and the lowest $B$ values were found to be 0 for trypsin, pepsin, plasmin, pancreatic elastase II, oligopeptidase B, glycyl endopeptidase, oligopeptidase $\mathrm{F}$ and $\mathrm{V}-8$ protease (Glutamyl endopeptidase). The maximum and minimum $V$ values were found to be 0.2057 and 0.0002 , respectively. The maximum value was observed in subtilisin and the minimum value was found in glycyl endopeptidase. ACE is known as dipeptidyl carboxypeptidase and one of its major roles is controlling blood pressure [39]. In the literature, Agirbasli and Cavas [13] evaluated the frequency of occurrence (A) values of ACE inhibitor peptides in Caulerpa RubisCO and found that $C$. racemosa var. lamourouxii, $C$. taxifolia and $C$. racemosa $f$. occidentalis had the highest $A$ values $(0.4330,0.4330$ and 0.3993 , respectively) and C. racemosa var. turbinata exhibited the lowest (0.3822). Another study revealed that C. microphysa had potential ACE inhibitory activity as a result of pepsin cleavage [40]. However, the number of bioactive peptides in the BIOPEP database has increased, and so the frequency values might have been altered.

The antioxidative properties of BPs from RubisCO of $H$. stipulacea are listed in Table 2. Results reveal that maximum and minimum $A$ values were 0.07282 and 0.07280 , respectively. The minimum $A$ value was obtained when proteinase $\mathrm{K}$ was used as protease. Minimum $A$ values were found in calpain 2 and proteinase P1 (lactocepin). The maximum and minimum $A_{E}$ values were obtained as 0.0243 (proteinase K) and 0.0049 (chmytripsin, cathepsin, chymase, papain, ficin, leukocyte elastase, metridin, bromelain and pepsin), respectively. Proteinase $K$ had the maximum $W$ value (0.3338) and chymase, papain, ficin, leukocyte elastase, metridin, bromelain and pepsin had the lowest $W$ values (0.0673). When thrombin, endopeptidase II, Xaa-Pro dipeptidase, chymosin and ginger protease (zingipain) were used for cleaving, no antioxidative fragment from RubisCO of H. stipulacea was found. The inhibition of lipid peroxidation, scavenging of radicals and metal chelation are among the antioxidative properties of BPs [41]. In the literature, the antioxidative activity of BPs have been evaluated in-silico. According to a recent study, the highest $A$ value for the antioxidative properties of RubisCO was found in Caulerpa taxifolia (0.0785) samples and C. cylindracea (0.0759) species [13]. Also, Udenigwe et al. $[19,30]$ found the maximum and minimum $A$ value of antioxidative properties of RubisCO of cereal crops to be 0.0568 and 0.0464 , respectively [19].

The inhibition effects of bioactive peptides from Rubis $\mathrm{CO}$ of $\mathrm{H}$. stipulacea on dipeptidyl peptidase IV (DPP-IV) (E.C. 3.4.14.5) are given in Table 3. According to the results, prolyl oligopeptidase, V-protease, clostripain and glycyl endopeptidase have the maximum (0.6533) and cathepsin, chymase and metridin have the minimum (0.6497) $A$ value. The maximum $A_{E}$ value was 0.1214 when calpain 2 was used as a protease in DPP-IV inhibitor activity. The minimum $A_{E}$ value (0.0049) was found in prolyl oligopeptidase, V-protease, clostripain and glycyl endopeptidase. Calpain 2 had the maximum (0.1866) and prolyl oligopeptidase, V-protease and clostripain had the minimum (0.0075) $W$ value. We found very low $B$ values for all the enzymes studied. The highest $V$ value was found in pepsin $(\mathrm{pH}>2$ ) (0.4569), while tripsin, prolyl oligopeptidase, V8-protease, plasmin, clostripain, oligopeptidase $\mathrm{B}$, glycyl endopeptidase and proteinase P1 had the lowest $V$ value (0.0000). DPP-IV is crucial in glucose metabolism and it degrades the incretins [42]. Thus, DPP-IV inhibitors play a major role in type-2 diabetes mellitus in which insulin secretion and blood glucose level stability are of great importance. [42]. Agirbasli and Cavas found the $A$ value of DPP-IV to be between 0.0550 and 0.0714 in all of Caulerpa species [13]. They also mentioned that caulerpenyne is found in Caulerpa species and its alpha-amylase inhibition activity may play an important role in reducing starch degradation. In another in silico study carried out by Udenigwe et al. [19,30], rice and oat showed the highest $A$ value (0.0758).

Table 4 shows the ubiquitin-mediated proteolysis (UbMP) activating properties of bioactive peptides from RubisCO of $H$. stipulacea. The $A$ value was 0.0146 in pancreatic elastase, leukocyte elastase, proteinase P1 (lactocepin) and pepsin $\left(\mathrm{pH}>2\right.$ ). The maximum $A_{E}$ value was 0.0097 (pancreatic elestase) and the minimum $A_{E}$ values were 0.0049 for leukocyte elastase and proteinase P1. Also, when thrombin, endopeptidase II and Xaa-Pro dipeptidase, chymosin and ginger protease were used, a ubiquitin-mediated proteolysis fragment from $\mathrm{H}$. stipulacea was not found. Pancreatic elastase and 
pepsin have the highest $W$ value (0.6644) and leukocyte elastase and proteinase P1 have the lowest $W$ value (0.3356). No $B$ or $W$ value was found for UbMP properties of bioactive peptides from RubisCO of H. stipulacea. UbMP is crucial for brain development [43] and its absence causes neurodegenerative diseases such as Parkinson's and Alzheimer's [44]. In the literature, Minkiewicz et al. [36] carried out an in-silico evaluation of bovine meat proteins and found that the highest $A$ value of activating UbMP was 0.028 in tropomyosin $\alpha-1$ chain [36].

Results for bioactive regulating fragments from H. stipulacea by proteases are shown in Table 5 . The results reveal that the only $A$ value (0.0146) was found in chymotrypsin, ficin, calpain 2 and pepsin. The maximum $A_{E}$ value (0.0049) was obtained in chymotrypsin, ficin, calpain 2 and pepsin. Chymotrypsin, ficin, calpain 2 and pepsin had the same $W$ values (0.3356). $B$ and $V$ values were not found for the bioactive regulating activity of $H$. stipulacea by proteases.

Table 6 shows the antithrombotic activity of BPs from H. stipulacea. According to the results, maximum $A, A_{E}$ and $W$ values $(0.0097,0.0049$ and 0.5052 , respectively) were obtained for chymotrypsin, calpain 2 and pepsin. The $B$ and $V$ values of the antithrombotic properties of $H$. stipulacea by proteases were not found. Antithrombic activity is essential for the reduction of thrombin. In the study of Agirbasli and Cavas [13], the $A$ values of antithrombic activity of BPs from Caulerpa genus were found within the range of 0.0010 to 0.0100 [13].

The antiamnestic activity values of the bioactive peptides are given in Table 7 . The only $A$ value found (0.0097) was found in chymotrypsin, calpain 2 and pepsin. Also, the maximum $A_{E}$ and $W$ values ( 0.0049 and 0.5052 , respectively) were obtained by chymotrypsin, calpain 2 and pepsin. Agirbasli and Cavas [13] found the $A$ values of antiamnestic activity of BPs from Caulerpa genus to be within the range of 0.0010 to 0.0100 , the same as for antihrombic activity, perhaps because they act in the similar pathway way [13].

The results of stimulating fragments of $H$. stipulacea are given in Table 8. The highest $A, A_{E}$ and $W$ values $(0.0340,0.0049$ and 0.1441$)$ were obtained by papain and pepsin $(\mathrm{pH}>2)$.

Table 9 provides the immunomodulating activity results of BPs from $H$. stipulacea. The results reveal that calpain 2 has the highest $A, A_{E}$ and $W$ values $(0.0097,0.0049$ and 0.5052 , respectively). It is interesting to note $A, A_{E}, W, B$ or $V$ values could not be calculated for other enzymes in this study.

In Table 10, the theoretical degree of hydrolysis $\left(\mathrm{DH}_{t}\right)$ are given for the following proteases: Chymotrypsin A, trypsin, pepsin, proteinase K, pancreatic elastase, prolyl oligopeptidase, V8-protease, thermolysin, chymotrypsin $C$, plasmin, cathepsin, clostripain, chymase, papain, ficin, leukocyte elastase, metridin, thrombin, pancreatic elastase II, bromelain, endopeptidase II, oligopeptidase B, calpain 2, glycyl endopeptidase, oligopeptidase F, proteinase P1 (lactocepin), Xaa-Pro dipeptidase, pepsin $(\mathrm{pH}>2$ ), cocolysin, subtilisin, chymosin, ginger protease (zingipain) and V-8 protease (Glutamyl endopeptidase). According to the results, the highest and the lowest $D H_{t}$ values were found in pepsin $\mathrm{pH}>2$ (70.7317) and thrombine, endopeptidase II, Xaa-Pro dipeptidase, chymocine, ginger protease (0), respectively.

In-silico analysis is regarded as an important tool by food scientists since in-silico results may reflect in-vitro and in-vivo results [10,45-48]. Lafarga et al. [48] defined new bioactive peptides that show ACE and DPP IV inhibition. They confirmed their biological activity by synthetic tripeptides. Sayd et al. [49] also used a similar strategy, grouping the bioactive meat proteins into three categories based on their digestion dynamic. In recent years, there has been a growth in meat consumption as a result of an increasing population. This demand may increase the use of growth hormones, which, in some countries, are banned, but in others allowed [50]. Therefore, an alternative protein source to meat would be of great interest. In this respect, marine seaweeds and seagrasses can be exploited on an industrial scale since there is no hormone ingredient. 


\section{Discussion}

Blue biotechnology and blue growth have become two of the hottest topics in recent years. The evaluation of invasive species may open up a new door in the search for novel agents such as vaccines, secondary metabolites and medicines. The present paper reveals that H.stipulacea contains bioactive peptides. These peptides can be harvested and evaluated in the countries affected. However, any possible industrial collection of H.stipulacea would have to be approved by local authorities. Since H.stipulacea forms a mixed vegetation with local Mediterranean macrophytes and seaweeds, its uncontrolled collection might damage the local species. In conclusion, invasive species in the Mediterranean Sea contain very important secondary metabolites and bioactive peptides. Instead of applying blunt eradication methods, biotechnological evaluation is needed.

Author Contributions: Conceptualization, L.C. and H.P.-S.; methodology, L.C.; software, C.K.-C., N.M.-O.; validation, C.K.-C., N.M.-O.; formal analysis, L.C. and H.P.-S.; investigation, L.C. and H.P.-S.; resources, L.C. and H.P.-S.; data curation, C.K.-C., N.M.-O.; writing-original draft preparation, L.C. and C.K.-C., N.M.O.; writing-review and editing, L.C., C.K.-C. and H.P.-S.; visualization, L.C., C.K.-C.; supervision, L.C., and H.P.-S.; project administration, L.C. and H.P.-S.; funding acquisition, L.C. and H.P.-S.

Funding: This project was financially supported by Turkish Higher Education Council (YÖK) under MevlanaProject Based Academic Exchange Programme (MEV-2017-230) and by grants from the Spanish Ministry of Economy and Competitiveness (CTQ2017-87974-R) and by the Fundación Séneca del Centro de Coordinación de la Investigación de la Región de Murcia under Projects 20988/PI/18 and 20524/PDC/18.

Acknowledgments: This project was financially supported by Turkish Higher Education Council (YÖK) under Mevlana-Project Based Academic Exchange Programme (MEV-2017-230) and by grants from the Spanish Ministry of Economy and Competitiveness (CTQ2017-87974-R) and by the Fundación Séneca del Centro de Coordinación de la Investigación de la Región de Murcia under Projects 20988/PI/18 and 20524/PDC/18.

Conflicts of Interest: The authors declare no conflict of interest. 


\section{Appendix A (Raw Data)}

Table A1. Bioactive peptides from RubisCO of Halophila stipulacea. In silico enzymatic cleavage was carried out by using chymotripsine.

\begin{tabular}{|c|c|c|c|c|c|c|c|c|}
\hline No. & $\begin{array}{l}\text { Peptide } \\
\text { ID }\end{array}$ & Sequence & Location & Name & Function & Activity & $\begin{array}{l}\text { Monoisotopic } \\
\text { Mass }\end{array}$ & $\begin{array}{l}\text { Chemical } \\
\text { Mass }\end{array}$ \\
\hline 1 & 3257 & RL & $(138-139)$ & beta-lactokinin & $\begin{array}{l}\text { Inhibitor of Angiotensin-Converting } \\
\text { Enzyme (ACE) (EC 3.4.15.1) (MEROPS } \\
\text { ID: XM02-001) }\end{array}$ & ACE inhibitor & 287.1850 & 287.3480 \\
\hline 2 & 3384 & VF & $(128-129)$ & ACE inhibitor & $\begin{array}{l}\text { Inhibitor of Angiotensin-Converting } \\
\text { Enzyme (ACE) (EC 3.4.15.1) (MEROPS } \\
\text { ID: XM02-001) }\end{array}$ & ACE inhibitor & 264.1360 & 264.3100 \\
\hline 3 & 3546 & VAY & $(103-105)$ & ACE inhibitor & $\begin{array}{l}\text { Inhibitor of Angiotensin-Converting } \\
\text { Enzyme (ACE) (EC 3.4.15.1) (MEROPS } \\
\text { ID: XM02-001) }\end{array}$ & ACE inhibitor & 351.1680 & 351.3820 \\
\hline 4 & 7513 & PL & $(106-107)$ & $\begin{array}{l}\text { ACE inhibitor from Alaskan } \\
\text { pollack skin }\end{array}$ & $\begin{array}{l}\text { Inhibitor of Angiotensin-converting } \\
\text { enzyme (EC 3.4.15.1) (MEROPS ID: } \\
\text { XM02-001) }\end{array}$ & ACE inhibitor & 228.1360 & 228.2770 \\
\hline 5 & 7591 & GF & $(130-131)$ & ACE inhibitor & $\begin{array}{l}\text { Inhibitor of Angiotensin-Converting } \\
\text { Enzyme (ACE) (EC 3.4.15.1) (MEROPS } \\
\text { ID: XM02-001) }\end{array}$ & ACE inhibitor & 222.0890 & 222.2290 \\
\hline 6 & 7599 & GL & $(183-184)$ & ACE inhibitor & $\begin{array}{l}\text { Inhibitor of Angiotensin-converting } \\
\text { enzyme (EC 3.4.15.1) (MEROPS ID: } \\
\text { XM02-001) }\end{array}$ & ACE inhibitor & 188.1050 & 188.2120 \\
\hline 7 & 7691 & KY & $(168-169)$ & ACE inhibitor from wakame & & ACE inhibitor & 309.1570 & 309.3440 \\
\hline 8 & 7693 & KL & $(21-22)$ & ACE inhibitor from wakame & & ACE inhibitor & 259.1780 & 259.3340 \\
\hline 9 & 8219 & TY & $(23-24)$ & antioxidative peptide & & antioxidative & 282.1100 & 282.2750 \\
\hline 10 & 8561 & GL & $(183-184)$ & $\begin{array}{l}\text { dipeptidyl peptidase IV } \\
\text { inhibitor (DPP IV inhibitor) }\end{array}$ & $\begin{array}{l}\text { Inhibitor of Dipeptidyl Peptidase IV } \\
\text { (EC 3.4.14.5) (MEROPS ID: S09.003) }\end{array}$ & $\begin{array}{l}\text { dipeptidyl peptidase } \\
\text { IV inhibitor }\end{array}$ & 188.1050 & 188.2120 \\
\hline 11 & 8638 & PL & $(106-107)$ & $\begin{array}{l}\text { dipeptidyl peptidase IV } \\
\text { inhibitor (DPP IV inhibitor) }\end{array}$ & $\begin{array}{l}\text { Inhibitor of Dipeptidyl Peptidase IV } \\
\text { (EC 3.4.14.5) (MEROPS ID: S09.003) }\end{array}$ & $\begin{array}{l}\text { dipeptidyl peptidase } \\
\text { IV inhibitor }\end{array}$ & 228.1360 & 228.2770 \\
\hline 12 & 8782 & GF & $(130-131)$ & $\begin{array}{l}\text { dipeptidyl peptidase IV } \\
\text { inhibitor (DPP IV inhibitor) }\end{array}$ & $\begin{array}{l}\text { Inhibitor of Dipeptidyl Peptidase IV } \\
\text { (EC 3.4.14.5) (MEROPS ID: S09.003) }\end{array}$ & $\begin{array}{l}\text { dipeptidyl peptidase } \\
\text { IV inhibitor }\end{array}$ & 222.0890 & 222.2290 \\
\hline 13 & 8819 & KY & $(168-169)$ & $\begin{array}{l}\text { dipeptidyl peptidase IV } \\
\text { inhibitor (DPP IV inhibitor) }\end{array}$ & $\begin{array}{l}\text { Inhibitor of Dipeptidyl Peptidase IV } \\
\text { (EC 3.4.14.5) (MEROPS ID: S09.003) }\end{array}$ & $\begin{array}{l}\text { dipeptidyl peptidase } \\
\text { IV inhibitor }\end{array}$ & 309.1570 & 309.3440 \\
\hline 14 & 8886 & RL & $(138-139)$ & $\begin{array}{l}\text { dipeptidyl peptidase IV } \\
\text { inhibitor (DPP IV inhibitor) }\end{array}$ & $\begin{array}{l}\text { Inhibitor of Dipeptidyl Peptidase IV } \\
\text { (EC 3.4.14.5) (MEROPS ID: S09.003) }\end{array}$ & $\begin{array}{l}\text { dipeptidyl peptidase } \\
\text { IV inhibitor }\end{array}$ & 287.1850 & 287.3480 \\
\hline 15 & 8914 & TY & $(23-24)$ & $\begin{array}{l}\text { dipeptidyl peptidase IV } \\
\text { inhibitor (DPP IV inhibitor) }\end{array}$ & $\begin{array}{l}\text { Inhibitor of Dipeptidyl Peptidase IV } \\
\text { (EC 3.4.14.5) (MEROPS ID: S09.003) }\end{array}$ & $\begin{array}{l}\text { dipeptidyl peptidase } \\
\text { IV inhibitor }\end{array}$ & 282.1100 & 282.2750 \\
\hline
\end{tabular}


Table A1. Cont.

\begin{tabular}{|c|c|c|c|c|c|c|c|c|}
\hline No. & $\begin{array}{l}\text { Peptide } \\
\text { ID }\end{array}$ & Sequence & Location & Name & Function & Activity & $\begin{array}{l}\text { Monoisotopic } \\
\text { Mass }\end{array}$ & $\begin{array}{l}\text { Chemical } \\
\text { Mass }\end{array}$ \\
\hline 16 & 8917 & VF & $(128-129)$ & $\begin{array}{l}\text { dipeptidyl peptidase IV } \\
\text { inhibitor (DPP IV inhibitor) }\end{array}$ & $\begin{array}{l}\text { Inhibitor of Dipeptidyl Peptidase IV } \\
\text { (EC 3.4.14.5) (MEROPS ID: S09.003) }\end{array}$ & $\begin{array}{l}\text { dipeptidyl peptidase } \\
\text { IV inhibitor }\end{array}$ & 264.1360 & 264.3100 \\
\hline 17 & 9071 & IAY & $(100-102)$ & ACE inhibitor & $\begin{array}{l}\text { Inhibitor of Angiotensin-Converting } \\
\text { Enzyme (ACE) (EC 3.4.15.1) (MEROPS } \\
\text { ID: M02-001) }\end{array}$ & ACE inhibitor & 365.1840 & 365.4090 \\
\hline 18 & 9074 & DF & $(204-205)$ & ACE inhibitor & $\begin{array}{l}\text { Inhibitor of Angiotensin-Converting } \\
\text { Enzyme (ACE) (EC 3.4.15.1) (MEROPS } \\
\text { ID: XM02-001) }\end{array}$ & ACE inhibitor & 280.0949 & 280.2660 \\
\hline
\end{tabular}

Table A2. $A_{E}, D H_{t}, W, B_{E}$ and $V$ values from RubisCO of Halophila stipulacea. In silico enzymatic cleavage carried out by using chymotripsin.

\begin{tabular}{llllll}
\hline $\begin{array}{l}\mathrm{DH} \\
\mathbf{2 3 . 4 1 4 6} \text { (\%) }\end{array}$ & & & & \\
\hline No. & Activity & $A_{E}$ & $W$ & $\boldsymbol{B}_{E}$ & $\boldsymbol{V}$ \\
\hline 1 & ACE inhibitor & 0.0485 & 0.0833 & 0.00172613144348533 & 0.06450702174869 \\
2 & antioxidative & 0.0049 & 0.0673 & 0 & 0 \\
3 & dipeptidyl peptidase IV inhibitor & 0.0340 & 0.0523 & $1.8563339357632 \mathrm{E}-6$ & 0.0086054864513139 \\
\hline
\end{tabular}

Table A3. Bioactive peptides from RubisCO of Halophila stipulacea. In silico enzymatic cleavage was carried out by using trypsine.

\begin{tabular}{|c|c|c|c|c|c|c|c|c|}
\hline No. & $\begin{array}{l}\text { Peptide } \\
\text { ID }\end{array}$ & Sequence & Location & Name & Function & Activity & $\begin{array}{l}\text { Monoisotopic } \\
\text { Mass }\end{array}$ & $\begin{array}{l}\text { Chemical } \\
\text { Mass }\end{array}$ \\
\hline 1 & 7603 & GR & $(84-85)$ & ACE inhibitor & $\begin{array}{l}\text { Inhibitor of Angiotensin-Converting } \\
\text { Enzyme (ACE) (EC 3.4.15.1) (MEROPS } \\
\text { ID: XM02-001) }\end{array}$ & ACE inhibitor & 231.1220 & 231.2400 \\
\hline 2 & 7697 & YK & $(82-83)$ & ACE inhibitor from wakame & & ACE inhibitor & 309.1570 & 309.3440 \\
\hline 3 & 8769 & $\mathrm{DR}$ & $(164-165)$ & $\begin{array}{l}\text { dipeptidyl peptidase IV } \\
\text { inhibitor (DPP IV inhibitor) }\end{array}$ & $\begin{array}{l}\text { Inhibitor of Dipeptidyl Peptidase IV } \\
\text { (EC 3.4.14.5) (MEROPS ID: S09.003) }\end{array}$ & $\begin{array}{l}\text { dipeptidyl peptidase } \\
\text { IV inhibitor }\end{array}$ & 289.1279 & 289.2770 \\
\hline 4 & 8858 & PK & $(180-181)$ & $\begin{array}{l}\text { dipeptidyl peptidase IV } \\
\text { inhibitor (DPP IV inhibitor) }\end{array}$ & $\begin{array}{l}\text { Inhibitor of Dipeptidyl Peptidase IV } \\
\text { (EC 3.4.14.5) (MEROPS ID: S09.003) }\end{array}$ & $\begin{array}{l}\text { dipeptidyl peptidase } \\
\text { IV inhibitor }\end{array}$ & 243.1460 & 243.2910 \\
\hline 5 & 8939 & YK & $(82-83)$ & $\begin{array}{l}\text { dipeptidyl peptidase IV } \\
\text { inhibitor (DPP IV inhibitor) }\end{array}$ & $\begin{array}{l}\text { Inhibitor of Dipeptidyl Peptidase IV } \\
\text { (EC 3.4.14.5) (MEROPS ID: S09.003) }\end{array}$ & $\begin{array}{l}\text { dipeptidyl peptidase } \\
\text { IV inhibitor }\end{array}$ & 309.1570 & 309.3440 \\
\hline
\end{tabular}


Table A4. $A_{E}, D H_{t}, W, B_{E}$ and $V$ values from RubisCO of Halophila stipulacea. In silico enzymatic cleavage carried out by using trypsine.

\begin{tabular}{llllll}
\hline $\begin{array}{l}\mathrm{DH}_{\boldsymbol{t}}(\mathbf{\%}) \\
\mathbf{1 0 . 7 3 1 7}\end{array}$ & & & & \\
\hline No. & Activity & $A_{E}$ & $\boldsymbol{W}$ & $\boldsymbol{B}_{\boldsymbol{E}}$ & $\boldsymbol{V}$ \\
\hline 1 & ACE inhibitor & 0.0097 & 0.0167 & $9.4749721470635 \mathrm{E}-6$ & 0.00035408788633428 \\
2 & dipeptidyl peptidase IV inhibitor & 0.0146 & 0.0224 & 0 & 0 \\
\hline
\end{tabular}

Table A5. Bioactive peptides from RubisCO of Halophila stipulacea. In silico enzymatic cleavage was carried out by using pepsin.

\begin{tabular}{|c|c|c|c|c|c|c|c|c|}
\hline No. & $\begin{array}{l}\text { Peptide } \\
\text { ID }\end{array}$ & Sequence & Location & Name & Function & Activity & $\begin{array}{l}\text { Monoisotopic } \\
\text { Mass }\end{array}$ & $\begin{array}{l}\text { Chemical } \\
\text { Mass }\end{array}$ \\
\hline 1 & 3257 & RL & $(138-139)$ & beta-lactokinin & $\begin{array}{l}\text { Inhibitor of Angiotensin-Converting } \\
\text { Enzyme (ACE) (EC 3.4.15.1) (MEROPS } \\
\text { ID: XM02-001) }\end{array}$ & ACE inhibitor & 287.1850 & 287.3480 \\
\hline 2 & 7591 & GF & $(130-131)$ & ACE inhibitor & $\begin{array}{l}\text { Inhibitor of Angiotensin-Converting } \\
\text { Enzyme (ACE) (EC 3.4.15.1) (MEROPS } \\
\text { ID: XM02-001) }\end{array}$ & ACE inhibitor & 222.0890 & 222.2290 \\
\hline 3 & 7599 & GL & $(183-184)$ & ACE inhibitor & $\begin{array}{l}\text { Inhibitor of Angiotensin-converting } \\
\text { enzyme (EC 3.4.15.1) (MEROPS ID: } \\
\text { XM02-001) }\end{array}$ & ACE inhibitor & 188.1050 & 188.2120 \\
\hline 4 & 8561 & GL & $(183-184)$ & $\begin{array}{l}\text { dipeptidyl peptidase IV } \\
\text { inhibitor (DPP IV inhibitor) }\end{array}$ & $\begin{array}{l}\text { Inhibitor of Dipeptidyl Peptidase IV } \\
\text { (EC 3.4.14.5) (MEROPS ID: S09.003) }\end{array}$ & $\begin{array}{l}\text { dipeptidyl peptidase } \\
\text { IV inhibitor }\end{array}$ & 188.1050 & 188.2120 \\
\hline 5 & 8782 & GF & $(130-131)$ & $\begin{array}{l}\text { dipeptidyl peptidase IV } \\
\text { inhibitor (DPP IV inhibitor) }\end{array}$ & $\begin{array}{l}\text { Inhibitor of Dipeptidyl Peptidase IV } \\
\text { (EC 3.4.14.5) (MEROPS ID: S09.003) }\end{array}$ & $\begin{array}{l}\text { dipeptidyl peptidase } \\
\text { IV inhibitor }\end{array}$ & 222.0890 & 222.2290 \\
\hline 6 & 8886 & RL & $(138-139)$ & $\begin{array}{l}\text { dipeptidyl peptidase IV } \\
\text { inhibitor (DPP IV inhibitor) }\end{array}$ & $\begin{array}{l}\text { Inhibitor of Dipeptidyl Peptidase IV } \\
\text { (EC 3.4.14.5) (MEROPS ID: S09.003) }\end{array}$ & $\begin{array}{l}\text { dipeptidyl peptidase } \\
\text { IV inhibitor }\end{array}$ & 287.1850 & 287.3480 \\
\hline 7 & 9074 & DF & $(204-205)$ & ACE inhibitor & $\begin{array}{l}\text { Inhibitor of Angiotensin-Converting } \\
\text { Enzyme (ACE) (EC 3.4.15.1) (MEROPS } \\
\text { ID: XM02-001) }\end{array}$ & ACE inhibitor & 280.0949 & 280.2660 \\
\hline
\end{tabular}


Table A6. $A_{E}, D H_{t}, W, B_{E}$ and $V$ values from RubisCO of Halophila stipulacea. In silico enzymatic cleavage carried out by using pepsin.

\begin{tabular}{llllll}
\hline $\begin{array}{l}\mathbf{D H}_{t} \mathbf{( \% )} \\
\mathbf{1 2 . 1 9 5 1}\end{array}$ & & & & \\
\hline No. & Activity & $\boldsymbol{A}_{\boldsymbol{E}}$ & $\boldsymbol{W}$ & $\boldsymbol{B}_{\boldsymbol{E}}$ & $\boldsymbol{V}$ \\
\hline 1 & ACE inhibitor & 0.0194 & 0.0333 & $2.5006640432763 \mathrm{E}-5$ & 0.00093451973448837 \\
2 & dipeptidyl peptidase IV inhibitor & 0.0146 & 0.0224 & $1.8563339357632 \mathrm{E}-6$ & 0.0086054864513139 \\
\hline
\end{tabular}

Table A7. Bioactive peptides from RubisCO of Halophila stipulacea. In silico enzymatic cleavage was carried out by using proteinase $\mathrm{K}$.

\begin{tabular}{|c|c|c|c|c|c|c|c|c|}
\hline No. & $\begin{array}{l}\text { Peptide } \\
\text { ID }\end{array}$ & Sequence & Location & Name & Function & Activity & $\begin{array}{l}\text { Monoisotopic } \\
\text { Mass }\end{array}$ & $\begin{array}{l}\text { Chemical } \\
\text { Mass }\end{array}$ \\
\hline 1 & 3257 & RL & $(138-139)$ & beta-lactokinin & $\begin{array}{l}\text { Inhibitor of Angiotensin-Converting } \\
\text { Enzyme (ACE) (EC 3.4.15.1) (MEROPS } \\
\text { ID: XM02-001) }\end{array}$ & ACE inhibitor & 287.1850 & 287.3480 \\
\hline 2 & 3378 & GRP & $(170-172)$ & ACE inhibitor & $\begin{array}{l}\text { Inhibitor of Angiotensin-Converting } \\
\text { Enzyme (ACE) (EC 3.4.15.1) (MEROPS } \\
\text { ID: XM02-001) }\end{array}$ & ACE inhibitor & 328.1740 & 328.3570 \\
\hline 3 & 3563 & AY & $(101-102)$ & ACE inhibitor & $\begin{array}{l}\text { Inhibitor of Angiotensin-Converting } \\
\text { Enzyme (ACE) (EC 3.4.15.1) (MEROPS } \\
\text { ID: XM02-001) }\end{array}$ & ACE inhibitor & 252.1000 & 252.2490 \\
\hline 4 & 3563 & AY & (104-105) & ACE inhibitor & $\begin{array}{l}\text { Inhibitor of Angiotensin-Converting } \\
\text { Enzyme (ACE) (EC 3.4.15.1) (MEROPS } \\
\text { ID: XM02-001) }\end{array}$ & ACE inhibitor & 252.1000 & 252.2490 \\
\hline 5 & 3563 & AY & (147-148) & ACE inhibitor & $\begin{array}{l}\text { Inhibitor of Angiotensin-Converting } \\
\text { Enzyme (ACE) (EC 3.4.15.1) (MEROPS } \\
\text { ID: XM02-001) }\end{array}$ & ACE inhibitor & 252.1000 & 252.2490 \\
\hline 6 & 7591 & GF & $(12-13)$ & ACE inhibitor & $\begin{array}{l}\text { Inhibitor of Angiotensin-Converting } \\
\text { Enzyme (ACE) (EC 3.4.15.1) (MEROPS } \\
\text { ID: XM02-001) }\end{array}$ & ACE inhibitor & 222.0890 & 222.2290 \\
\hline 7 & 7591 & GF & $(130-131)$ & ACE inhibitor & $\begin{array}{l}\text { Inhibitor of Angiotensin-Converting } \\
\text { Enzyme (ACE) (EC 3.4.15.1) (MEROPS } \\
\text { ID: XM02-001) }\end{array}$ & ACE inhibitor & 222.0890 & 222.2290 \\
\hline 8 & 7599 & GL & $(183-184)$ & ACE inhibitor & $\begin{array}{l}\text { Inhibitor of Angiotensin-converting } \\
\text { enzyme (EC 3.4.15.1) (MEROPS ID: } \\
\text { XM02-001) }\end{array}$ & ACE inhibitor & 188.1050 & 188.2120 \\
\hline
\end{tabular}


Table A7. Cont.

\begin{tabular}{|c|c|c|c|c|c|c|c|c|}
\hline No. & $\begin{array}{l}\text { Peptide } \\
\text { ID }\end{array}$ & Sequence & Location & Name & Function & Activity & $\begin{array}{l}\text { Monoisotopic } \\
\text { Mass }\end{array}$ & $\begin{array}{l}\text { Chemical } \\
\text { Mass }\end{array}$ \\
\hline 9 & 7608 & GV & $(47-48)$ & ACE inhibitor & $\begin{array}{l}\text { Inhibitor of Angiotensin-Converting } \\
\text { Enzyme (ACE) (EC 3.4.15.1) (MEROPS } \\
\text { ID: XM02-001) }\end{array}$ & ACE inhibitor & 174.0890 & 174.1850 \\
\hline 10 & 7693 & KL & $(21-22)$ & ACE inhibitor from wakame & & ACE inhibitor & 259.1780 & 259.3340 \\
\hline 11 & 7693 & KL & $(181-182)$ & ACE inhibitor from wakame & & ACE inhibitor & 259.1780 & 259.3340 \\
\hline 12 & 7752 & $\mathrm{EY}$ & $(28-29)$ & $\begin{array}{l}\text { ACE inhibitor from shark meat } \\
\text { hydrolysate }\end{array}$ & $\begin{array}{l}\text { Inhibitor of Angiotensin-Converting } \\
\text { Enzyme (ACE) (EC 3.4.15.1) (MEROPS } \\
\text { ID: XM02-001) }\end{array}$ & ACE inhibitor & 310.1050 & 310.2860 \\
\hline 13 & 7810 & $\mathrm{KP}$ & $(179-180)$ & $\begin{array}{l}\text { ACE inhibitor from anchovy } \\
\text { and bonito }\end{array}$ & $\begin{array}{l}\text { Inhibitor of Angiotensin-Converting } \\
\text { Enzyme (ACE) (EC 3.4.15.1) (MEROPS } \\
\text { ID: XM02-001) }\end{array}$ & ACE inhibitor & 243.1460 & 243.2910 \\
\hline 14 & 7866 & AY & $(101-102)$ & peptide from Okara protein & $\begin{array}{l}\text { Peptide obtained by hydrolysis of } \\
\text { Okara protein by use of enzymatic } \\
\text { preparation Protease N. }\end{array}$ & antioxidative & 252.1000 & 252.2490 \\
\hline 15 & 7866 & AY & $(104-105)$ & peptide from Okara protein & $\begin{array}{l}\text { Peptide obtained by hydrolysis of } \\
\text { Okara protein by use of enzymatic } \\
\text { preparation Protease N. }\end{array}$ & antioxidative & 252.1000 & 252.2490 \\
\hline 16 & 7866 & AY & $(147-148)$ & peptide from Okara protein & $\begin{array}{l}\text { Peptide obtained by hydrolysis of } \\
\text { Okara protein by use of enzymatic } \\
\text { preparation Protease N. }\end{array}$ & antioxidative & 252.1000 & 252.2490 \\
\hline 17 & 8218 & $\mathrm{KP}$ & $(179-180)$ & Antioxidative peptide & Free radical scavenger & antioxidative & 243.1460 & 243.2910 \\
\hline 18 & 8219 & TY & $(23-24)$ & antioxidative peptide & & antioxidative & 282.1100 & 282.2750 \\
\hline 19 & 8503 & $\mathrm{TP}$ & $(26-27)$ & $\begin{array}{l}\text { Dipeptidyl peptidase IV } \\
\text { inhibitor (DPP IV inhibitor) }\end{array}$ & $\begin{array}{l}\text { Inhibitor of Dipeptidyl Peptidase IV } \\
\text { (EC 3.4.14.5) (MEROPS ID: S09.003) }\end{array}$ & $\begin{array}{l}\text { dipeptidyl peptidase } \\
\text { IV inhibitor }\end{array}$ & 216.0990 & 216.2220 \\
\hline 20 & 8505 & SP & $(2-3)$ & $\begin{array}{l}\text { Dipeptidyl peptidase IV } \\
\text { inhibitor (DPP IV inhibitor) }\end{array}$ & $\begin{array}{l}\text { Inhibitor of Dipeptidyl Peptidase IV } \\
\text { (EC 3.4.14.5) (MEROPS ID: S09.003) }\end{array}$ & $\begin{array}{l}\text { dipeptidyl peptidase } \\
\text { IV inhibitor }\end{array}$ & 202.0840 & 202.1970 \\
\hline 21 & 8505 & SP & $(43-44)$ & $\begin{array}{l}\text { Dipeptidyl peptidase IV } \\
\text { inhibitor (DPP IV inhibitor) }\end{array}$ & $\begin{array}{l}\text { Inhibitor of Dipeptidyl Peptidase IV } \\
\text { (EC 3.4.14.5) (MEROPS ID: S09.003) }\end{array}$ & $\begin{array}{l}\text { dipeptidyl peptidase } \\
\text { IV inhibitor }\end{array}$ & 202.0840 & 202.1970 \\
\hline 22 & 8519 & $\mathrm{KP}$ & $(179-180)$ & $\begin{array}{l}\text { dipeptidyl peptidase IV } \\
\text { inhibitor (DPP IV inhibitor) }\end{array}$ & $\begin{array}{l}\text { Inhibitor of Dipeptidyl Peptidase IV } \\
\text { (EC 3.4.14.5) (MEROPS ID: S09.003) }\end{array}$ & $\begin{array}{l}\text { dipeptidyl peptidase } \\
\text { IV inhibitor }\end{array}$ & 243.1460 & 243.2910 \\
\hline 23 & 8529 & $\mathrm{EP}$ & $(90-91)$ & $\begin{array}{l}\text { dipeptidyl peptidase IV } \\
\text { inhibitor (DPP IV inhibitor) }\end{array}$ & $\begin{array}{l}\text { Inhibitor of Dipeptidyl Peptidase IV } \\
\text { (EC 3.4.14.5) (MEROPS ID: S09.003) }\end{array}$ & $\begin{array}{l}\text { dipeptidyl peptidase } \\
\text { IV inhibitor }\end{array}$ & 244.0940 & 244.2330 \\
\hline 24 & 8532 & $\mathrm{QP}$ & $(45-46)$ & $\begin{array}{l}\text { dipeptidyl peptidase IV } \\
\text { inhibitor (DPP IV inhibitor) }\end{array}$ & $\begin{array}{l}\text { Inhibitor of Dipeptidyl Peptidase IV } \\
\text { (EC 3.4.14.5) (MEROPS ID: S09.003) }\end{array}$ & $\begin{array}{l}\text { dipeptidyl peptidase } \\
\text { IV inhibitor }\end{array}$ & 243.1100 & 243.2480 \\
\hline 25 & 8561 & GL & $(183-184)$ & $\begin{array}{l}\text { dipeptidyl peptidase IV } \\
\text { inhibitor (DPP IV inhibitor) }\end{array}$ & $\begin{array}{l}\text { Inhibitor of Dipeptidyl Peptidase IV } \\
\text { (EC 3.4.14.5) (MEROPS ID: S09.003) }\end{array}$ & $\begin{array}{l}\text { dipeptidyl peptidase } \\
\text { IV inhibitor }\end{array}$ & 188.1050 & 188.2120 \\
\hline
\end{tabular}


Table A7. Cont.

\begin{tabular}{|c|c|c|c|c|c|c|c|c|}
\hline No. & $\begin{array}{l}\text { Peptide } \\
\text { ID }\end{array}$ & Sequence & Location & Name & Function & Activity & $\begin{array}{l}\text { Monoisotopic } \\
\text { Mass }\end{array}$ & $\begin{array}{l}\text { Chemical } \\
\text { Mass }\end{array}$ \\
\hline 26 & 8765 & AY & (101-102) & $\begin{array}{l}\text { dipeptidyl peptidase IV } \\
\text { inhibitor (DPP IV inhibitor) }\end{array}$ & $\begin{array}{l}\text { Inhibitor of Dipeptidyl Peptidase IV } \\
\text { (EC 3.4.14.5) (MEROPS ID: S09.003) }\end{array}$ & $\begin{array}{l}\text { dipeptidyl peptidase } \\
\text { IV inhibitor }\end{array}$ & 252.1000 & 252.2490 \\
\hline 27 & 8765 & AY & $(104-105)$ & $\begin{array}{l}\text { dipeptidyl peptidase IV } \\
\text { inhibitor (DPP IV inhibitor) }\end{array}$ & $\begin{array}{l}\text { Inhibitor of Dipeptidyl Peptidase IV } \\
\text { (EC 3.4.14.5) (MEROPS ID: S09.003) }\end{array}$ & $\begin{array}{l}\text { dipeptidyl peptidase } \\
\text { IV inhibitor }\end{array}$ & 252.1000 & 252.2490 \\
\hline 28 & 8765 & AY & $(147-148)$ & $\begin{array}{l}\text { dipeptidyl peptidase IV } \\
\text { inhibitor (DPP IV inhibitor) }\end{array}$ & $\begin{array}{l}\text { Inhibitor of Dipeptidyl Peptidase IV } \\
\text { (EC 3.4.14.5) (MEROPS ID: S09.003) }\end{array}$ & $\begin{array}{l}\text { dipeptidyl peptidase } \\
\text { IV inhibitor }\end{array}$ & 252.1000 & 252.2490 \\
\hline 29 & 8777 & EY & (28-29) & $\begin{array}{l}\text { dipeptidyl peptidase IV } \\
\text { inhibitor (DPP IV inhibitor) }\end{array}$ & $\begin{array}{l}\text { Inhibitor of Dipeptidyl Peptidase IV } \\
\text { (EC 3.4.14.5) (MEROPS ID: S09.003) }\end{array}$ & $\begin{array}{l}\text { dipeptidyl peptidase } \\
\text { IV inhibitor }\end{array}$ & 310.1050 & 310.2860 \\
\hline 30 & 8782 & GF & $(12-13)$ & $\begin{array}{l}\text { dipeptidyl peptidase IV } \\
\text { inhibitor (DPP IV inhibitor) }\end{array}$ & $\begin{array}{l}\text { Inhibitor of Dipeptidyl Peptidase IV } \\
\text { (EC 3.4.14.5) (MEROPS ID: S09.003) }\end{array}$ & $\begin{array}{l}\text { dipeptidyl peptidase } \\
\text { IV inhibitor }\end{array}$ & 222.0890 & 222.2290 \\
\hline 31 & 8782 & GF & $(130-131)$ & $\begin{array}{l}\text { dipeptidyl peptidase IV } \\
\text { inhibitor (DPP IV inhibitor) }\end{array}$ & $\begin{array}{l}\text { Inhibitor of Dipeptidyl Peptidase IV } \\
\text { (EC 3.4.14.5) (MEROPS ID: S09.003) }\end{array}$ & $\begin{array}{l}\text { dipeptidyl peptidase } \\
\text { IV inhibitor }\end{array}$ & 222.0890 & 222.2290 \\
\hline 32 & 8786 & GV & $(47-48)$ & $\begin{array}{l}\text { dipeptidyl peptidase IV } \\
\text { inhibitor (DPP IV inhibitor) }\end{array}$ & $\begin{array}{l}\text { Inhibitor of Dipeptidyl Peptidase IV } \\
\text { (EC 3.4.14.5) (MEROPS ID: S09.003) }\end{array}$ & $\begin{array}{l}\text { dipeptidyl peptidase } \\
\text { IV inhibitor }\end{array}$ & 174.0890 & 174.1850 \\
\hline 33 & 8793 & $\mathrm{HI}$ & (88-89) & $\begin{array}{l}\text { dipeptidyl peptidase IV } \\
\text { inhibitor (DPP IV inhibitor) }\end{array}$ & $\begin{array}{l}\text { Inhibitor of Dipeptidyl Peptidase IV } \\
\text { (EC 3.4.14.5) (MEROPS ID: S09.003) }\end{array}$ & $\begin{array}{l}\text { dipeptidyl peptidase } \\
\text { IV inhibitor }\end{array}$ & 268.1420 & 268.3020 \\
\hline 34 & 8879 & QV & $(160-161)$ & $\begin{array}{l}\text { dipeptidyl peptidase IV } \\
\text { inhibitor (DPP IV inhibitor) }\end{array}$ & $\begin{array}{l}\text { Inhibitor of Dipeptidyl Peptidase IV } \\
\text { (EC 3.4.14.5) (MEROPS ID: S09.003) }\end{array}$ & $\begin{array}{l}\text { dipeptidyl peptidase } \\
\text { IV inhibitor }\end{array}$ & 245.1260 & 245.2640 \\
\hline 35 & 8884 & RI & $(143-144)$ & $\begin{array}{l}\text { dipeptidyl peptidase IV } \\
\text { inhibitor (DPP IV inhibitor) }\end{array}$ & $\begin{array}{l}\text { Inhibitor of Dipeptidyl Peptidase IV } \\
\text { (EC 3.4.14.5) (MEROPS ID: S09.003) }\end{array}$ & $\begin{array}{l}\text { dipeptidyl peptidase } \\
\text { IV inhibitor }\end{array}$ & 287.1850 & 287.3480 \\
\hline 36 & 8886 & RL & $(138-139)$ & $\begin{array}{l}\text { dipeptidyl peptidase IV } \\
\text { inhibitor (DPP IV inhibitor) }\end{array}$ & $\begin{array}{l}\text { Inhibitor of Dipeptidyl Peptidase IV } \\
\text { (EC 3.4.14.5) (MEROPS ID: S09.003) }\end{array}$ & $\begin{array}{l}\text { dipeptidyl peptidase } \\
\text { IV inhibitor }\end{array}$ & 287.1850 & 287.3480 \\
\hline 37 & 8914 & TY & $(23-24)$ & $\begin{array}{l}\text { dipeptidyl peptidase IV } \\
\text { inhibitor (DPP IV inhibitor) }\end{array}$ & $\begin{array}{l}\text { Inhibitor of Dipeptidyl Peptidase IV } \\
\text { (EC 3.4.14.5) (MEROPS ID: S09.003) }\end{array}$ & $\begin{array}{l}\text { dipeptidyl peptidase } \\
\text { IV inhibitor }\end{array}$ & 282.1100 & 282.2750 \\
\hline 38 & 9073 & $\mathrm{TP}$ & $(26-27)$ & ACE inhibitor & $\begin{array}{l}\text { Inhibitor of Angiotensin-Converting } \\
\text { Enzyme (ACE) (EC 3.4.15.1) (MEROPS } \\
\text { ID: M02-001) }\end{array}$ & ACE inhibitor & 216.0990 & 216.2220 \\
\hline 39 & 9074 & DF & $(204-205)$ & ACE inhibitor & $\begin{array}{l}\text { Inhibitor of Angiotensin-Converting } \\
\text { Enzyme (ACE) (EC 3.4.15.1) (MEROPS } \\
\text { ID: XM02-001) }\end{array}$ & ACE inhibitor & 280.0949 & 280.2660 \\
\hline 40 & 9146 & QGP & $(153-155)$ & ACE inhibitor & $\begin{array}{l}\text { Inhibitor of Angiotensin-Converting } \\
\text { Enzyme (ACE) (EC 3.4.15.1) (MEROPS } \\
\text { ID: XM02-001) }\end{array}$ & ACE inhibitor & 300.1310 & 300.3000 \\
\hline
\end{tabular}


Table A8. $A_{E}, D H_{t}, W, B_{E}$ and $V$ values from RubisCO of Halophila stipulacea. In silico enzymatic cleavage was carried out by proteinase $\mathrm{K}$.

\begin{tabular}{llllll}
\hline $\begin{array}{l}D H_{t} \mathbf{( \% )} \\
\mathbf{3 7 . 0 7 3 2}\end{array}$ & & & & & \\
\hline No. & Activity & $A_{E}$ & $W$ & $B_{E}$ & $\boldsymbol{V}$ \\
\hline 1 & ACE inhibitor & 0.0777 & 0.1334 & 0.00331887346989932 & 0.12402916586194 \\
2 & antioxidative & 0.0243 & 0.3338 & 0 & 0 \\
3 & dipeptidyl peptidase IV inhibitor & 0.0922 & 0.1417 & $7.4392944998736 \mathrm{E}-6$ & 0.034486655009987 \\
\hline
\end{tabular}

Table A9. Bioactive peptides from RubisCO of Halophila stipulacea. In silico enzymatic cleavage was carried out by using pancreatic elastase.

\begin{tabular}{|c|c|c|c|c|c|c|c|c|}
\hline No. & $\begin{array}{l}\text { Peptide } \\
\text { ID }\end{array}$ & Sequence & Location & Name & Function & Activity & $\begin{array}{l}\text { Monoisotopic } \\
\text { Mass }\end{array}$ & $\begin{array}{l}\text { Chemica } \\
\text { Mass }\end{array}$ \\
\hline 1 & 3174 & KA & $(8-9)$ & $\begin{array}{l}\text { dipeptidyl peptidase IV } \\
\text { inhibitor (DPP IV inhibitor) }\end{array}$ & $\begin{array}{l}\text { Inhibitor of Dipeptidyl Peptidase IV } \\
\text { (EC 3.4.14.5) (MEROPS ID: S09.003) }\end{array}$ & $\begin{array}{l}\text { dipeptidyl peptidase } \\
\text { IV inhibitor }\end{array}$ & 217.1310 & 217.2530 \\
\hline 2 & 3257 & RL & $(138-139)$ & beta-lactokinin & $\begin{array}{l}\text { Inhibitor of Angiotensin-Converting } \\
\text { Enzyme (ACE) (EC 3.4.15.1) (MEROPS } \\
\text { ID: XM02-001) }\end{array}$ & ACE inhibitor & 287.1850 & 287.3480 \\
\hline 3 & 4005 & RA & $(135-136)$ & & $\begin{array}{l}\text { Activation of ubiquitin-dependent } \\
\text { proteolysis }\end{array}$ & $\begin{array}{l}\text { activating } \\
\text { ubiquitin-mediated } \\
\text { proteolysis }\end{array}$ & 245.1380 & 245.2670 \\
\hline 4 & 4005 & RA & $(193-194)$ & & $\begin{array}{l}\text { Activation of ubiquitin-dependent } \\
\text { proteolysis }\end{array}$ & $\begin{array}{l}\text { activating } \\
\text { ubiquitin-mediated } \\
\text { proteolysis }\end{array}$ & 245.1380 & 245.2670 \\
\hline 5 & 7513 & PL & $(106-107)$ & $\begin{array}{l}\text { ACE inhibitor from Alaskan } \\
\text { pollack skin }\end{array}$ & $\begin{array}{l}\text { Inhibitor of Angiotensin-converting } \\
\text { enzyme (EC 3.4.15.1) (MEROPS ID: } \\
\text { XM02-001) }\end{array}$ & ACE inhibitor & 228.1360 & 228.2770 \\
\hline 6 & 7588 & RA & $(135-136)$ & ACE inhibitor & $\begin{array}{l}\text { Inhibitor of Angiotensin-Converting } \\
\text { Enzyme (ACE) (EC 3.4.15.1) (MEROPS } \\
\text { ID: XM02-001) }\end{array}$ & ACE inhibitor & 245.1380 & 245.2670 \\
\hline 7 & 7588 & RA & $(193-194)$ & ACE inhibitor & $\begin{array}{l}\text { Inhibitor of Angiotensin-Converting } \\
\text { Enzyme (ACE) (EC 3.4.15.1) (MEROPS } \\
\text { ID: XM02-001) }\end{array}$ & ACE inhibitor & 245.1380 & 245.2670 \\
\hline 8 & 7604 & KG & $(83-84)$ & ACE inhibitor & $\begin{array}{l}\text { Inhibitor of Angiotensin-converting } \\
\text { enzyme (EC 3.4.15.1; MEROPS ID: } \\
\text { XM02-001) }\end{array}$ & ACE inhibitor & 203.1150 & 203.2260 \\
\hline 9 & 7605 & FG & $(129-130)$ & ACE inhibitor & $\begin{array}{l}\text { Inhibitor of Angiotensin-Converting } \\
\text { Enzyme (ACE) (EC 3.4.15.1) (MEROPS } \\
\text { ID: XM02-001) }\end{array}$ & ACE inhibitor & 222.0890 & 222.2290 \\
\hline
\end{tabular}


Table A9. Cont.

\begin{tabular}{|c|c|c|c|c|c|c|c|c|}
\hline No. & $\begin{array}{l}\text { Peptide } \\
\text { ID }\end{array}$ & Sequence & Location & Name & Function & Activity & $\begin{array}{l}\text { Monoisotopic } \\
\text { Mass }\end{array}$ & $\begin{array}{l}\text { Chemical } \\
\text { Mass }\end{array}$ \\
\hline 10 & 7681 & DG & $(74-75)$ & ACE inhibitor from soy & $\begin{array}{l}\text { Inhibitor of Angiotensin-converting } \\
\text { enzyme (ACE) (EC 3.4.15.1) (MEROPS } \\
\text { ID: XM02-001) }\end{array}$ & ACE inhibitor & 190.0479 & 190.1410 \\
\hline 11 & 7693 & KL & $(21-22)$ & ACE inhibitor from wakame & & ACE inhibitor & 259.1780 & 259.3340 \\
\hline 12 & 7743 & KA & $(8-9)$ & ACE inhibitor & $\begin{array}{l}\text { Inhibitor of angiotensin-converting } \\
\text { enzyme (EC 3.4.15.1) (MEROPS ID: } \\
\text { XM02-001) }\end{array}$ & ACE inhibitor & 217.1310 & 217.2530 \\
\hline 13 & 8526 & RA & $(135-136)$ & $\begin{array}{l}\text { dipeptidyl peptidase IV } \\
\text { inhibitor (DPP IV inhibitor) }\end{array}$ & $\begin{array}{l}\text { Inhibitor of Dipeptidyl Peptidase IV } \\
\text { (EC 3.4.14.5) (MEROPS ID: S09.003) }\end{array}$ & $\begin{array}{l}\text { dipeptidyl peptidase } \\
\text { IV inhibitor }\end{array}$ & 245.1380 & 245.2670 \\
\hline 14 & 8526 & RA & $(193-194)$ & $\begin{array}{l}\text { dipeptidyl peptidase IV } \\
\text { inhibitor (DPP IV inhibitor) }\end{array}$ & $\begin{array}{l}\text { Inhibitor of Dipeptidyl Peptidase IV } \\
\text { (EC 3.4.14.5) (MEROPS ID: S09.003) }\end{array}$ & $\begin{array}{l}\text { dipeptidyl peptidase } \\
\text { IV inhibitor }\end{array}$ & 245.1380 & 245.2670 \\
\hline 15 & 8638 & PL & $(106-107)$ & $\begin{array}{l}\text { dipeptidyl peptidase IV } \\
\text { inhibitor (DPP IV inhibitor) }\end{array}$ & $\begin{array}{l}\text { Inhibitor of Dipeptidyl Peptidase IV } \\
\text { (EC 3.4.14.5) (MEROPS ID: S09.003) }\end{array}$ & $\begin{array}{l}\text { dipeptidyl peptidase } \\
\text { IV inhibitor }\end{array}$ & 228.1360 & 228.2770 \\
\hline 16 & 8685 & WT & $(68-69)$ & $\begin{array}{l}\text { dipeptidyl peptidase IV } \\
\text { inhibitor (DPP IV inhibitor) }\end{array}$ & $\begin{array}{l}\text { Inhibitor of Dipeptidyl Peptidase IV } \\
\text { (EC 3.4.14.5) (MEROPS ID: S09.003) }\end{array}$ & $\begin{array}{l}\text { dipeptidyl peptidase } \\
\text { IV inhibitor }\end{array}$ & 305.1260 & 305.3180 \\
\hline 17 & 8685 & WT & $(72-73)$ & $\begin{array}{l}\text { dipeptidyl peptidase IV } \\
\text { inhibitor (DPP IV inhibitor) }\end{array}$ & $\begin{array}{l}\text { Inhibitor of Dipeptidyl Peptidase IV } \\
\text { (EC 3.4.14.5) (MEROPS ID: S09.003) }\end{array}$ & $\begin{array}{l}\text { dipeptidyl peptidase } \\
\text { IV inhibitor }\end{array}$ & 305.1260 & 305.3180 \\
\hline 18 & 8774 & ET & $(6-7)$ & $\begin{array}{l}\text { dipeptidyl peptidase IV } \\
\text { inhibitor (DPP IV inhibitor) }\end{array}$ & $\begin{array}{l}\text { Inhibitor of Dipeptidyl Peptidase IV } \\
\text { (EC 3.4.14.5) (MEROPS ID: S09.003) }\end{array}$ & $\begin{array}{l}\text { dipeptidyl peptidase } \\
\text { IV inhibitor }\end{array}$ & 248.0890 & 248.2210 \\
\hline 19 & 8774 & ET & $(30-31)$ & $\begin{array}{l}\text { dipeptidyl peptidase IV } \\
\text { inhibitor (DPP IV inhibitor) }\end{array}$ & $\begin{array}{l}\text { Inhibitor of Dipeptidyl Peptidase IV } \\
\text { (EC 3.4.14.5) (MEROPS ID: S09.003) }\end{array}$ & $\begin{array}{l}\text { dipeptidyl peptidase } \\
\text { IV inhibitor }\end{array}$ & 248.0890 & 248.2210 \\
\hline 20 & 8793 & $\mathrm{HI}$ & $(88-89)$ & $\begin{array}{l}\text { dipeptidyl peptidase IV } \\
\text { inhibitor (DPP IV inhibitor) }\end{array}$ & $\begin{array}{l}\text { Inhibitor of Dipeptidyl Peptidase IV } \\
\text { (EC 3.4.14.5) (MEROPS ID: S09.003) }\end{array}$ & $\begin{array}{l}\text { dipeptidyl peptidase } \\
\text { IV inhibitor }\end{array}$ & 268.1420 & 268.3020 \\
\hline 21 & 8810 & KG & $(83-84)$ & $\begin{array}{l}\text { dipeptidyl peptidase IV } \\
\text { inhibitor (DPP IV inhibitor) }\end{array}$ & $\begin{array}{l}\text { Inhibitor of Dipeptidyl Peptidase IV } \\
\text { (EC 3.4.14.5) (MEROPS ID: S09.003) }\end{array}$ & $\begin{array}{l}\text { dipeptidyl peptidase } \\
\text { IV inhibitor }\end{array}$ & 203.1150 & 203.2260 \\
\hline 22 & 8816 & $\mathrm{KT}$ & $(150-151)$ & $\begin{array}{l}\text { dipeptidyl peptidase IV } \\
\text { inhibitor (DPP IV inhibitor) }\end{array}$ & $\begin{array}{l}\text { Inhibitor of Dipeptidyl Peptidase IV } \\
\text { (EC 3.4.14.5) (MEROPS ID: S09.003) }\end{array}$ & $\begin{array}{l}\text { dipeptidyl peptidase } \\
\text { IV inhibitor }\end{array}$ & 247.1410 & 247.2790 \\
\hline 23 & 8851 & NV & $(127-128)$ & $\begin{array}{l}\text { dipeptidyl peptidase IV } \\
\text { inhibitor (DPP IV inhibitor) }\end{array}$ & $\begin{array}{l}\text { Inhibitor of Dipeptidyl Peptidase IV } \\
\text { (EC 3.4.14.5) (MEROPS ID: S09.003) }\end{array}$ & $\begin{array}{l}\text { dipeptidyl peptidase } \\
\text { IV inhibitor }\end{array}$ & 231.1109 & 231.2370 \\
\hline 24 & 8879 & QV & $(160-161)$ & $\begin{array}{l}\text { dipeptidyl peptidase IV } \\
\text { inhibitor (DPP IV inhibitor) }\end{array}$ & $\begin{array}{l}\text { Inhibitor of Dipeptidyl Peptidase IV } \\
\text { (EC 3.4.14.5) (MEROPS ID: S09.003) }\end{array}$ & $\begin{array}{l}\text { dipeptidyl peptidase } \\
\text { IV inhibitor }\end{array}$ & 245.1260 & 245.2640 \\
\hline 25 & 8882 & RG & $(200-201)$ & $\begin{array}{l}\text { dipeptidyl peptidase IV } \\
\text { inhibitor (DPP IV inhibitor) }\end{array}$ & $\begin{array}{l}\text { Inhibitor of Dipeptidyl Peptidase IV } \\
\text { (EC 3.4.14.5) (MEROPS ID: S09.003) }\end{array}$ & $\begin{array}{l}\text { dipeptidyl peptidase } \\
\text { IV inhibitor }\end{array}$ & 231.1220 & 231.2400 \\
\hline 26 & 8884 & RI & $(143-144)$ & $\begin{array}{l}\text { dipeptidyl peptidase IV } \\
\text { inhibitor (DPP IV inhibitor) }\end{array}$ & $\begin{array}{l}\text { Inhibitor of Dipeptidyl Peptidase IV } \\
\text { (EC 3.4.14.5) (MEROPS ID: S09.003) }\end{array}$ & $\begin{array}{l}\text { dipeptidyl peptidase } \\
\text { IV inhibitor }\end{array}$ & 287.1850 & 287.3480 \\
\hline 27 & 8886 & RL & $(138-139)$ & $\begin{array}{l}\text { dipeptidyl peptidase IV } \\
\text { inhibitor (DPP IV inhibitor) }\end{array}$ & $\begin{array}{l}\text { Inhibitor of Dipeptidyl Peptidase IV } \\
\text { (EC 3.4.14.5) (MEROPS ID: S09.003) }\end{array}$ & $\begin{array}{l}\text { dipeptidyl peptidase } \\
\text { IV inhibitor }\end{array}$ & 287.1850 & 287.3480 \\
\hline
\end{tabular}


Table A10. $A_{E}, D H_{t}, W, B_{E}$ and $V$ values from RubisCO of Halophila stipulacea. In silico enzymatic cleavage was carried out by pancreatic elastase.

\begin{tabular}{|c|c|c|c|c|c|}
\hline \multicolumn{6}{|c|}{$\begin{array}{l}D H_{t}(\%) \\
54.6341\end{array}$} \\
\hline No. & Activity & $A_{E}$ & $W$ & $B_{E}$ & $V$ \\
\hline 1 & dipeptidyl peptidase IV inhibitorinhibitor & 0.0777 & 0.1194 & 2.0912653098933E-5 & 0.096945678488557 \\
\hline 2 & ACE inhibitor & 0.0437 & 0.0750 & 0.0006857879028624 & 0.025628485786464 \\
\hline 3 & activating ubiquitin-mediated proteolysis & 0.0097 & 0.6644 & 0 & \\
\hline
\end{tabular}

Table A11. Bioactive peptides from RubisCO of Halophila stipulacea. In silico enzymatic cleavage was carried out by using prolyl oligopeptidase.

\begin{tabular}{|c|c|c|c|c|c|c|c|c|}
\hline No. & $\begin{array}{l}\text { Peptide } \\
\text { ID }\end{array}$ & Sequence & Location & Name & Function & Activity & $\begin{array}{l}\text { Monoisotopic } \\
\text { Mass }\end{array}$ & $\begin{array}{l}\text { Chemical } \\
\text { Mass }\end{array}$ \\
\hline 1 & 8532 & QP & $(45-46)$ & $\begin{array}{l}\text { dipeptidyl peptidase IV } \\
\text { inhibitor (DPP IV inhibitor) }\end{array}$ & $\begin{array}{l}\text { Inhibitor of Dipeptidyl Peptidase IV } \\
\text { (EC 3.4.14.5) (MEROPS ID: S09.003) }\end{array}$ & $\begin{array}{l}\text { dipeptidyl peptidase } \\
\text { IV inhibitor }\end{array}$ & 243.1100 & 243.2480 \\
\hline
\end{tabular}

Table A12. $A_{E}, D H_{t}, W, B_{E}$ and $V$ values from RubisCO of Halophila stipulacea. In silico enzymatic cleavage was carried out by prolyl oligopeptidase.

\begin{tabular}{llllll}
\hline $\begin{array}{l}\mathrm{DH}_{t} \text { (\%) } \\
6.8293\end{array}$ & & & & & \\
No. & Activity & $A_{E}$ & $W$ & $B_{E}$ & $V$ \\
\hline $1 \quad$ dipeptidyl peptidase IV inhibitor & 0.0049 & 0.0075 & 0 & 0 \\
\hline
\end{tabular}

Table A13. Bioactive peptides from RubisCO of Halophila stipulacea. In silico enzymatic cleavage was carried out by using V-protease.

\begin{tabular}{|c|c|c|c|c|c|c|c|c|}
\hline No. & $\begin{array}{l}\text { Peptide } \\
\text { ID }\end{array}$ & Sequence & Location & Name & Function & Activity & $\begin{array}{l}\text { Monoisotopic } \\
\text { Mass }\end{array}$ & $\begin{array}{l}\text { Chemical } \\
\text { Mass }\end{array}$ \\
\hline 1 & 8934 & YE & $(29-30)$ & $\begin{array}{l}\text { dipeptidyl peptidase IV } \\
\text { inhibitor (DPP IV inhibitor) }\end{array}$ & $\begin{array}{l}\text { Inhibitor of Dipeptidyl Peptidase IV } \\
\text { (EC 3.4.14.5) (MEROPS ID: S09.003) }\end{array}$ & $\begin{array}{l}\text { dipeptidyl peptidase } \\
\text { IV inhibitor }\end{array}$ & 310.1050 & 310.2860 \\
\hline 2 & 9078 & YE & $(29-30)$ & ACE inhibitor & $\begin{array}{l}\text { Inhibitor of Angiotensin-Converting } \\
\text { Enzyme (ACE) (EC 3.4.15.1) (MEROPS } \\
\text { ID: XM02-001) }\end{array}$ & ACE inhibitor & 310.1050 & 310.2860 \\
\hline
\end{tabular}


Table A14. $A_{E}, D H_{t}, W, B_{E}$ and $V$ values from RubisCO of Halophila stipulacea. In silico enzymatic cleavage was carried out by V-protease.

\begin{tabular}{llllll}
\hline $\begin{array}{l}\mathrm{DH}_{\boldsymbol{t}}(\mathbf{\%}) \\
7.3171\end{array}$ & & & & & \\
\hline No. & Activity & $A_{E}$ & $\boldsymbol{W}$ & $\boldsymbol{B}_{E}$ & $\boldsymbol{V}$ \\
\hline 1 & dipeptidyl peptidase IV inhibitor & 0.0049 & 0.0075 & 0 & 0 \\
2 & ACE inhibitor & 0.0049 & 0.0084 & $7.6943555746376 \mathrm{E}-6$ & 0.0002875447082947 \\
\hline
\end{tabular}

Table A15. Bioactive peptides from RubisCO of Halophila stipulacea. In silico enzymatic cleavage was carried out by using thermolysin.

\begin{tabular}{|c|c|c|c|c|c|c|c|c|}
\hline No. & $\begin{array}{l}\text { Peptide } \\
\text { ID }\end{array}$ & Sequence & Location & Name & Function & Activity & $\begin{array}{l}\text { Monoisotopic } \\
\text { Mass }\end{array}$ & $\begin{array}{l}\text { Chemical } \\
\text { Mass }\end{array}$ \\
\hline 1 & 3522 & IPP & $(144-146)$ & $\begin{array}{l}\text { ACE inhibitor (from bovine } \\
\text { b-CN) }\end{array}$ & & ACE inhibitor & 325.1880 & 325.3940 \\
\hline 2 & 3666 & YP & $(105-106)$ & ACE inhibitor & $\begin{array}{l}\text { Inhibitor of Angiotensin-Converting Enzyme } \\
\text { (ACE) (EC 3.4.15.1) (MEROPS ID: XM02-001) }\end{array}$ & ACE inhibitor & 278.1150 & 278.2870 \\
\hline 3 & 7592 & FR & $(40-41)$ & ACE inhibitor & & ACE inhibitor & 321.1690 & 321.3650 \\
\hline 4 & 7594 & VG & $(11-12)$ & ACE inhibitor & $\begin{array}{l}\text { Inhibitor of Angiotensin-Converting Enzyme } \\
\text { (ACE) (EC 3.4.15.1) (MEROPS ID: XM02-001) }\end{array}$ & ACE inhibitor & 174.0890 & 174.1850 \\
\hline 5 & 7600 & AG & $(9-10)$ & ACE inhibitor & $\begin{array}{l}\text { Inhibitor of Angiotensin-Converting Enzyme } \\
\text { (ACE) (EC 3.4.15.1) (MEROPS ID: XM02-001) }\end{array}$ & ACE inhibitor & 146.0580 & 146.1310 \\
\hline 6 & 7600 & AG & $(15-16)$ & ACE inhibitor & $\begin{array}{l}\text { Inhibitor of Angiotensin-Converting Enzyme } \\
\text { (ACE) (EC 3.4.15.1) (MEROPS ID: XM02-001) }\end{array}$ & ACE inhibitor & 146.0580 & 146.1310 \\
\hline 7 & 7600 & AG & $(53-54)$ & ACE inhibitor & $\begin{array}{l}\text { Inhibitor of Angiotensin-Converting Enzyme } \\
\text { (ACE) (EC 3.4.15.1) (MEROPS ID: XM02-001) }\end{array}$ & ACE inhibitor & 146.0580 & 146.1310 \\
\hline 8 & 7605 & FG & $(129-130)$ & ACE inhibitor & $\begin{array}{l}\text { Inhibitor of Angiotensin-Converting Enzyme } \\
\text { (ACE) (EC 3.4.15.1) (MEROPS ID: XM02-001) }\end{array}$ & ACE inhibitor & 222.0890 & 222.2290 \\
\hline 9 & 7619 & LG & $(182-183)$ & ACE inhibitor & $\begin{array}{l}\text { Inhibitor of Angiotensin-converting enzyme (EC } \\
\text { 3.4.15.1) (MEROPS ID: XM02-001) }\end{array}$ & ACE inhibitor & 188.1050 & 188.2120 \\
\hline 10 & 7697 & YK & $(20-21)$ & ACE inhibitor from wakame & & ACE inhibitor & 309.1570 & 309.3440 \\
\hline 11 & 7859 & IEP & $(89-91)$ & ACE inhibitor & $\begin{array}{l}\text { Inhibitor of Angiotensin-Converting Enzyme } \\
\text { (ACE) (EC 3.4.15.1) (MEROPS ID: XM02-001) }\end{array}$ & ACE inhibitor & 357.1780 & 357.3930 \\
\hline 12 & 8521 & YP & $(105-106)$ & $\begin{array}{l}\text { dipeptidyl peptidase IV } \\
\text { inhibitor (DPP IV inhibitor) }\end{array}$ & $\begin{array}{l}\text { Inhibitor of Dipeptidyl Peptidase IV (EC 3.4.14.5) } \\
\text { (MEROPS ID: S09.003) }\end{array}$ & $\begin{array}{l}\text { dipeptidyl peptidase } \\
\text { IV inhibitor }\end{array}$ & 278.1150 & 278.2870 \\
\hline
\end{tabular}


Table A15. Cont

\begin{tabular}{|c|c|c|c|c|c|c|c|c|}
\hline No. & $\begin{array}{l}\text { Peptide } \\
\text { ID }\end{array}$ & Sequence & Location & Name & Function & Activity & $\begin{array}{l}\text { Monoisotopic } \\
\text { Mass }\end{array}$ & $\begin{array}{l}\text { Chemical } \\
\text { Mass }\end{array}$ \\
\hline 13 & 8760 & AG & $(9-10)$ & $\begin{array}{l}\text { dipeptidyl peptidase IV } \\
\text { inhibitor (DPP IV inhibitor) }\end{array}$ & $\begin{array}{l}\text { Inhibitor of Dipeptidyl Peptidase IV (EC 3.4.14.5) } \\
\text { (MEROPS ID: S09.003) }\end{array}$ & $\begin{array}{l}\text { dipeptidyl peptidase } \\
\text { IV inhibitor }\end{array}$ & 146.0580 & 146.1310 \\
\hline 14 & 8760 & AG & $(15-16)$ & $\begin{array}{l}\text { dipeptidyl peptidase IV } \\
\text { inhibitor (DPP IV inhibitor) }\end{array}$ & $\begin{array}{l}\text { Inhibitor of Dipeptidyl Peptidase IV (EC 3.4.14.5) } \\
\text { (MEROPS ID: S09.003) }\end{array}$ & $\begin{array}{l}\text { dipeptidyl peptidase } \\
\text { IV inhibitor }\end{array}$ & 146.0580 & 146.1310 \\
\hline 15 & 8760 & AG & $(53-54)$ & $\begin{array}{l}\text { dipeptidyl peptidase IV } \\
\text { inhibitor (DPP IV inhibitor) }\end{array}$ & $\begin{array}{l}\text { Inhibitor of Dipeptidyl Peptidase IV (EC 3.4.14.5) } \\
\text { (MEROPS ID: S09.003) }\end{array}$ & $\begin{array}{l}\text { dipeptidyl peptidase } \\
\text { IV inhibitor }\end{array}$ & 146.0580 & 146.1310 \\
\hline 16 & 8779 & FQ & $(13-14)$ & $\begin{array}{l}\text { dipeptidyl peptidase IV } \\
\text { inhibitor (DPP IV inhibitor) }\end{array}$ & $\begin{array}{l}\text { Inhibitor of Dipeptidyl Peptidase IV (EC 3.4.14.5) } \\
\text { (MEROPS ID: S09.003) }\end{array}$ & $\begin{array}{l}\text { dipeptidyl peptidase } \\
\text { IV inhibitor }\end{array}$ & 293.1260 & 293.3080 \\
\hline 17 & 8780 & FR & $(40-41)$ & $\begin{array}{l}\text { dipeptidyl peptidase IV } \\
\text { inhibitor (DPP IV inhibitor) }\end{array}$ & $\begin{array}{l}\text { Inhibitor of Dipeptidyl Peptidase IV (EC 3.4.14.5) } \\
\text { (MEROPS ID: S09.003) }\end{array}$ & $\begin{array}{l}\text { dipeptidyl peptidase } \\
\text { IV inhibitor }\end{array}$ & 321.1690 & 321.3650 \\
\hline 18 & 8805 & IQ & $(159-160)$ & $\begin{array}{l}\text { dipeptidyl peptidase IV } \\
\text { inhibitor (DPP IV inhibitor) }\end{array}$ & $\begin{array}{l}\text { Inhibitor of Dipeptidyl Peptidase IV (EC 3.4.14.5) } \\
\text { (MEROPS ID: S09.003) }\end{array}$ & $\begin{array}{l}\text { dipeptidyl peptidase } \\
\text { IV inhibitor }\end{array}$ & 259.1420 & 259.2910 \\
\hline 19 & 8824 & LT & $(22-23)$ & $\begin{array}{l}\text { dipeptidyl peptidase IV } \\
\text { inhibitor (DPP IV inhibitor) }\end{array}$ & $\begin{array}{l}\text { Inhibitor of Dipeptidyl Peptidase IV (EC 3.4.14.5) } \\
\text { (MEROPS ID: S09.003) }\end{array}$ & $\begin{array}{l}\text { dipeptidyl peptidase } \\
\text { IV inhibitor }\end{array}$ & 232.1310 & 232.2650 \\
\hline 20 & 8918 & VG & $(11-12)$ & $\begin{array}{l}\text { dipeptidyl peptidase IV } \\
\text { inhibitor (DPP IV inhibitor) }\end{array}$ & $\begin{array}{l}\text { Inhibitor of Dipeptidyl Peptidase IV (EC 3.4.14.5) } \\
\text { (MEROPS ID: S09.003) }\end{array}$ & $\begin{array}{l}\text { dipeptidyl peptidase } \\
\text { IV inhibitor }\end{array}$ & 174.0890 & 174.1850 \\
\hline 21 & 8937 & YH & $(87-88)$ & $\begin{array}{l}\text { dipeptidyl peptidase IV } \\
\text { inhibitor (DPP IV inhibitor) }\end{array}$ & $\begin{array}{l}\text { Inhibitor of Dipeptidyl Peptidase IV (EC 3.4.14.5) } \\
\text { (MEROPS ID: S09.003) }\end{array}$ & $\begin{array}{l}\text { dipeptidyl peptidase } \\
\text { IV inhibitor }\end{array}$ & 318.1210 & 318.3120 \\
\hline 22 & 8939 & YK & $(20-21)$ & $\begin{array}{l}\text { dipeptidyl peptidase IV } \\
\text { inhibitor (DPP IV inhibitor) }\end{array}$ & $\begin{array}{l}\text { Inhibitor of Dipeptidyl Peptidase IV (EC 3.4.14.5) } \\
\text { (MEROPS ID: S09.003) }\end{array}$ & $\begin{array}{l}\text { dipeptidyl peptidase } \\
\text { IV inhibitor }\end{array}$ & 309.1570 & 309.3440 \\
\hline 23 & 9076 & FQ & $(13-14)$ & ACE inhibitor & $\begin{array}{l}\text { Inhibitor of Angiotensin-Converting Enzyme } \\
\text { (ACE) (EC 3.4.15.1) (MEROPS ID: XM02-001) }\end{array}$ & ACE inhibitor & 293.1260 & 293.3080 \\
\hline 24 & 9087 & $\mathrm{YH}$ & $(87-88)$ & ACE inhibitor & $\begin{array}{l}\text { Inhibitor of Angiotensin-Converting Enzyme } \\
\text { (ACE) (EC 3.4.15.1) (MEROPS ID: XM02-001) }\end{array}$ & ACE inhibitor & 318.1210 & 318.3120 \\
\hline 25 & 9213 & LR & $(134-135)$ & ACE inhibitor & $\begin{array}{l}\text { Inhibitor of Angiotensin-Converting Enzyme } \\
\text { (ACE) (EC 3.4.15.1) (MEROPS ID: M02-001) }\end{array}$ & ACE inhibitor & 287.1850 & 287.3480 \\
\hline 26 & 9213 & LR & $(137-138)$ & ACE inhibitor & $\begin{array}{l}\text { Inhibitor of Angiotensin-Converting Enzyme } \\
\text { (ACE) (EC 3.4.15.1) (MEROPS ID: M02-001) }\end{array}$ & ACE inhibitor & 287.1850 & 287.3480 \\
\hline 27 & 9213 & LR & $(142-143)$ & ACE inhibitor & $\begin{array}{l}\text { Inhibitor of Angiotensin-Converting Enzyme } \\
\text { (ACE) (EC 3.4.15.1) (MEROPS ID: M02-001) }\end{array}$ & ACE inhibitor & 287.1850 & 287.3480 \\
\hline
\end{tabular}


Table A16. $A_{E}, D H_{t}, W, B_{E}$ and $V$ values from RubisCO of Halophila stipulacea. In silico enzymatic cleavage was carried out by thermolysin.

\begin{tabular}{llllll}
\hline $\begin{array}{l}\mathbf{D H}_{\boldsymbol{t}} \mathbf{( \% )} \\
\mathbf{3 6 . 5 8 5 4}\end{array}$ & & & & \\
\hline No. & Activity & $\boldsymbol{A}_{E}$ & $\boldsymbol{W}$ & $\boldsymbol{B}_{\boldsymbol{E}}$ & $\boldsymbol{V}$ \\
\hline 1 & ACE inhibitor & 0.0777 & 0.1334 & 0.0051700207807555 & 0.19320813846713 \\
2 & dipeptidyl peptidase IV inhibitor & 0.0534 & 0.0821 & $1.5313466662583 \mathrm{E}-6$ & 0.0070989290961449 \\
\hline
\end{tabular}

Table A17. Bioactive peptides from RubisCO of Halophila stipulacea. In silico enzymatic cleavage was carried out by using Chymotrypsin.

\begin{tabular}{|c|c|c|c|c|c|c|c|c|}
\hline No. & $\begin{array}{l}\text { Peptide } \\
\text { ID }\end{array}$ & Sequence & Location & Name & Function & Activity & $\begin{array}{l}\text { Monoisotopic } \\
\text { Mass }\end{array}$ & $\begin{array}{l}\text { Chemica } \\
\text { Mass }\end{array}$ \\
\hline 1 & 2753 & GP & $(154-155)$ & $\begin{array}{l}\text { peptide regulating the stomach } \\
\text { mucosal membrane activity }\end{array}$ & $\begin{array}{l}\text { regulating the stomach mucosal } \\
\text { membrane activity }\end{array}$ & regulating & 172.0730 & 172.1690 \\
\hline 2 & 3169 & GP & $(154-155)$ & $\begin{array}{l}\text { dipeptidyl peptidase IV } \\
\text { inhibitor (DPP IV inhibitor) }\end{array}$ & $\begin{array}{l}\text { Inhibitor of Dipeptidyl Peptidase IV } \\
\text { (EC 3.4.14.5) (MEROPS ID: S09.003) }\end{array}$ & $\begin{array}{l}\text { dipeptidyl peptidase } \\
\text { IV inhibitor }\end{array}$ & 172.0730 & 172.1690 \\
\hline 3 & 3257 & RL & $(138-139)$ & beta-lactokinin & $\begin{array}{l}\text { Inhibitor of Angiotensin-Converting } \\
\text { Enzyme (ACE) (EC 3.4.15.1) (MEROPS } \\
\text { ID: XM02-001) }\end{array}$ & ACE inhibitor & 287.1850 & 287.3480 \\
\hline 4 & 3283 & GP & $(154-155)$ & & antithrombotic & antithrombotic & 172.0730 & 172.1690 \\
\hline 5 & 3378 & GRP & $(170-172)$ & ACE inhibitor & $\begin{array}{l}\text { Inhibitor of Angiotensin-Converting } \\
\text { Enzyme (ACE) (EC 3.4.15.1) (MEROPS } \\
\text { ID: XM02-001) }\end{array}$ & ACE inhibitor & 328.1740 & 328.3570 \\
\hline 6 & 3461 & GP & $(154-155)$ & Prolyl endopeptidase inhibitor & $\begin{array}{l}\text { Inhibitor of Prolyl Endopeptidase } \\
\text { (PEP) (EC 3.4.21.26) (MEROPS ID: } \\
\text { S09.001) }\end{array}$ & antiamnestic & 172.0730 & 172.1690 \\
\hline 7 & 3546 & VAY & $(103-105)$ & ACE inhibitor & $\begin{array}{l}\text { Inhibitor of Angiotensin-Converting } \\
\text { Enzyme (ACE) (EC 3.4.15.1) (MEROPS } \\
\text { ID: XM02-001) }\end{array}$ & ACE inhibitor & 351.1680 & 351.3820 \\
\hline 8 & 3563 & AY & $(147-148)$ & ACE inhibitor & $\begin{array}{l}\text { Inhibitor of Angiotensin-Converting } \\
\text { Enzyme (ACE) (EC 3.4.15.1) (MEROPS } \\
\text { ID: XM02-001) }\end{array}$ & ACE inhibitor & 252.1000 & 252.2490 \\
\hline 9 & 7512 & GP & $(154-155)$ & $\begin{array}{l}\text { ACE inhibitor from Alaskan } \\
\text { pollack skin }\end{array}$ & $\begin{array}{l}\text { Inhibitor of Angiotensin-Converting } \\
\text { Enzyme (ACE) (EC 3.4.15.1) (MEROPS } \\
\text { ID: XM02-001) }\end{array}$ & ACE inhibitor & 172.0730 & 172.1690 \\
\hline 10 & 7599 & GL & $(183-184)$ & ACE inhibitor & $\begin{array}{l}\text { Inhibitor of Angiotensin-converting } \\
\text { enzyme (EC 3.4.15.1) (MEROPS ID: } \\
\text { XM02-001) }\end{array}$ & ACE inhibitor & 188.1050 & 188.2120 \\
\hline
\end{tabular}


Table A17. Cont

\begin{tabular}{|c|c|c|c|c|c|c|c|c|}
\hline No. & $\begin{array}{l}\text { Peptide } \\
\text { ID }\end{array}$ & Sequence & Location & Name & Function & Activity & $\begin{array}{l}\text { Monoisotopic } \\
\text { Mass }\end{array}$ & $\begin{array}{l}\text { Chemical } \\
\text { Mass }\end{array}$ \\
\hline 11 & 7691 & KY & $(168-169)$ & ACE inhibitor from wakame & & ACE inhibitor & 309.1570 & 309.3440 \\
\hline 12 & 7693 & KL & $(21-22)$ & ACE inhibitor from wakame & & ACE inhibitor & 259.1780 & 259.3340 \\
\hline 13 & 7693 & KL & $(181-182)$ & ACE inhibitor from wakame & & ACE inhibitor & 259.1780 & 259.3340 \\
\hline 14 & 7829 & VE & $(161-162)$ & ACE inhibitor & $\begin{array}{l}\text { Inhibitor of Angiotensin-Converting } \\
\text { Enzyme (ACE) (EC 3.4.15.1) (MEROPS } \\
\text { ID: XM02-001) }\end{array}$ & ACE inhibitor & 246.1100 & 246.2490 \\
\hline 15 & 7830 & $\mathrm{TE}$ & $(5-6)$ & ACE inhibitor & $\begin{array}{l}\text { Inhibitor of Angiotensin-Converting } \\
\text { Enzyme (EC 3.4.15.1) (MEROPS ID: } \\
\text { XM02-001) }\end{array}$ & ACE inhibitor & 248.0890 & 248.2210 \\
\hline 16 & 7866 & AY & $(147-148)$ & peptide from Okara protein & $\begin{array}{l}\text { Peptide obtained by hydrolysis of } \\
\text { Okara protein by use of enzymatic } \\
\text { preparation Protease N. }\end{array}$ & antioxidative & 252.1000 & 252.2490 \\
\hline 17 & 8219 & TY & $(23-24)$ & antioxidative peptide & & antioxidative & 282.1100 & 282.2750 \\
\hline 18 & 8503 & $\mathrm{TP}$ & $(26-27)$ & $\begin{array}{l}\text { Dipeptidyl peptidase IV } \\
\text { inhibitor (DPP IV inhibitor) }\end{array}$ & $\begin{array}{l}\text { Inhibitor of Dipeptidyl Peptidase IV } \\
\text { (EC 3.4.14.5) (MEROPS ID: S09.003) }\end{array}$ & $\begin{array}{l}\text { dipeptidyl peptidase } \\
\text { IV inhibitor }\end{array}$ & 216.0990 & 216.2220 \\
\hline 19 & 8505 & SP & $(2-3)$ & $\begin{array}{l}\text { Dipeptidyl peptidase IV } \\
\text { inhibitor (DPP IV inhibitor) }\end{array}$ & $\begin{array}{l}\text { Inhibitor of Dipeptidyl Peptidase IV } \\
\text { (EC 3.4.14.5) (MEROPS ID: S09.003) }\end{array}$ & $\begin{array}{l}\text { dipeptidyl peptidase } \\
\text { IV inhibitor }\end{array}$ & 202.0840 & 202.1970 \\
\hline 20 & 8561 & GL & $(183-184)$ & $\begin{array}{l}\text { dipeptidyl peptidase IV } \\
\text { inhibitor (DPP IV inhibitor) }\end{array}$ & $\begin{array}{l}\text { Inhibitor of Dipeptidyl Peptidase IV } \\
\text { (EC 3.4.14.5) (MEROPS ID: S09.003) }\end{array}$ & $\begin{array}{l}\text { dipeptidyl peptidase } \\
\text { IV inhibitor }\end{array}$ & 188.1050 & 188.2120 \\
\hline 21 & 8765 & AY & $(147-148)$ & $\begin{array}{l}\text { dipeptidyl peptidase IV } \\
\text { inhibitor (DPP IV inhibitor) }\end{array}$ & $\begin{array}{l}\text { Inhibitor of Dipeptidyl Peptidase IV } \\
\text { (EC 3.4.14.5) (MEROPS ID: S09.003) }\end{array}$ & $\begin{array}{l}\text { dipeptidyl peptidase } \\
\text { IV inhibitor }\end{array}$ & 252.1000 & 252.2490 \\
\hline 22 & 8819 & KY & $(168-169)$ & $\begin{array}{l}\text { dipeptidyl peptidase IV } \\
\text { inhibitor (DPP IV inhibitor) }\end{array}$ & $\begin{array}{l}\text { Inhibitor of Dipeptidyl Peptidase IV } \\
\text { (EC 3.4.14.5) (MEROPS ID: S09.003) }\end{array}$ & $\begin{array}{l}\text { dipeptidyl peptidase } \\
\text { IV inhibitor }\end{array}$ & 309.1570 & 309.3440 \\
\hline 23 & 8886 & RL & $(138-139)$ & $\begin{array}{l}\text { dipeptidyl peptidase IV } \\
\text { inhibitor (DPP IV inhibitor) }\end{array}$ & $\begin{array}{l}\text { Inhibitor of Dipeptidyl Peptidase IV } \\
\text { (EC 3.4.14.5) (MEROPS ID: S09.003) }\end{array}$ & $\begin{array}{l}\text { dipeptidyl peptidase } \\
\text { IV inhibitor }\end{array}$ & 287.1850 & 287.3480 \\
\hline 24 & 8899 & $\mathrm{TE}$ & $(5-6)$ & $\begin{array}{l}\text { dipeptidyl peptidase IV } \\
\text { inhibitor (DPP IV inhibitor) }\end{array}$ & $\begin{array}{l}\text { Inhibitor of Dipeptidyl Peptidase IV } \\
\text { (EC 3.4.14.5) (MEROPS ID: S09.003) }\end{array}$ & $\begin{array}{l}\text { dipeptidyl peptidase } \\
\text { IV inhibitor }\end{array}$ & 248.0890 & 248.2210 \\
\hline 25 & 8914 & TY & $(23-24)$ & $\begin{array}{l}\text { dipeptidyl peptidase IV } \\
\text { inhibitor (DPP IV inhibitor) }\end{array}$ & $\begin{array}{l}\text { Inhibitor of Dipeptidyl Peptidase IV } \\
\text { (EC 3.4.14.5) (MEROPS ID: S09.003) }\end{array}$ & $\begin{array}{l}\text { dipeptidyl peptidase } \\
\text { IV inhibitor }\end{array}$ & 282.1100 & 282.2750 \\
\hline 26 & 8916 & VE & $(161-162)$ & $\begin{array}{l}\text { dipeptidyl peptidase IV } \\
\text { inhibitor (DPP IV inhibitor) }\end{array}$ & $\begin{array}{l}\text { Inhibitor of Dipeptidyl Peptidase IV } \\
\text { (EC 3.4.14.5) (MEROPS ID: S09.003) }\end{array}$ & $\begin{array}{l}\text { dipeptidyl peptidase } \\
\text { IV inhibitor }\end{array}$ & 246.1100 & 246.2490 \\
\hline 27 & 9071 & IAY & $(100-102)$ & ACE inhibitor & $\begin{array}{l}\text { Inhibitor of Angiotensin-Converting } \\
\text { Enzyme (ACE) (EC 3.4.15.1) (MEROPS } \\
\text { ID: M02-001) }\end{array}$ & ACE inhibitor & 365.1840 & 365.4090 \\
\hline 28 & 9073 & $\mathrm{TP}$ & $(26-27)$ & ACE inhibitor & $\begin{array}{l}\text { Inhibitor of Angiotensin-Converting } \\
\text { Enzyme (ACE) (EC 3.4.15.1) (MEROPS } \\
\text { ID: M02-001) }\end{array}$ & ACE inhibitor & 216.0990 & 216.2220 \\
\hline
\end{tabular}


Table A18. $A_{E}, D H_{t}, W, B_{E}$ and $V$ values from RubisCO of Halophila stipulacea. In silico enzymatic cleavage was carried out by Chymotrypsin.

\begin{tabular}{|c|c|c|c|c|c|}
\hline \multicolumn{6}{|c|}{$\begin{array}{l}\mathrm{DH}_{t}(\%) \\
35.6098\end{array}$} \\
\hline No. & Activity & $A_{E}$ & $W$ & $B_{E}$ & $V$ \\
\hline 1 & regulating & 0.0049 & 0.3356 & 0 & \\
\hline 2 & dipeptidyl peptidase IV inhibitor & 0.0485 & 0.0746 & $5.217325115104 \mathrm{E}-6$ & 0.024186176702991 \\
\hline 3 & ACE inhibitor & 0.0631 & 0.1083 & 0.0017951962898486 & 0.067088034662415 \\
\hline 4 & antithrombotic & 0.0049 & 0.5052 & 0 & \\
\hline 5 & antiamnestic & 0.0049 & 0.5052 & 0 & \\
\hline 6 & antioxidative & 0.0097 & 0.1332 & 0 & 0 \\
\hline
\end{tabular}

Table A19. Bioactive peptides from RubisCO of Halophila stipulacea. In silico enzymatic cleavage was carried out by using plasmin.

\begin{tabular}{|c|c|c|c|c|c|c|c|c|}
\hline No. & $\begin{array}{l}\text { Peptide } \\
\text { ID }\end{array}$ & Sequence & Location & Name & Function & Activity & $\begin{array}{l}\text { Monoisotopic } \\
\text { Mass }\end{array}$ & $\begin{array}{l}\text { Chemical } \\
\text { Mass }\end{array}$ \\
\hline 1 & 7603 & GR & $(84-85)$ & ACE inhibitor & $\begin{array}{l}\text { Inhibitor of Angiotensin-Converting } \\
\text { Enzyme (ACE) (EC 3.4.15.1) (MEROPS } \\
\text { ID: XM02-001) }\end{array}$ & ACE inhibitor & 231.1220 & 231.2400 \\
\hline 2 & 7697 & YK & $(82-83)$ & ACE inhibitor from wakame & & ACE inhibitor & 309.1570 & 309.3440 \\
\hline 3 & 8769 & DR & (164-165) & $\begin{array}{l}\text { dipeptidyl peptidase IV } \\
\text { inhibitor (DPP IV inhibitor) }\end{array}$ & $\begin{array}{l}\text { Inhibitor of Dipeptidyl Peptidase IV } \\
\text { (EC 3.4.14.5) (MEROPS ID: S09.003) }\end{array}$ & $\begin{array}{l}\text { dipeptidyl peptidase } \\
\text { IV inhibitor }\end{array}$ & 289.1279 & 289.2770 \\
\hline 4 & 8858 & PK & $(180-181)$ & $\begin{array}{l}\text { dipeptidyl peptidase IV } \\
\text { inhibitor (DPP IV inhibitor) }\end{array}$ & $\begin{array}{l}\text { Inhibitor of Dipeptidyl Peptidase IV } \\
\text { (EC 3.4.14.5) (MEROPS ID: S09.003) }\end{array}$ & $\begin{array}{l}\text { dipeptidyl peptidase } \\
\text { IV inhibitor }\end{array}$ & 243.1460 & 243.2910 \\
\hline 5 & 8939 & YK & $(82-83)$ & $\begin{array}{l}\text { dipeptidyl peptidase IV } \\
\text { inhibitor (DPP IV inhibitor) }\end{array}$ & $\begin{array}{l}\text { Inhibitor of Dipeptidyl Peptidase IV } \\
\text { (EC 3.4.14.5) (MEROPS ID: S09.003) }\end{array}$ & $\begin{array}{l}\text { dipeptidyl peptidase } \\
\text { IV inhibitor }\end{array}$ & 309.1570 & 309.3440 \\
\hline
\end{tabular}

Table A20. $A_{E}, D H_{t}, W, B_{E}$ and $V$ values from RubisCO of Halophila stipulacea. In silico enzymatic cleavage was carried out by plasmin.

\begin{tabular}{llllll}
\hline $\begin{array}{ll}\mathrm{DH} \\
\mathbf{1 0 . 7 3 1 7}\end{array}$ & & & & \\
\hline No. & Activity & $A_{E}$ & $W$ & $\boldsymbol{B}_{E}$ & $\boldsymbol{V}$ \\
\hline 1 & ACE inhibitor & 0.0097 & 0.0167 & $9.4749721470635 \mathrm{E}-6$ & 0.00035408788633428 \\
2 & dipeptidyl peptidase IV inhibitor & 0.0146 & 0.0224 & 0 & 0 \\
\hline
\end{tabular}


Table A21. Bioactive peptides from RubisCO of Halophila stipulacea. In silico enzymatic cleavage was carried out by using cathepsin.

\begin{tabular}{|c|c|c|c|c|c|c|c|c|}
\hline No. & $\begin{array}{l}\text { Peptide } \\
\text { ID }\end{array}$ & Sequence & Location & Name & Function & Activity & $\begin{array}{l}\text { Monoisotopic } \\
\text { Mass }\end{array}$ & $\begin{array}{l}\text { Chemical } \\
\text { Mass }\end{array}$ \\
\hline 1 & 3257 & RL & $(138-139)$ & beta-lactokinin & $\begin{array}{l}\text { Inhibitor of Angiotensin-Converting } \\
\text { Enzyme (ACE) (EC 3.4.15.1) (MEROPS } \\
\text { ID: XM02-001) }\end{array}$ & ACE inhibitor & 287.1850 & 287.3480 \\
\hline 2 & 3546 & VAY & $(103-105)$ & ACE inhibitor & $\begin{array}{l}\text { Inhibitor of Angiotensin-Converting } \\
\text { Enzyme (ACE) (EC 3.4.15.1) (MEROPS } \\
\text { ID: XM02-001) }\end{array}$ & ACE inhibitor & 351.1680 & 351.3820 \\
\hline 3 & 7513 & PL & $(106-107)$ & $\begin{array}{l}\text { ACE inhibitor from Alaskan } \\
\text { pollack skin }\end{array}$ & $\begin{array}{l}\text { Inhibitor of Angiotensin-converting } \\
\text { enzyme (EC 3.4.15.1) (MEROPS ID: } \\
\text { XM02-001) }\end{array}$ & ACE inhibitor & 228.1360 & 228.2770 \\
\hline 4 & 7591 & GF & $(130-131)$ & ACE inhibitor & $\begin{array}{l}\text { Inhibitor of Angiotensin-Converting } \\
\text { Enzyme (ACE) (EC 3.4.15.1) (MEROPS } \\
\text { ID: XM02-001) }\end{array}$ & ACE inhibitor & 222.0890 & 222.2290 \\
\hline 5 & 7599 & GL & $(183-184)$ & ACE inhibitor & $\begin{array}{l}\text { Inhibitor of Angiotensin-converting } \\
\text { enzyme (EC 3.4.15.1) (MEROPS ID: } \\
\text { XM02-001) }\end{array}$ & ACE inhibitor & 188.1050 & 188.2120 \\
\hline 6 & 7693 & KL & $(21-22)$ & ACE inhibitor from wakame & & ACE inhibitor & 259.1780 & 259.3340 \\
\hline 7 & 8219 & TY & $(23-24)$ & antioxidative peptide & & antioxidative & 282.1100 & 282.2750 \\
\hline 8 & 8561 & GL & $(183-184)$ & $\begin{array}{l}\text { dipeptidyl peptidase IV } \\
\text { inhibitor (DPP IV inhibitor) }\end{array}$ & $\begin{array}{l}\text { Inhibitor of Dipeptidyl Peptidase IV } \\
\text { (EC 3.4.14.5) (MEROPS ID: S09.003) }\end{array}$ & $\begin{array}{l}\text { dipeptidyl peptidase } \\
\text { IV inhibitor }\end{array}$ & 188.1050 & 188.2120 \\
\hline 9 & 8638 & PL & $(106-107)$ & $\begin{array}{l}\text { dipeptidyl peptidase IV } \\
\text { inhibitor (DPP IV inhibitor) }\end{array}$ & $\begin{array}{l}\text { Inhibitor of Dipeptidyl Peptidase IV } \\
\text { (EC 3.4.14.5) (MEROPS ID: S09.003) }\end{array}$ & $\begin{array}{l}\text { dipeptidyl peptidase } \\
\text { IV inhibitor }\end{array}$ & 228.1360 & 228.2770 \\
\hline 10 & 8782 & GF & $(130-131)$ & $\begin{array}{l}\text { dipeptidyl peptidase IV } \\
\text { inhibitor (DPP IV inhibitor) }\end{array}$ & $\begin{array}{l}\text { Inhibitor of Dipeptidyl Peptidase IV } \\
\text { (EC 3.4.14.5) (MEROPS ID: S09.003) }\end{array}$ & $\begin{array}{l}\text { dipeptidyl peptidase } \\
\text { IV inhibitor }\end{array}$ & 222.0890 & 222.2290 \\
\hline 11 & 8886 & RL & $(138-139)$ & $\begin{array}{l}\text { dipeptidyl peptidase IV } \\
\text { inhibitor (DPP IV inhibitor) }\end{array}$ & $\begin{array}{l}\text { Inhibitor of Dipeptidyl Peptidase IV } \\
\text { (EC 3.4.14.5) (MEROPS ID: S09.003) }\end{array}$ & $\begin{array}{l}\text { dipeptidyl peptidase } \\
\text { IV inhibitor }\end{array}$ & 287.1850 & 287.3480 \\
\hline 12 & 8914 & TY & $(23-24)$ & $\begin{array}{l}\text { dipeptidyl peptidase IV } \\
\text { inhibitor (DPP IV inhibitor) }\end{array}$ & $\begin{array}{l}\text { Inhibitor of Dipeptidyl Peptidase IV } \\
\text { (EC 3.4.14.5) (MEROPS ID: S09.003) }\end{array}$ & $\begin{array}{l}\text { dipeptidyl peptidase } \\
\text { IV inhibitor }\end{array}$ & 282.1100 & 282.2750 \\
\hline 13 & 9071 & IAY & $(100-102)$ & ACE inhibitor & $\begin{array}{l}\text { Inhibitor of Angiotensin-Converting } \\
\text { Enzyme (ACE) (EC 3.4.15.1) (MEROPS } \\
\text { ID: M02-001) }\end{array}$ & ACE inhibitor & 365.1840 & 365.4090 \\
\hline 14 & 9074 & DF & $(204-205)$ & ACE inhibitor & $\begin{array}{l}\text { Inhibitor of Angiotensin-Converting } \\
\text { Enzyme (ACE) (EC 3.4.15.1) (MEROPS } \\
\text { ID: XM02-001) }\end{array}$ & ACE inhibitor & 280.0949 & 280.2660 \\
\hline
\end{tabular}


Table A22. $A_{E}, D H_{t}, W, B_{E}$ and $V$ values from RubisCO of Halophila stipulacea. In silico enzymatic cleavage was carried out by cathepsin.

\begin{tabular}{llllll}
\hline $\begin{array}{l}D H_{t}(\%) \\
\mathbf{2 0 . 4 8 7 8}\end{array}$ & & & & \\
\hline No. & Activity & $A_{E}$ & $W$ & $\boldsymbol{B}_{E}$ & $\boldsymbol{V}$ \\
\hline 1 & ACE inhibitor & 0.0388 & 0.0666 & 0.00082506965175237 & 0.030833564947006 \\
2 & antioxidative & 0.0049 & 0.0673 & 0 & 0 \\
3 & dipeptidyl peptidase IV inhibitor & 0.0243 & 0.0374 & $1.8563339357632 \mathrm{E}-6$ & 0.0086054864513139 \\
\hline
\end{tabular}

Table A23. Bioactive peptides from RubisCO of Halophila stipulacea. In silico enzymatic cleavage was carried out by using clostripain.

\begin{tabular}{llllllll}
\hline No. & $\begin{array}{l}\text { Peptide } \\
\text { ID }\end{array}$ & Sequence & Location & Name & Function & Activity & $\begin{array}{l}\text { Monoisotopic } \\
\text { Mass }\end{array}$ \\
\hline 1 & 8769 & DR & $(164-165)$ & $\begin{array}{l}\text { dipeptidyl peptidase IV } \\
\text { inhibitor (DPP IV inhibitor) }\end{array}$ & $\begin{array}{l}\text { Inhibitor of Dipeptidyl Peptidase IV } \\
\text { (EC 3.4.14.5) (MEROPS ID: S09.003) }\end{array}$ & $\begin{array}{l}\text { dipeptidyl peptidase } \\
\text { IV inhibitor }\end{array}$ & $\begin{array}{l}\text { 289.1279 } \\
289.2770\end{array}$ \\
\hline
\end{tabular}

Table A24. $A_{E}, D H_{t}, W, B_{E}$ and $V$ values from RubisCO of Halophila stipulacea. In silico enzymatic cleavage was carried out by clostripain.

\begin{tabular}{llllll}
\hline $\begin{array}{l}D H_{t}(\%) \\
5.3659\end{array}$ & & & & & \\
\hline No. & Activity & $A_{E}$ & $W$ & $B_{E}$ & $V$ \\
\hline 1 & dipeptidyl peptidase IV inhibitor & 0.0049 & 0.0075 & 0 & 0 \\
\hline
\end{tabular}


Table A25. Bioactive peptides from RubisCO of Halophila stipulacea. In silico enzymatic cleavage was carried out by using chymase.

\begin{tabular}{|c|c|c|c|c|c|c|c|c|}
\hline No. & $\begin{array}{l}\text { Peptide } \\
\text { ID }\end{array}$ & Sequence & Location & Name & Function & Activity & $\begin{array}{l}\text { Monoisotopic } \\
\text { Mass }\end{array}$ & $\begin{array}{l}\text { Chemical } \\
\text { Mass }\end{array}$ \\
\hline 1 & 3257 & RL & $(138-139)$ & beta-lactokinin & $\begin{array}{l}\text { Inhibitor of Angiotensin-Converting } \\
\text { Enzyme (ACE) (EC 3.4.15.1) (MEROPS } \\
\text { ID: XM02-001) }\end{array}$ & ACE inhibitor & 287.1850 & 287.3480 \\
\hline 2 & 3546 & VAY & $(103-105)$ & ACE inhibitor & $\begin{array}{l}\text { Inhibitor of Angiotensin-Converting } \\
\text { Enzyme (ACE) (EC 3.4.15.1) (MEROPS } \\
\text { ID: XM02-001) }\end{array}$ & ACE inhibitor & 351.1680 & 351.3820 \\
\hline 3 & 7513 & PL & $(106-107)$ & $\begin{array}{l}\text { ACE inhibitor from Alaskan } \\
\text { pollack skin }\end{array}$ & $\begin{array}{l}\text { Inhibitor of Angiotensin-converting } \\
\text { enzyme (EC 3.4.15.1) (MEROPS ID: } \\
\text { XM02-001) }\end{array}$ & ACE inhibitor & 228.1360 & 228.2770 \\
\hline 4 & 7591 & GF & $(130-131)$ & ACE inhibitor & $\begin{array}{l}\text { Inhibitor of Angiotensin-Converting } \\
\text { Enzyme (ACE) (EC 3.4.15.1) (MEROPS } \\
\text { ID: XM02-001) }\end{array}$ & ACE inhibitor & 222.0890 & 222.2290 \\
\hline 5 & 7599 & GL & $(183-184)$ & ACE inhibitor & $\begin{array}{l}\text { Inhibitor of Angiotensin-converting } \\
\text { enzyme (EC 3.4.15.1) (MEROPS ID: } \\
\text { XM02-001) }\end{array}$ & ACE inhibitor & 188.1050 & 188.2120 \\
\hline 6 & 7693 & KL & $(21-22)$ & ACE inhibitor from wakame & & ACE inhibitor & 259.1780 & 259.3340 \\
\hline 7 & 8219 & TY & $(23-24)$ & antioxidative peptide & & antioxidative & 282.1100 & 282.2750 \\
\hline 8 & 8561 & GL & $(183-184)$ & $\begin{array}{l}\text { dipeptidyl peptidase IV } \\
\text { inhibitor (DPP IV inhibitor) }\end{array}$ & $\begin{array}{l}\text { Inhibitor of Dipeptidyl Peptidase IV } \\
\text { (EC 3.4.14.5) (MEROPS ID: S09.003) }\end{array}$ & $\begin{array}{l}\text { dipeptidyl peptidase } \\
\text { IV inhibitor }\end{array}$ & 188.1050 & 188.2120 \\
\hline 9 & 8638 & PL & $(106-107)$ & $\begin{array}{l}\text { dipeptidyl peptidase IV } \\
\text { inhibitor (DPP IV inhibitor) }\end{array}$ & $\begin{array}{l}\text { Inhibitor of Dipeptidyl Peptidase IV } \\
\text { (EC 3.4.14.5) (MEROPS ID: S09.003) }\end{array}$ & $\begin{array}{l}\text { dipeptidyl peptidase } \\
\text { IV inhibitor }\end{array}$ & 228.1360 & 228.2770 \\
\hline 10 & 8782 & GF & $(130-131)$ & $\begin{array}{l}\text { dipeptidyl peptidase IV } \\
\text { inhibitor (DPP IV inhibitor) }\end{array}$ & $\begin{array}{l}\text { Inhibitor of Dipeptidyl Peptidase IV } \\
\text { (EC 3.4.14.5) (MEROPS ID: S09.003) }\end{array}$ & $\begin{array}{l}\text { dipeptidyl peptidase } \\
\text { IV inhibitor }\end{array}$ & 222.0890 & 222.2290 \\
\hline 11 & 8886 & RL & $(138-139)$ & $\begin{array}{l}\text { dipeptidyl peptidase IV } \\
\text { inhibitor (DPP IV inhibitor) }\end{array}$ & $\begin{array}{l}\text { Inhibitor of Dipeptidyl Peptidase IV } \\
\text { (EC 3.4.14.5) (MEROPS ID: S09.003) }\end{array}$ & $\begin{array}{l}\text { dipeptidyl peptidase } \\
\text { IV inhibitor }\end{array}$ & 287.1850 & 287.3480 \\
\hline 12 & 8914 & TY & $(23-24)$ & $\begin{array}{l}\text { dipeptidyl peptidase IV } \\
\text { inhibitor (DPP IV inhibitor) }\end{array}$ & $\begin{array}{l}\text { Inhibitor of Dipeptidyl Peptidase IV } \\
\text { (EC 3.4.14.5) (MEROPS ID: S09.003) }\end{array}$ & $\begin{array}{l}\text { dipeptidyl peptidase } \\
\text { IV inhibitor }\end{array}$ & 282.1100 & 282.2750 \\
\hline 13 & 9071 & IAY & $(100-102)$ & ACE inhibitor & $\begin{array}{l}\text { Inhibitor of Angiotensin-Converting } \\
\text { Enzyme (ACE) (EC 3.4.15.1) (MEROPS } \\
\text { ID: M02-001) }\end{array}$ & ACE inhibitor & 365.1840 & 365.4090 \\
\hline 14 & 9074 & $\mathrm{DF}$ & $(204-205)$ & ACE inhibitor & $\begin{array}{l}\text { Inhibitor of Angiotensin-Converting } \\
\text { Enzyme (ACE) (EC 3.4.15.1) (MEROPS } \\
\text { ID: XM02-001) }\end{array}$ & ACE inhibitor & 280.0949 & 280.2660 \\
\hline
\end{tabular}


Table A26. $A_{E}, D H_{t}, W, B_{E}$ and $V$ values from RubisCO of Halophila stipulacea. In silico enzymatic cleavage was carried out by chymase.

\begin{tabular}{llllll}
\hline $\begin{array}{l}\boldsymbol{D} \boldsymbol{H}_{\boldsymbol{t}} \mathbf{( \% )} \\
\mathbf{1 9 . 5 1 2 2}\end{array}$ & & & & \\
\hline No. & Activity & $A_{E}$ & $\boldsymbol{W}$ & $\boldsymbol{B}_{\boldsymbol{E}}$ & $\boldsymbol{V}$ \\
\hline 1 & ACE inhibitor & 0.0388 & 0.0666 & 0.00082506965175237 & 0.030833564947006 \\
2 & antioxidative & 0.0049 & 0.0673 & 0 & 0 \\
3 & dipeptidyl peptidase IV inhibitor & 0.0243 & 0.0374 & $1.8563339357632 \mathrm{E}-6$ & 0.0086054864513139 \\
\hline
\end{tabular}

Table A27. Bioactive peptides from RubisCO of Halophila stipulacea. In silico enzymatic cleavage was carried out by using papain.

\begin{tabular}{|c|c|c|c|c|c|c|c|c|}
\hline No. & $\begin{array}{l}\text { Peptide } \\
\text { ID }\end{array}$ & Sequence & Location & Name & Function & Activity & $\begin{array}{l}\text { Monoisotopic } \\
\text { Mass }\end{array}$ & $\begin{array}{l}\text { Chemical } \\
\text { Mass }\end{array}$ \\
\hline 1 & 3351 & EEE & $(95-97)$ & $\begin{array}{l}\text { Stimulating vasoactive } \\
\text { substance release }\end{array}$ & & stimulating & 405.1260 & 405.3480 \\
\hline 2 & 3522 & IPP & $(144-146)$ & $\begin{array}{l}\text { ACE inhibitor (from bovine } \\
b-C N \text { ) }\end{array}$ & & ACE inhibitor & 325.1880 & 325.3940 \\
\hline 3 & 3538 & VSP & $(42-44)$ & ACE inhibitor & $\begin{array}{l}\text { Inhibitor of Angiotensin-Converting } \\
\text { Enzyme (ACE) (EC 3.4.15.1) (MEROPS } \\
\text { ID: XM02-001) }\end{array}$ & ACE inhibitor & 301.1520 & 301.3300 \\
\hline 4 & 7513 & PL & $(172-173)$ & $\begin{array}{l}\text { ACE inhibitor from Alaskan } \\
\text { pollack skin }\end{array}$ & $\begin{array}{l}\text { Inhibitor of Angiotensin-converting } \\
\text { enzyme (EC 3.4.15.1) (MEROPS ID: } \\
\text { XM02-001) }\end{array}$ & ACE inhibitor & 228.1360 & 228.2770 \\
\hline 5 & 7583 & $\mathrm{AF}$ & $(39-40)$ & ACE inhibitor & $\begin{array}{l}\text { Inhibitor of Angiotensin-Converting } \\
\text { Enzyme (ACE) (EC 3.4.15.1) (MEROPS } \\
\text { ID: XM02-001) }\end{array}$ & ACE inhibitor & 236.1050 & 236.2560 \\
\hline 6 & 7594 & VG & $(11-12)$ & ACE inhibitor & $\begin{array}{l}\text { Inhibitor of Angiotensin-Converting } \\
\text { Enzyme (ACE) (EC 3.4.15.1) (MEROPS } \\
\text { ID: XM02-001) }\end{array}$ & ACE inhibitor & 174.0890 & 174.1850 \\
\hline 7 & 7600 & AG & $(9-10)$ & ACE inhibitor & $\begin{array}{l}\text { Inhibitor of Angiotensin-Converting } \\
\text { Enzyme (ACE) (EC 3.4.15.1) (MEROPS } \\
\text { ID: XM02-001) }\end{array}$ & ACE inhibitor & 146.0580 & 146.1310 \\
\hline 8 & 7600 & AG & $(15-16)$ & ACE inhibitor & $\begin{array}{l}\text { Inhibitor of Angiotensin-Converting } \\
\text { Enzyme (ACE) (EC 3.4.15.1) (MEROPS } \\
\text { ID: XM02-001) }\end{array}$ & ACE inhibitor & 146.0580 & 146.1310 \\
\hline
\end{tabular}


Table A27. Cont.

\begin{tabular}{|c|c|c|c|c|c|c|c|c|}
\hline No. & $\begin{array}{l}\text { Peptide } \\
\text { ID }\end{array}$ & Sequence & Location & Name & Function & Activity & $\begin{array}{l}\text { Monoisotopic } \\
\text { Mass }\end{array}$ & $\begin{array}{l}\text { Chemical } \\
\text { Mass }\end{array}$ \\
\hline 9 & 7600 & AG & $(53-54)$ & ACE inhibitor & $\begin{array}{l}\text { Inhibitor of Angiotensin-Converting } \\
\text { Enzyme (ACE) (EC 3.4.15.1) (MEROPS } \\
\text { ID: XM02-001) }\end{array}$ & ACE inhibitor & 146.0580 & 146.1310 \\
\hline 10 & 7600 & AG & $(93-94)$ & ACE inhibitor & $\begin{array}{l}\text { Inhibitor of Angiotensin-Converting } \\
\text { Enzyme (ACE) (EC 3.4.15.1) (MEROPS } \\
\text { ID: XM02-001) }\end{array}$ & ACE inhibitor & 146.0580 & 146.1310 \\
\hline 11 & 7617 & QG & $(153-154)$ & ACE inhibitor & & ACE inhibitor & 203.0790 & 203.1830 \\
\hline 12 & 7681 & $\widehat{\mathrm{DG}}$ & $(74-75)$ & ACE inhibitor from soy & $\begin{array}{l}\text { Inhibitor of Angiotensin-converting } \\
\text { enzyme (ACE) (EC 3.4.15.1) (MEROPS } \\
\text { ID: XM02-001) }\end{array}$ & ACE inhibitor & 190.0479 & 190.1410 \\
\hline 13 & 7951 & YYT & $(24-26)$ & synthetic peptide & & antioxidative & 445.1730 & 445.4450 \\
\hline 14 & 8559 & $\mathrm{AL}$ & $(133-134)$ & $\begin{array}{l}\text { dipeptidyl peptidase IV } \\
\text { inhibitor (DPP IV inhibitor) }\end{array}$ & $\begin{array}{l}\text { Inhibitor of Dipeptidyl Peptidase IV } \\
\text { (EC 3.4.14.5) (MEROPS ID: S09.003) }\end{array}$ & $\begin{array}{l}\text { dipeptidyl peptidase } \\
\text { IV inhibitor }\end{array}$ & 202.1210 & 202.2390 \\
\hline 15 & 8559 & $\mathrm{AL}$ & $(136-137)$ & $\begin{array}{l}\text { dipeptidyl peptidase IV } \\
\text { inhibitor (DPP IV inhibitor) }\end{array}$ & $\begin{array}{l}\text { Inhibitor of Dipeptidyl Peptidase IV } \\
\text { (EC 3.4.14.5) (MEROPS ID: S09.003) }\end{array}$ & $\begin{array}{l}\text { dipeptidyl peptidase } \\
\text { IV inhibitor }\end{array}$ & 202.1210 & 202.2390 \\
\hline 16 & 8560 & SL & $(78-79)$ & $\begin{array}{l}\text { dipeptidyl peptidase IV } \\
\text { inhibitor (DPP IV inhibitor) }\end{array}$ & $\begin{array}{l}\text { Inhibitor of Dipeptidyl Peptidase IV } \\
\text { (EC 3.4.14.5) (MEROPS ID: S09.003) }\end{array}$ & $\begin{array}{l}\text { dipeptidyl peptidase } \\
\text { IV inhibitor }\end{array}$ & 218.1160 & 218.2400 \\
\hline 17 & 8638 & PL & $(172-173)$ & $\begin{array}{l}\text { dipeptidyl peptidase IV } \\
\text { inhibitor (DPP IV inhibitor) }\end{array}$ & $\begin{array}{l}\text { Inhibitor of Dipeptidyl Peptidase IV } \\
\text { (EC 3.4.14.5) (MEROPS ID: S09.003) }\end{array}$ & $\begin{array}{l}\text { dipeptidyl peptidase } \\
\text { IV inhibitor }\end{array}$ & 228.1360 & 228.2770 \\
\hline 18 & 8685 & WT & $(68-69)$ & $\begin{array}{l}\text { dipeptidyl peptidase IV } \\
\text { inhibitor (DPP IV inhibitor) }\end{array}$ & $\begin{array}{l}\text { Inhibitor of Dipeptidyl Peptidase IV } \\
\text { (EC 3.4.14.5) (MEROPS ID: S09.003) }\end{array}$ & $\begin{array}{l}\text { dipeptidyl peptidase } \\
\text { IV inhibitor }\end{array}$ & 305.1260 & 305.3180 \\
\hline 19 & 8759 & $\mathrm{AF}$ & $(39-40)$ & $\begin{array}{l}\text { dipeptidyl peptidase IV } \\
\text { inhibitor (DPP IV inhibitor) }\end{array}$ & $\begin{array}{l}\text { Inhibitor of Dipeptidyl Peptidase IV } \\
\text { (EC 3.4.14.5) (MEROPS ID: S09.003) }\end{array}$ & $\begin{array}{l}\text { dipeptidyl peptidase } \\
\text { IV inhibitor }\end{array}$ & 236.1050 & 236.2560 \\
\hline 20 & 8760 & AG & $(9-10)$ & $\begin{array}{l}\text { dipeptidyl peptidase IV } \\
\text { inhibitor (DPP IV inhibitor) }\end{array}$ & $\begin{array}{l}\text { Inhibitor of Dipeptidyl Peptidase IV } \\
\text { (EC 3.4.14.5) (MEROPS ID: S09.003) }\end{array}$ & $\begin{array}{l}\text { dipeptidyl peptidase } \\
\text { IV inhibitor }\end{array}$ & 146.0580 & 146.1310 \\
\hline 21 & 8760 & AG & $(15-16)$ & $\begin{array}{l}\text { dipeptidyl peptidase IV } \\
\text { inhibitor (DPP IV inhibitor) }\end{array}$ & $\begin{array}{l}\text { Inhibitor of Dipeptidyl Peptidase IV } \\
\text { (EC 3.4.14.5) (MEROPS ID: S09.003) }\end{array}$ & $\begin{array}{l}\text { dipeptidyl peptidase } \\
\text { IV inhibitor }\end{array}$ & 146.0580 & 146.1310 \\
\hline 22 & 8760 & AG & $(53-54)$ & $\begin{array}{l}\text { dipeptidyl peptidase IV } \\
\text { inhibitor (DPP IV inhibitor) }\end{array}$ & $\begin{array}{l}\text { Inhibitor of Dipeptidyl Peptidase IV } \\
\text { (EC 3.4.14.5) (MEROPS ID: S09.003) }\end{array}$ & $\begin{array}{l}\text { dipeptidyl peptidase } \\
\text { IV inhibitor }\end{array}$ & 146.0580 & 146.1310 \\
\hline 23 & 8760 & AG & $(93-94)$ & $\begin{array}{l}\text { dipeptidyl peptidase IV } \\
\text { inhibitor (DPP IV inhibitor) }\end{array}$ & $\begin{array}{l}\text { Inhibitor of Dipeptidyl Peptidase IV } \\
\text { (EC 3.4.14.5) (MEROPS ID: S09.003) }\end{array}$ & $\begin{array}{l}\text { dipeptidyl peptidase } \\
\text { IV inhibitor }\end{array}$ & 146.0580 & 146.1310 \\
\hline 24 & 8764 & $\mathrm{AV}$ & $(56-57)$ & $\begin{array}{l}\text { dipeptidyl peptidase IV } \\
\text { inhibitor (DPP IV inhibitor) }\end{array}$ & $\begin{array}{l}\text { Inhibitor of Dipeptidyl Peptidase IV } \\
\text { (EC 3.4.14.5) (MEROPS ID: S09.003) }\end{array}$ & $\begin{array}{l}\text { dipeptidyl peptidase } \\
\text { IV inhibitor }\end{array}$ & 188.1050 & 188.2120 \\
\hline 25 & 8769 & DR & $(80-81)$ & $\begin{array}{l}\text { dipeptidyl peptidase IV } \\
\text { inhibitor (DPP IV inhibitor) }\end{array}$ & $\begin{array}{l}\text { Inhibitor of Dipeptidyl Peptidase IV } \\
\text { (EC 3.4.14.5) (MEROPS ID: S09.003) }\end{array}$ & $\begin{array}{l}\text { dipeptidyl peptidase } \\
\text { IV inhibitor }\end{array}$ & 289.1279 & 289.2770 \\
\hline
\end{tabular}


Table A27. Cont

\begin{tabular}{|c|c|c|c|c|c|c|c|c|}
\hline No. & $\begin{array}{l}\text { Peptide } \\
\text { ID }\end{array}$ & Sequence & Location & Name & Function & Activity & $\begin{array}{l}\text { Monoisotopic } \\
\text { Mass }\end{array}$ & $\begin{array}{l}\text { Chemical } \\
\text { Mass }\end{array}$ \\
\hline 26 & 8769 & DR & $(164-165)$ & $\begin{array}{l}\text { dipeptidyl peptidase IV } \\
\text { inhibitor (DPP IV inhibitor) }\end{array}$ & $\begin{array}{l}\text { Inhibitor of Dipeptidyl Peptidase IV } \\
\text { (EC 3.4.14.5) (MEROPS ID: S09.003) }\end{array}$ & $\begin{array}{l}\text { dipeptidyl peptidase } \\
\text { IV inhibitor }\end{array}$ & 289.1279 & 289.2770 \\
\hline 27 & 8774 & ET & $(6-7)$ & $\begin{array}{l}\text { dipeptidyl peptidase IV } \\
\text { inhibitor (DPP IV inhibitor) }\end{array}$ & $\begin{array}{l}\text { Inhibitor of Dipeptidyl Peptidase IV } \\
\text { (EC 3.4.14.5) (MEROPS ID: S09.003) }\end{array}$ & $\begin{array}{l}\text { dipeptidyl peptidase } \\
\text { IV inhibitor }\end{array}$ & 248.0890 & 248.2210 \\
\hline 28 & 8871 & QG & $(153-154)$ & $\begin{array}{l}\text { dipeptidyl peptidase IV } \\
\text { inhibitor (DPP IV inhibitor) }\end{array}$ & $\begin{array}{l}\text { Inhibitor of Dipeptidyl Peptidase IV } \\
\text { (EC 3.4.14.5) (MEROPS ID: S09.003) }\end{array}$ & $\begin{array}{l}\text { dipeptidyl peptidase } \\
\text { IV inhibitor }\end{array}$ & 203.0790 & 203.1830 \\
\hline 29 & 8878 & QT & $(4-5)$ & $\begin{array}{l}\text { dipeptidyl peptidase IV } \\
\text { inhibitor (DPP IV inhibitor) }\end{array}$ & $\begin{array}{l}\text { Inhibitor of Dipeptidyl Peptidase IV } \\
\text { (EC 3.4.14.5) (MEROPS ID: S09.003) }\end{array}$ & $\begin{array}{l}\text { dipeptidyl peptidase } \\
\text { IV inhibitor }\end{array}$ & 247.1050 & 247.2360 \\
\hline 30 & 8918 & VG & $(11-12)$ & $\begin{array}{l}\text { dipeptidyl peptidase IV } \\
\text { inhibitor (DPP IV inhibitor) }\end{array}$ & $\begin{array}{l}\text { Inhibitor of Dipeptidyl Peptidase IV } \\
\text { (EC 3.4.14.5) (MEROPS ID: S09.003) }\end{array}$ & $\begin{array}{l}\text { dipeptidyl peptidase } \\
\text { IV inhibitor }\end{array}$ & 174.0890 & 174.1850 \\
\hline 31 & 8951 & $\mathrm{AV}$ & $(56-57)$ & ACE inhibitor & $\begin{array}{l}\text { Inhibitor of Angiotensin-Converting } \\
\text { Enzyme (ACE) (EC 3.4.15.1) (MEROPS } \\
\text { ID: XM02-001) }\end{array}$ & ACE inhibitor & 188.1050 & 188.2120 \\
\hline 32 & 9074 & $\mathrm{DF}$ & $(204-205)$ & ACE inhibitor & $\begin{array}{l}\text { Inhibitor of Angiotensin-Converting } \\
\text { Enzyme (ACE) (EC 3.4.15.1) (MEROPS } \\
\text { ID: XM02-001) }\end{array}$ & ACE inhibitor & 280.0949 & 280.2660 \\
\hline
\end{tabular}

Table A28. $A_{E}, D H_{t}, W, B_{E}$ and $V$ values from RubisCO of Halophila stipulacea. In silico enzymatic cleavage was carried out by using papain.

\begin{tabular}{llllll}
\hline $\begin{array}{l}\mathrm{DH} \\
\mathbf{4 3 . 4 1 4 6} \text { (\%) }\end{array}$ & & & & \\
\hline No. & Activity & $A_{E}$ & $W$ & $B_{E}$ & $V$ \\
\hline 1 & stimulating & 0.0049 & 0.1441 & 0 & \\
2 & ACE inhibitor & 0.0631 & 0.1083 & 0.0019221967090735 & 0.071834149934202 \\
3 & antioxidative & 0.0049 & 0.0673 & 0 & 0 \\
4 & dipeptidyl peptidase IV inhibitor & 0.0825 & 0.1268 & $2.3003804384162 \mathrm{E}-5$ & 0.10663971774841 \\
\hline
\end{tabular}


Table A29. Bioactive peptides from RubisCO of Halophila stipulacea. In silico enzymatic cleavage was carried out by using ficin.

\begin{tabular}{|c|c|c|c|c|c|c|c|c|}
\hline No. & $\begin{array}{l}\text { Peptide } \\
\text { ID }\end{array}$ & Sequence & Location & Name & Function & Activity & $\begin{array}{l}\text { Monoisotopic } \\
\text { Mass }\end{array}$ & $\begin{array}{l}\text { Chemical } \\
\text { Mass }\end{array}$ \\
\hline 1 & 2749 & DY & $(19-20)$ & ion flow regulating peptide & ion flow regulating peptide & regulating & 296.0899 & 296.2590 \\
\hline 2 & 3546 & VAY & $(103-105)$ & ACE inhibitor & $\begin{array}{l}\text { Inhibitor of Angiotensin-Converting } \\
\text { Enzyme (ACE) (EC 3.4.15.1) (MEROPS } \\
\text { ID: XM02-001) }\end{array}$ & ACE inhibitor & 351.1680 & 351.3820 \\
\hline 3 & 7513 & PL & $(106-107)$ & $\begin{array}{l}\text { ACE inhibitor from Alaskan } \\
\text { pollack skin }\end{array}$ & $\begin{array}{l}\text { Inhibitor of Angiotensin-converting } \\
\text { enzyme (EC 3.4.15.1) (MEROPS ID: } \\
\text { XM02-001) }\end{array}$ & ACE inhibitor & 228.1360 & 228.2770 \\
\hline 4 & 7513 & PL & $(172-173)$ & $\begin{array}{l}\text { ACE inhibitor from Alaskan } \\
\text { pollack skin }\end{array}$ & $\begin{array}{l}\text { Inhibitor of Angiotensin-converting } \\
\text { enzyme (EC 3.4.15.1) (MEROPS ID: } \\
\text { XM02-001) }\end{array}$ & ACE inhibitor & 228.1360 & 228.2770 \\
\hline 5 & 7558 & VK & $(17-18)$ & ACE inhibitor from buckwheat & & ACE inhibitor & 245.1620 & 245.3070 \\
\hline 6 & 7594 & VG & $(11-12)$ & ACE inhibitor & $\begin{array}{l}\text { Inhibitor of Angiotensin-Converting } \\
\text { Enzyme (ACE) (EC 3.4.15.1) (MEROPS } \\
\text { ID: XM02-001) }\end{array}$ & ACE inhibitor & 174.0890 & 174.1850 \\
\hline 7 & 7600 & AG & $(9-10)$ & ACE inhibitor & $\begin{array}{l}\text { Inhibitor of Angiotensin-Converting } \\
\text { Enzyme (ACE) (EC 3.4.15.1) (MEROPS } \\
\text { ID: XM02-001) }\end{array}$ & ACE inhibitor & 146.0580 & 146.1310 \\
\hline 8 & 7617 & QG & $(153-154)$ & ACE inhibitor & & ACE inhibitor & 203.0790 & 203.1830 \\
\hline 9 & 7621 & $\widehat{\mathrm{TG}}$ & $(65-66)$ & ACE inhibitor & & ACE inhibitor & 176.0680 & 176.1570 \\
\hline 10 & 7682 & NY & $(190-191)$ & ACE inhibitor from garlic & & ACE inhibitor & 295.1059 & 295.2740 \\
\hline 11 & 7698 & NK & $(167-168)$ & ACE inhibitor from wakame & & ACE inhibitor & 260.1369 & 260.2780 \\
\hline 12 & 8185 & $\mathrm{TF}$ & $(151-152)$ & ACE inhibitor & $\begin{array}{l}\text { Inhibitor of Angiotensin-Converting } \\
\text { Enzyme (ACE) (EC 3.4.15.1) (MEROPS } \\
\text { ID: XM02-001) }\end{array}$ & ACE inhibitor & 266.1150 & 266.2820 \\
\hline 13 & 8219 & TY & $(23-24)$ & antioxidative peptide & & antioxidative & 282.1100 & 282.2750 \\
\hline 14 & 8559 & $\mathrm{AL}$ & $(133-134)$ & $\begin{array}{l}\text { dipeptidyl peptidase IV } \\
\text { inhibitor (DPP IV inhibitor) }\end{array}$ & $\begin{array}{l}\text { Inhibitor of Dipeptidyl Peptidase IV } \\
\text { (EC 3.4.14.5) (MEROPS ID: S09.003) }\end{array}$ & $\begin{array}{l}\text { dipeptidyl peptidase } \\
\text { IV inhibitor }\end{array}$ & 202.1210 & 202.2390 \\
\hline 15 & 8559 & AL & $(136-137)$ & $\begin{array}{l}\text { dipeptidyl peptidase IV } \\
\text { inhibitor (DPP IV inhibitor) }\end{array}$ & $\begin{array}{l}\text { Inhibitor of Dipeptidyl Peptidase IV } \\
\text { (EC 3.4.14.5) (MEROPS ID: S09.003) }\end{array}$ & $\begin{array}{l}\text { dipeptidyl peptidase } \\
\text { IV inhibitor }\end{array}$ & 202.1210 & 202.2390 \\
\hline 16 & 8638 & PL & $(106-107)$ & $\begin{array}{l}\text { dipeptidyl peptidase IV } \\
\text { inhibitor (DPP IV inhibitor) }\end{array}$ & $\begin{array}{l}\text { Inhibitor of Dipeptidyl Peptidase IV } \\
\text { (EC 3.4.14.5) (MEROPS ID: S09.003) }\end{array}$ & $\begin{array}{l}\text { dipeptidyl peptidase } \\
\text { IV inhibitor }\end{array}$ & 228.1360 & 228.2770 \\
\hline 17 & 8638 & PL & $(172-173)$ & $\begin{array}{l}\text { dipeptidyl peptidase IV } \\
\text { inhibitor (DPP IV inhibitor) }\end{array}$ & $\begin{array}{l}\text { Inhibitor of Dipeptidyl Peptidase IV } \\
\text { (EC 3.4.14.5) (MEROPS ID: S09.003) }\end{array}$ & $\begin{array}{l}\text { dipeptidyl peptidase } \\
\text { IV inhibitor }\end{array}$ & 228.1360 & 228.2770 \\
\hline 18 & 8760 & AG & $(9-10)$ & $\begin{array}{l}\text { dipeptidyl peptidase IV } \\
\text { inhibitor (DPP IV inhibitor) }\end{array}$ & $\begin{array}{l}\text { Inhibitor of Dipeptidyl Peptidase IV } \\
\text { (EC 3.4.14.5) (MEROPS ID: S09.003) }\end{array}$ & $\begin{array}{l}\text { dipeptidyl peptidase } \\
\text { IV inhibitor }\end{array}$ & 146.0580 & 146.1310 \\
\hline 19 & 8769 & DR & $(80-81)$ & $\begin{array}{l}\text { dipeptidyl peptidase IV } \\
\text { inhibitor (DPP IV inhibitor) }\end{array}$ & $\begin{array}{l}\text { Inhibitor of Dipeptidyl Peptidase IV } \\
\text { (EC 3.4.14.5) (MEROPS ID: S09.003) }\end{array}$ & $\begin{array}{l}\text { dipeptidyl peptidase } \\
\text { IV inhibitor }\end{array}$ & 289.1279 & 289.2770 \\
\hline
\end{tabular}


Table A29. Cont.

\begin{tabular}{|c|c|c|c|c|c|c|c|c|}
\hline No. & $\begin{array}{l}\text { Peptide } \\
\text { ID }\end{array}$ & Sequence & Location & Name & Function & Activity & $\begin{array}{l}\text { Monoisotopic } \\
\text { Mass }\end{array}$ & $\begin{array}{l}\text { Chemical } \\
\text { Mass }\end{array}$ \\
\hline 20 & 8769 & $\mathrm{DR}$ & $(164-165)$ & $\begin{array}{l}\text { dipeptidyl peptidase IV } \\
\text { inhibitor (DPP IV inhibitor) }\end{array}$ & $\begin{array}{l}\text { Inhibitor of Dipeptidyl Peptidase IV } \\
\text { (EC 3.4.14.5) (MEROPS ID: S09.003) }\end{array}$ & $\begin{array}{l}\text { dipeptidyl peptidase } \\
\text { IV inhibitor }\end{array}$ & 289.1279 & 289.2770 \\
\hline 21 & 8853 & NY & $(190-191)$ & $\begin{array}{l}\text { dipeptidyl peptidase IV } \\
\text { inhibitor (DPP IV inhibitor) }\end{array}$ & $\begin{array}{l}\text { Inhibitor of Dipeptidyl Peptidase IV } \\
\text { (EC 3.4.14.5) (MEROPS ID: S09.003) }\end{array}$ & $\begin{array}{l}\text { dipeptidyl peptidase } \\
\text { IV inhibitor }\end{array}$ & 295.1059 & 295.2740 \\
\hline 22 & 8858 & PK & $(180-181)$ & $\begin{array}{l}\text { dipeptidyl peptidase IV } \\
\text { inhibitor (DPP IV inhibitor) }\end{array}$ & $\begin{array}{l}\text { Inhibitor of Dipeptidyl Peptidase IV } \\
\text { (EC 3.4.14.5) (MEROPS ID: S09.003) }\end{array}$ & $\begin{array}{l}\text { dipeptidyl peptidase } \\
\text { IV inhibitor }\end{array}$ & 243.1460 & 243.2910 \\
\hline 23 & 8871 & QG & $(153-154)$ & $\begin{array}{l}\text { dipeptidyl peptidase IV } \\
\text { inhibitor (DPP IV inhibitor) }\end{array}$ & $\begin{array}{l}\text { Inhibitor of Dipeptidyl Peptidase IV } \\
\text { (EC 3.4.14.5) (MEROPS ID: S09.003) }\end{array}$ & $\begin{array}{l}\text { dipeptidyl peptidase } \\
\text { IV inhibitor }\end{array}$ & 203.0790 & 203.1830 \\
\hline 24 & 8900 & $\mathrm{TF}$ & $(151-152)$ & $\begin{array}{l}\text { dipeptidyl peptidase IV } \\
\text { inhibitor (DPP IV inhibitor) }\end{array}$ & $\begin{array}{l}\text { Inhibitor of Dipeptidyl Peptidase IV } \\
\text { (EC 3.4.14.5) (MEROPS ID: S09.003) }\end{array}$ & $\begin{array}{l}\text { dipeptidyl peptidase } \\
\text { IV inhibitor }\end{array}$ & 266.1150 & 266.2820 \\
\hline 25 & 8901 & TG & $(65-66)$ & $\begin{array}{l}\text { dipeptidyl peptidase IV } \\
\text { inhibitor (DPP IV inhibitor) }\end{array}$ & $\begin{array}{l}\text { Inhibitor of Dipeptidyl Peptidase IV } \\
\text { (EC 3.4.14.5) (MEROPS ID: S09.003) }\end{array}$ & $\begin{array}{l}\text { dipeptidyl peptidase } \\
\text { IV inhibitor }\end{array}$ & 176.0680 & 176.1570 \\
\hline 26 & 8910 & TS & $(77-78)$ & $\begin{array}{l}\text { dipeptidyl peptidase IV } \\
\text { inhibitor (DPP IV inhibitor) }\end{array}$ & $\begin{array}{l}\text { Inhibitor of Dipeptidyl Peptidase IV } \\
\text { (EC 3.4.14.5) (MEROPS ID: S09.003) }\end{array}$ & $\begin{array}{l}\text { dipeptidyl peptidase } \\
\text { IV inhibitor }\end{array}$ & 206.0790 & 206.1850 \\
\hline 27 & 8910 & TS & $(120-121)$ & $\begin{array}{l}\text { dipeptidyl peptidase IV } \\
\text { inhibitor (DPP IV inhibitor) }\end{array}$ & $\begin{array}{l}\text { Inhibitor of Dipeptidyl Peptidase IV } \\
\text { (EC 3.4.14.5) (MEROPS ID: S09.003) }\end{array}$ & $\begin{array}{l}\text { dipeptidyl peptidase } \\
\text { IV inhibitor }\end{array}$ & 206.0790 & 206.1850 \\
\hline 28 & 8914 & TY & $(23-24)$ & $\begin{array}{l}\text { dipeptidyl peptidase IV } \\
\text { inhibitor (DPP IV inhibitor) }\end{array}$ & $\begin{array}{l}\text { Inhibitor of Dipeptidyl Peptidase IV } \\
\text { (EC 3.4.14.5) (MEROPS ID: S09.003) }\end{array}$ & $\begin{array}{l}\text { dipeptidyl peptidase } \\
\text { IV inhibitor }\end{array}$ & 282.1100 & 282.2750 \\
\hline 29 & 8918 & VG & $(11-12)$ & $\begin{array}{l}\text { dipeptidyl peptidase IV } \\
\text { inhibitor (DPP IV inhibitor) }\end{array}$ & $\begin{array}{l}\text { Inhibitor of Dipeptidyl Peptidase IV } \\
\text { (EC 3.4.14.5) (MEROPS ID: S09.003) }\end{array}$ & $\begin{array}{l}\text { dipeptidyl peptidase } \\
\text { IV inhibitor }\end{array}$ & 174.0890 & 174.1850 \\
\hline 30 & 8921 & VK & $(17-18)$ & $\begin{array}{l}\text { dipeptidyl peptidase IV } \\
\text { inhibitor (DPP IV inhibitor) }\end{array}$ & $\begin{array}{l}\text { Inhibitor of Dipeptidyl Peptidase IV } \\
\text { (EC 3.4.14.5) (MEROPS ID: S09.003) }\end{array}$ & $\begin{array}{l}\text { dipeptidyl peptidase } \\
\text { IV inhibitor }\end{array}$ & 245.1620 & 245.3070 \\
\hline 31 & 8926 & VS & $(42-43)$ & $\begin{array}{l}\text { dipeptidyl peptidase IV } \\
\text { inhibitor (DPP IV inhibitor) }\end{array}$ & $\begin{array}{l}\text { Inhibitor of Dipeptidyl Peptidase IV } \\
\text { (EC 3.4.14.5) (MEROPS ID: S09.003) }\end{array}$ & $\begin{array}{l}\text { dipeptidyl peptidase } \\
\text { IV inhibitor }\end{array}$ & 204.1000 & 204.2130 \\
\hline 32 & 9071 & IAY & $(100-102)$ & ACE inhibitor & $\begin{array}{l}\text { Inhibitor of Angiotensin-Converting } \\
\text { Enzyme (ACE) (EC 3.4.15.1) (MEROPS } \\
\text { ID: M02-001) }\end{array}$ & ACE inhibitor & 365.1840 & 365.4090 \\
\hline 33 & 9072 & DY & $(19-20)$ & ACE inhibitor & $\begin{array}{l}\text { Inhibitor of Angiotensin-Converting } \\
\text { Enzyme (ACE) (EC 3.4.15.1) (MEROPS } \\
\text { ID: XM02-001) }\end{array}$ & ACE inhibitor & 296.0899 & 296.2590 \\
\hline 34 & 9074 & DF & $(204-205)$ & ACE inhibitor & $\begin{array}{l}\text { Inhibitor of Angiotensin-Converting } \\
\text { Enzyme (ACE) (EC 3.4.15.1) (MEROPS } \\
\text { ID: XM02-001) }\end{array}$ & ACE inhibitor & 280.0949 & 280.2660 \\
\hline
\end{tabular}


Table A30. $A_{E}, D H_{t}, W, B_{E}$ and $V$ values from RubisCO of Halophila stipulacea. In silico enzymatic cleavage was carried out by using ficin.

\begin{tabular}{llllll}
\hline $\begin{array}{l}\mathrm{DH} \\
\mathbf{4 4 . 3 9 0 2}\end{array}$ & & & & \\
\hline No. & Activity & $A_{E}$ & $W$ & $\boldsymbol{B}_{\boldsymbol{E}}$ & $\boldsymbol{V}$ \\
\hline 1 & regulating & 0.0049 & 0.3356 & 0 & \\
2 & ACE inhibitor & 0.0680 & 0.1167 & 0.001585167723556 & 0.059239085878814 \\
3 & antioxidative & 0.0049 & 0.0673 & 0 & 0 \\
4 & dipeptidyl peptidase IV inhibitor & 0.0874 & 0.1344 & $1.1006017099609 \mathrm{E}-5$ & 0.051021063187465 \\
\hline
\end{tabular}

Table A31. Bioactive peptides from RubisCO of Halophila stipulacea. In silico enzymatic cleavage was carried out by using leukocyte elastase.

\begin{tabular}{|c|c|c|c|c|c|c|c|c|}
\hline No. & $\begin{array}{l}\text { Peptide } \\
\text { ID }\end{array}$ & Sequence & Location & Name & Function & Activity & $\begin{array}{l}\text { Monoisotopic } \\
\text { Mass }\end{array}$ & $\begin{array}{l}\text { Chemical } \\
\text { Mass }\end{array}$ \\
\hline 1 & 3174 & KA & $(8-9)$ & $\begin{array}{l}\text { dipeptidyl peptidase IV } \\
\text { inhibitor (DPP IV inhibitor) }\end{array}$ & $\begin{array}{l}\text { Inhibitor of Dipeptidyl Peptidase IV } \\
\text { (EC 3.4.14.5) (MEROPS ID: S09.003) }\end{array}$ & $\begin{array}{l}\text { dipeptidyl peptidase } \\
\text { IV inhibitor }\end{array}$ & 217.1310 & 217.2530 \\
\hline 2 & 3257 & RL & $(138-139)$ & beta-lactokinin & $\begin{array}{l}\text { Inhibitor of Angiotensin-Converting } \\
\text { Enzyme (ACE) (EC 3.4.15.1) (MEROPS } \\
\text { ID: XM02-001) }\end{array}$ & ACE inhibitor & 287.1850 & 287.3480 \\
\hline 3 & 4005 & RA & $(135-136)$ & & $\begin{array}{l}\text { Activation of ubiquitin-dependent } \\
\text { proteolysis }\end{array}$ & $\begin{array}{l}\text { activating } \\
\text { ubiquitin-mediated } \\
\text { proteolysis }\end{array}$ & 245.1380 & 245.2670 \\
\hline 4 & 7588 & RA & $(135-136)$ & ACE inhibitor & $\begin{array}{l}\text { Inhibitor of Angiotensin-Converting } \\
\text { Enzyme (ACE) (EC 3.4.15.1) (MEROPS } \\
\text { ID: XM02-001) }\end{array}$ & ACE inhibitor & 245.1380 & 245.2670 \\
\hline 5 & 7598 & GA & $(54-55)$ & ACE inhibitor & & ACE inhibitor & 146.0580 & 146.1310 \\
\hline 6 & 7599 & GL & $(183-184)$ & ACE inhibitor & $\begin{array}{l}\text { Inhibitor of Angiotensin-converting } \\
\text { enzyme (EC 3.4.15.1) (MEROPS ID: } \\
\text { XM02-001) }\end{array}$ & ACE inhibitor & 188.1050 & 188.2120 \\
\hline 7 & 7608 & GV & $(10-11)$ & ACE inhibitor & $\begin{array}{l}\text { Inhibitor of Angiotensin-Converting } \\
\text { Enzyme (ACE) (EC 3.4.15.1) (MEROPS } \\
\text { ID: XM02-001) }\end{array}$ & ACE inhibitor & 174.0890 & 174.1850 \\
\hline 8 & 7608 & GV & $(16-17)$ & ACE inhibitor & $\begin{array}{l}\text { Inhibitor of Angiotensin-Converting } \\
\text { Enzyme (ACE) (EC 3.4.15.1) (MEROPS } \\
\text { ID: XM02-001) }\end{array}$ & ACE inhibitor & 174.0890 & 174.1850 \\
\hline 9 & 7612 & GT & $(66-67)$ & ACE inhibitor & & ACE inhibitor & 176.0680 & 176.1570 \\
\hline 10 & 7743 & KA & $(8-9)$ & ACE inhibitor & $\begin{array}{l}\text { Inhibitor of angiotensin-converting } \\
\text { enzyme (EC 3.4.15.1) (MEROPS ID: } \\
\text { XM02-001) }\end{array}$ & ACE inhibitor & 217.1310 & 217.2530 \\
\hline
\end{tabular}


Table A31. Cont.

\begin{tabular}{|c|c|c|c|c|c|c|c|c|}
\hline No. & $\begin{array}{l}\text { Peptide } \\
\text { ID }\end{array}$ & Sequence & Location & Name & Function & Activity & $\begin{array}{l}\text { Monoisotopic } \\
\text { Mass }\end{array}$ & $\begin{array}{l}\text { Chemical } \\
\text { Mass }\end{array}$ \\
\hline 11 & 7951 & YYT & $(24-26)$ & synthetic peptide & & antioxidative & 445.1730 & 445.4450 \\
\hline 12 & 8524 & GA & $(54-55)$ & $\begin{array}{l}\text { dipeptidyl peptidase IV } \\
\text { inhibitor (DPP IV inhibitor) }\end{array}$ & $\begin{array}{l}\text { Inhibitor of Dipeptidyl Peptidase IV } \\
\text { (EC 3.4.14.5) (MEROPS ID: S09.003) }\end{array}$ & $\begin{array}{l}\text { dipeptidyl peptidase } \\
\text { IV inhibitor }\end{array}$ & 146.0580 & 146.1310 \\
\hline 13 & 8526 & RA & $(135-136)$ & $\begin{array}{l}\text { dipeptidyl peptidase IV } \\
\text { inhibitor (DPP IV inhibitor) }\end{array}$ & $\begin{array}{l}\text { Inhibitor of Dipeptidyl Peptidase IV } \\
\text { (EC 3.4.14.5) (MEROPS ID: S09.003) }\end{array}$ & $\begin{array}{l}\text { dipeptidyl peptidase } \\
\text { IV inhibitor }\end{array}$ & 245.1380 & 245.2670 \\
\hline 14 & 8561 & GL & $(183-184)$ & $\begin{array}{l}\text { dipeptidyl peptidase IV } \\
\text { inhibitor (DPP IV inhibitor) }\end{array}$ & $\begin{array}{l}\text { Inhibitor of Dipeptidyl Peptidase IV } \\
\text { (EC 3.4.14.5) (MEROPS ID: S09.003) }\end{array}$ & $\begin{array}{l}\text { dipeptidyl peptidase } \\
\text { IV inhibitor }\end{array}$ & 188.1050 & 188.2120 \\
\hline 15 & 8685 & WT & $(68-69)$ & $\begin{array}{l}\text { dipeptidyl peptidase IV } \\
\text { inhibitor (DPP IV inhibitor) }\end{array}$ & $\begin{array}{l}\text { Inhibitor of Dipeptidyl Peptidase IV } \\
\text { (EC 3.4.14.5) (MEROPS ID: S09.003) }\end{array}$ & $\begin{array}{l}\text { dipeptidyl peptidase } \\
\text { IV inhibitor }\end{array}$ & 305.1260 & 305.3180 \\
\hline 16 & 8685 & WT & $(72-73)$ & $\begin{array}{l}\text { dipeptidyl peptidase IV } \\
\text { inhibitor (DPP IV inhibitor) }\end{array}$ & $\begin{array}{l}\text { Inhibitor of Dipeptidyl Peptidase IV } \\
\text { (EC 3.4.14.5) (MEROPS ID: S09.003) }\end{array}$ & $\begin{array}{l}\text { dipeptidyl peptidase } \\
\text { IV inhibitor }\end{array}$ & 305.1260 & 305.3180 \\
\hline 17 & 8774 & ET & $(6-7)$ & $\begin{array}{l}\text { dipeptidyl peptidase IV } \\
\text { inhibitor (DPP IV inhibitor) }\end{array}$ & $\begin{array}{l}\text { Inhibitor of Dipeptidyl Peptidase IV } \\
\text { (EC 3.4.14.5) (MEROPS ID: S09.003) }\end{array}$ & $\begin{array}{l}\text { dipeptidyl peptidase } \\
\text { IV inhibitor }\end{array}$ & 248.0890 & 248.2210 \\
\hline 18 & 8786 & GV & $(10-11)$ & $\begin{array}{l}\text { dipeptidyl peptidase IV } \\
\text { inhibitor (DPP IV inhibitor) }\end{array}$ & $\begin{array}{l}\text { Inhibitor of Dipeptidyl Peptidase IV } \\
\text { (EC 3.4.14.5) (MEROPS ID: S09.003) }\end{array}$ & $\begin{array}{l}\text { dipeptidyl peptidase } \\
\text { IV inhibitor }\end{array}$ & 174.0890 & 174.1850 \\
\hline 19 & 8786 & GV & $(16-17)$ & $\begin{array}{l}\text { dipeptidyl peptidase IV } \\
\text { inhibitor (DPP IV inhibitor) }\end{array}$ & $\begin{array}{l}\text { Inhibitor of Dipeptidyl Peptidase IV } \\
\text { (EC 3.4.14.5) (MEROPS ID: S09.003) }\end{array}$ & $\begin{array}{l}\text { dipeptidyl peptidase } \\
\text { IV inhibitor }\end{array}$ & 174.0890 & 174.1850 \\
\hline 20 & 8816 & KT & $(150-151)$ & $\begin{array}{l}\text { dipeptidyl peptidase IV } \\
\text { inhibitor (DPP IV inhibitor) }\end{array}$ & $\begin{array}{l}\text { Inhibitor of Dipeptidyl Peptidase IV } \\
\text { (EC 3.4.14.5) (MEROPS ID: S09.003) }\end{array}$ & $\begin{array}{l}\text { dipeptidyl peptidase } \\
\text { IV inhibitor }\end{array}$ & 247.1410 & 247.2790 \\
\hline 21 & 8879 & QV & $(160-161)$ & $\begin{array}{l}\text { dipeptidyl peptidase IV } \\
\text { inhibitor (DPP IV inhibitor) }\end{array}$ & $\begin{array}{l}\text { Inhibitor of Dipeptidyl Peptidase IV } \\
\text { (EC 3.4.14.5) (MEROPS ID: S09.003) }\end{array}$ & $\begin{array}{l}\text { dipeptidyl peptidase } \\
\text { IV inhibitor }\end{array}$ & 245.1260 & 245.2640 \\
\hline 22 & 8884 & RI & $(143-144)$ & $\begin{array}{l}\text { dipeptidyl peptidase IV } \\
\text { inhibitor (DPP IV inhibitor) }\end{array}$ & $\begin{array}{l}\text { Inhibitor of Dipeptidyl Peptidase IV } \\
\text { (EC 3.4.14.5) (MEROPS ID: S09.003) }\end{array}$ & $\begin{array}{l}\text { dipeptidyl peptidase } \\
\text { IV inhibitor }\end{array}$ & 287.1850 & 287.3480 \\
\hline 23 & 8886 & RL & $(138-139)$ & $\begin{array}{l}\text { dipeptidyl peptidase IV } \\
\text { inhibitor (DPP IV inhibitor) }\end{array}$ & $\begin{array}{l}\text { Inhibitor of Dipeptidyl Peptidase IV } \\
\text { (EC 3.4.14.5) (MEROPS ID: S09.003) }\end{array}$ & $\begin{array}{l}\text { dipeptidyl peptidase } \\
\text { IV inhibitor }\end{array}$ & 287.1850 & 287.3480 \\
\hline 24 & 8945 & YS & $(148-149)$ & $\begin{array}{l}\text { dipeptidyl peptidase IV } \\
\text { inhibitor (DPP IV inhibitor) }\end{array}$ & $\begin{array}{l}\text { Inhibitor of Dipeptidyl Peptidase IV } \\
\text { (EC 3.4.14.5) (MEROPS ID: S09.003) }\end{array}$ & $\begin{array}{l}\text { dipeptidyl peptidase } \\
\text { IV inhibitor }\end{array}$ & 268.0950 & 268.2500 \\
\hline 25 & 8946 & YV & $(102-103)$ & $\begin{array}{l}\text { dipeptidyl peptidase IV } \\
\text { inhibitor (DPP IV inhibitor) }\end{array}$ & $\begin{array}{l}\text { Inhibitor of Dipeptidyl Peptidase IV } \\
\text { (EC 3.4.14.5) (MEROPS ID: S09.003) }\end{array}$ & $\begin{array}{l}\text { dipeptidyl peptidase } \\
\text { IV inhibitor }\end{array}$ & 280.1310 & 280.3030 \\
\hline 26 & 9056 & DGL & $(74-76)$ & ACE inhibitor & $\begin{array}{l}\text { Inhibitor of Angiotensin-Converting } \\
\text { Enzyme (ACE) (EC 3.4.15.1) (MEROPS } \\
\text { ID: XM02-001) }\end{array}$ & ACE inhibitor & 303.1319 & 303.3010 \\
\hline 27 & 9077 & YV & $(102-103)$ & ACE inhibitor & $\begin{array}{l}\text { Inhibitor of Angiotensin-Converting } \\
\text { Enzyme (ACE) (EC 3.4.15.1) (MEROPS } \\
\text { ID: XM02-001) }\end{array}$ & ACE inhibitor & 280.1310 & 280.3030 \\
\hline
\end{tabular}


Table A32. $A_{E}, D H_{t}, W, B_{E}$ and $V$ values from RubisCO of Halophila stipulacea. In silico enzymatic cleavage was carried out by using leukocyte elastase.

\begin{tabular}{|c|c|c|c|c|c|}
\hline \multicolumn{6}{|c|}{$\begin{array}{l}\mathrm{DH}_{t}(\%) \\
38.5366\end{array}$} \\
\hline No. & Activity & $A_{E}$ & $W$ & $B_{E}$ & $V$ \\
\hline 1 & dipeptidyl peptidase IV inhibitor & 0.0728 & 0.1119 & $2.2768987034696 \mathrm{E}-5$ & 0.10555116493987 \\
\hline 2 & ACE inhibitor & 0.0485 & 0.0833 & 0.0024508146173148 & 0.091589057379035 \\
\hline 3 & activating ubiquitin-mediated proteolysis & 0.0049 & 0.3356 & 0 & \\
\hline 4 & antioxidative & 0.0049 & 0.0673 & 0 & 0 \\
\hline
\end{tabular}

Table A33. Bioactive peptides from RubisCO of Halophila stipulacea. In silico enzymatic cleavage was carried out by using metridin.

\begin{tabular}{|c|c|c|c|c|c|c|c|c|}
\hline No. & $\begin{array}{l}\text { Peptide } \\
\text { ID }\end{array}$ & Sequence & Location & Name & Function & Activity & $\begin{array}{l}\text { Monoisotopic } \\
\text { Mass }\end{array}$ & $\begin{array}{l}\text { Chemical } \\
\text { Mass }\end{array}$ \\
\hline 1 & 3257 & RL & $(138-139)$ & beta-lactokinin & $\begin{array}{l}\text { Inhibitor of Angiotensin-Converting Enzyme } \\
\text { (ACE) (EC 3.4.15.1) (MEROPS ID: XM02-001) }\end{array}$ & ACE inhibitor & 287.1850 & 287.3480 \\
\hline 2 & 3546 & VAY & $(103-105)$ & ACE inhibitor & $\begin{array}{l}\text { Inhibitor of Angiotensin-Converting Enzyme } \\
\text { (ACE) (EC 3.4.15.1) (MEROPS ID: XM02-001) }\end{array}$ & ACE inhibitor & 351.1680 & 351.3820 \\
\hline 3 & 7513 & PL & $(106-107)$ & $\begin{array}{l}\text { ACE inhibitor from Alaskan } \\
\text { pollack skin }\end{array}$ & $\begin{array}{l}\text { Inhibitor of Angiotensin-converting enzyme (EC } \\
\text { 3.4.15.1) (MEROPS ID: XM02-001) }\end{array}$ & ACE inhibitor & 228.1360 & 228.2770 \\
\hline 4 & 7591 & GF & $(130-131)$ & ACE inhibitor & $\begin{array}{l}\text { Inhibitor of Angiotensin-Converting Enzyme } \\
\text { (ACE) (EC 3.4.15.1) (MEROPS ID: XM02-001) }\end{array}$ & ACE inhibitor & 222.0890 & 222.2290 \\
\hline 5 & 7599 & GL & $(183-184)$ & ACE inhibitor & $\begin{array}{l}\text { Inhibitor of Angiotensin-converting enzyme (EC } \\
\text { 3.4.15.1) (MEROPS ID: XM02-001) }\end{array}$ & ACE inhibitor & 188.1050 & 188.2120 \\
\hline 6 & 7693 & KL & $(21-22)$ & ACE inhibitor from wakame & & ACE inhibitor & 259.1780 & 259.3340 \\
\hline 7 & 8219 & TY & $(23-24)$ & antioxidative peptide & & antioxidative & 282.1100 & 282.2750 \\
\hline 8 & 8561 & GL & $(183-184)$ & $\begin{array}{l}\text { dipeptidyl peptidase IV } \\
\text { inhibitor (DPP IV inhibitor) }\end{array}$ & $\begin{array}{l}\text { Inhibitor of Dipeptidyl Peptidase IV (EC 3.4.14.5) } \\
\text { (MEROPS ID: S09.003) }\end{array}$ & $\begin{array}{l}\text { dipeptidyl peptidase } \\
\text { IV inhibitor }\end{array}$ & 188.1050 & 188.2120 \\
\hline 9 & 8638 & PL & $(106-107)$ & $\begin{array}{l}\text { dipeptidyl peptidase IV } \\
\text { inhibitor (DPP IV inhibitor) }\end{array}$ & $\begin{array}{l}\text { Inhibitor of Dipeptidyl Peptidase IV (EC 3.4.14.5) } \\
\text { (MEROPS ID: S09.003) }\end{array}$ & $\begin{array}{l}\text { dipeptidyl peptidase } \\
\text { IV inhibitor }\end{array}$ & 228.1360 & 228.2770 \\
\hline 10 & 8782 & GF & $(130-131)$ & $\begin{array}{l}\text { dipeptidyl peptidase IV } \\
\text { inhibitor (DPP IV inhibitor) }\end{array}$ & $\begin{array}{l}\text { Inhibitor of Dipeptidyl Peptidase IV (EC 3.4.14.5) } \\
\text { (MEROPS ID: S09.003) }\end{array}$ & $\begin{array}{l}\text { dipeptidyl peptidase } \\
\text { IV inhibitor }\end{array}$ & 222.0890 & 222.2290 \\
\hline 11 & 8886 & RL & $(138-139)$ & $\begin{array}{l}\text { dipeptidyl peptidase IV } \\
\text { inhibitor (DPP IV inhibitor) }\end{array}$ & $\begin{array}{l}\text { Inhibitor of Dipeptidyl Peptidase IV (EC 3.4.14.5) } \\
\text { (MEROPS ID: S09.003) }\end{array}$ & $\begin{array}{l}\text { dipeptidyl peptidase } \\
\text { IV inhibitor }\end{array}$ & 287.1850 & 287.3480 \\
\hline 12 & 8914 & TY & $(23-24)$ & $\begin{array}{l}\text { dipeptidyl peptidase IV } \\
\text { inhibitor (DPP IV inhibitor) }\end{array}$ & $\begin{array}{l}\text { Inhibitor of Dipeptidyl Peptidase IV (EC 3.4.14.5) } \\
\text { (MEROPS ID: S09.003) }\end{array}$ & $\begin{array}{l}\text { dipeptidyl peptidase } \\
\text { IV inhibitor }\end{array}$ & 282.1100 & 282.2750 \\
\hline 13 & 9071 & IAY & $(100-102)$ & ACE inhibitor & $\begin{array}{l}\text { Inhibitor of Angiotensin-Converting Enzyme } \\
\text { (ACE) (EC 3.4.15.1) (MEROPS ID: M02-001) }\end{array}$ & ACE inhibitor & 365.1840 & 365.4090 \\
\hline 14 & 9074 & DF & $(204-205)$ & ACE inhibitor & $\begin{array}{l}\text { Inhibitor of Angiotensin-Converting Enzyme } \\
\text { (ACE) (EC 3.4.15.1) (MEROPS ID: XM02-001) }\end{array}$ & ACE inhibitor & 280.0949 & 280.2660 \\
\hline
\end{tabular}


Table A34. $A_{E}, D H_{t}, W, B_{E}$ and $V$ values from RubisCO of Halophila stipulacea. In silico enzymatic cleavage was carried out by using metridin.

\begin{tabular}{llllll}
\hline $\begin{array}{l}\mathbf{D H}_{\boldsymbol{t}} \mathbf{( \% )} \\
\mathbf{1 9 . 5 1 2 2}\end{array}$ & & & & & \\
\hline No. & Activity & $A_{E}$ & $W$ & $\boldsymbol{B}_{E}$ & $\boldsymbol{V}$ \\
\hline 1 & ACE inhibitor & 0.0388 & 0.0666 & 0.00082506965175237 & 0.030833564947006 \\
2 & antioxidative & 0.0049 & 0.0673 & 0 & 0 \\
3 & dipeptidyl peptidase IV inhibitor & 0.0243 & 0.0374 & $1.8563339357632 \mathrm{E}-6$ & 0.0086054864513139 \\
\hline
\end{tabular}

Table A35. Bioactive peptides from RubisCO of Halophila stipulacea. In silico enzymatic cleavage was carried out by using pancreatic elastase II.

\begin{tabular}{|c|c|c|c|c|c|c|c|c|}
\hline No. & $\begin{array}{l}\text { Peptide } \\
\text { ID }\end{array}$ & Sequence & Location & Name & Function & Activity & $\begin{array}{l}\text { Monoisotopic } \\
\text { Mass }\end{array}$ & $\begin{array}{l}\text { Chemical } \\
\text { Mass }\end{array}$ \\
\hline 1 & 3257 & RL & $(138-139)$ & beta-lactokinin & $\begin{array}{l}\text { Inhibitor of Angiotensin-Converting } \\
\text { Enzyme (ACE) (EC 3.4.15.1) (MEROPS } \\
\text { ID: XM02-001) }\end{array}$ & ACE inhibitor & 287.1850 & 287.3480 \\
\hline 2 & 7591 & GF & $(130-131)$ & ACE inhibitor & $\begin{array}{l}\text { Inhibitor of Angiotensin-Converting } \\
\text { Enzyme (ACE) (EC 3.4.15.1) (MEROPS } \\
\text { ID: XM02-001) }\end{array}$ & ACE inhibitor & 222.0890 & 222.2290 \\
\hline 3 & 7599 & GL & $(183-184)$ & ACE inhibitor & $\begin{array}{l}\text { Inhibitor of Angiotensin-converting } \\
\text { enzyme (EC 3.4.15.1) (MEROPS ID: } \\
\text { XM02-001) }\end{array}$ & ACE inhibitor & 188.1050 & 188.2120 \\
\hline 4 & 8561 & GL & $(183-184)$ & $\begin{array}{l}\text { dipeptidyl peptidase IV } \\
\text { inhibitor (DPP IV inhibitor) }\end{array}$ & $\begin{array}{l}\text { Inhibitor of Dipeptidyl Peptidase IV } \\
\text { (EC 3.4.14.5) (MEROPS ID: S09.003) }\end{array}$ & $\begin{array}{l}\text { dipeptidyl peptidase } \\
\text { IV inhibitor }\end{array}$ & 188.1050 & 188.2120 \\
\hline 5 & 8782 & GF & $(130-131)$ & $\begin{array}{l}\text { dipeptidyl peptidase IV } \\
\text { inhibitor (DPP IV inhibitor) }\end{array}$ & $\begin{array}{l}\text { Inhibitor of Dipeptidyl Peptidase IV } \\
\text { (EC 3.4.14.5) (MEROPS ID: S09.003) }\end{array}$ & $\begin{array}{l}\text { dipeptidyl peptidase } \\
\text { IV inhibitor }\end{array}$ & 222.0890 & 222.2290 \\
\hline 6 & 8886 & RL & $(138-139)$ & $\begin{array}{l}\text { dipeptidyl peptidase IV } \\
\text { inhibitor (DPP IV inhibitor) }\end{array}$ & $\begin{array}{l}\text { Inhibitor of Dipeptidyl Peptidase IV } \\
\text { (EC 3.4.14.5) (MEROPS ID: S09.003) }\end{array}$ & $\begin{array}{l}\text { dipeptidyl peptidase } \\
\text { IV inhibitor }\end{array}$ & 287.1850 & 287.3480 \\
\hline 7 & 9074 & DF & $(204-205)$ & ACE inhibitor & $\begin{array}{l}\text { Inhibitor of Angiotensin-Converting } \\
\text { Enzyme (ACE) (EC 3.4.15.1) (MEROPS } \\
\text { ID: XM02-001) }\end{array}$ & ACE inhibitor & 280.0949 & 280.2660 \\
\hline
\end{tabular}


Table A36. $A_{E}, D H_{t}, W, B_{E}$ and $V$ values from RubisCO of Halophila stipulacea. In silico enzymatic cleavage was carried out by using pancreatic elastase II.

\begin{tabular}{llllll}
\hline $\begin{array}{l}\mathrm{DH} \\
\mathbf{1 3 . 1 \% )}\end{array}$ & & & & \\
\hline No. & Activity & $A_{E}$ & $W$ & $\boldsymbol{B}_{E}$ & $\boldsymbol{V}$ \\
\hline 1 & ACE inhibitor & 0.0194 & 0.0333 & $2.5006640432763 \mathrm{E}-5$ & 0.00093451973448837 \\
2 & dipeptidyl peptidase IV inhibitor & 0.0146 & 0.0224 & $1.8563339357632 \mathrm{E}-6$ & 0.0086054864513139 \\
\hline
\end{tabular}

Table A37. Bioactive peptides from RubisCO of Halophila stipulacea. In silico enzymatic cleavage was carried out by using stem bromelain.

\begin{tabular}{|c|c|c|c|c|c|c|c|c|}
\hline No. & $\begin{array}{l}\text { Peptide } \\
\text { ID }\end{array}$ & Sequence & Location & Name & Function & Activity & $\begin{array}{l}\text { Monoisotopic } \\
\text { Mass }\end{array}$ & $\begin{array}{l}\text { Chemical } \\
\text { Mass }\end{array}$ \\
\hline 1 & 3174 & KA & $(8-9)$ & $\begin{array}{l}\text { dipeptidyl peptidase IV } \\
\text { inhibitor (DPP IV inhibitor) }\end{array}$ & $\begin{array}{l}\text { Inhibitor of Dipeptidyl Peptidase IV } \\
\text { (EC 3.4.14.5) (MEROPS ID: S09.003) }\end{array}$ & $\begin{array}{l}\text { dipeptidyl peptidase } \\
\text { IV inhibitor }\end{array}$ & 217.1310 & 217.2530 \\
\hline 2 & 3174 & KA & $(132-133)$ & $\begin{array}{l}\text { dipeptidyl peptidase IV } \\
\text { inhibitor (DPP IV inhibitor) }\end{array}$ & $\begin{array}{l}\text { Inhibitor of Dipeptidyl Peptidase IV } \\
\text { (EC 3.4.14.5) (MEROPS ID: S09.003) }\end{array}$ & $\begin{array}{l}\text { dipeptidyl peptidase } \\
\text { IV inhibitor }\end{array}$ & 217.1310 & 217.2530 \\
\hline 3 & 7513 & PL & $(172-173)$ & $\begin{array}{l}\text { ACE inhibitor from Alaskan } \\
\text { pollack skin }\end{array}$ & $\begin{array}{l}\text { Inhibitor of Angiotensin-converting } \\
\text { enzyme (EC 3.4.15.1) (MEROPS ID: } \\
\text { XM02-001) }\end{array}$ & ACE inhibitor & 228.1360 & 228.2770 \\
\hline 4 & 7617 & QG & $(153-154)$ & ACE inhibitor & & ACE inhibitor & 203.0790 & 203.1830 \\
\hline 5 & 7681 & DG & $(74-75)$ & ACE inhibitor from soy & $\begin{array}{l}\text { Inhibitor of Angiotensin-converting } \\
\text { enzyme (ACE) (EC 3.4.15.1) (MEROPS } \\
\text { ID: XM02-001) }\end{array}$ & ACE inhibitor & 190.0479 & 190.1410 \\
\hline 6 & 7743 & KA & $(8-9)$ & ACE inhibitor & $\begin{array}{l}\text { Inhibitor of angiotensin-converting } \\
\text { enzyme (EC 3.4.15.1) (MEROPS ID: } \\
\text { XM02-001) }\end{array}$ & ACE inhibitor & 217.1310 & 217.2530 \\
\hline 7 & 7743 & KA & $(132-133)$ & ACE inhibitor & $\begin{array}{l}\text { Inhibitor of angiotensin-converting } \\
\text { enzyme (EC 3.4.15.1) (MEROPS ID: } \\
\text { XM02-001) }\end{array}$ & ACE inhibitor & 217.1310 & 217.2530 \\
\hline 8 & 7951 & YYT & $(24-26)$ & synthetic peptide & & antioxidative & 445.1730 & 445.4450 \\
\hline 9 & 8638 & PL & $(172-173)$ & $\begin{array}{l}\text { dipeptidyl peptidase IV } \\
\text { inhibitor (DPP IV inhibitor) }\end{array}$ & $\begin{array}{l}\text { Inhibitor of Dipeptidyl Peptidase IV } \\
\text { (EC 3.4.14.5) (MEROPS ID: S09.003) }\end{array}$ & $\begin{array}{l}\text { dipeptidyl peptidase } \\
\text { IV inhibitor }\end{array}$ & 228.1360 & 228.2770 \\
\hline 10 & 8685 & WT & $(68-69)$ & $\begin{array}{l}\text { dipeptidyl peptidase IV } \\
\text { inhibitor (DPP IV inhibitor) }\end{array}$ & $\begin{array}{l}\text { Inhibitor of Dipeptidyl Peptidase IV } \\
\text { (EC 3.4.14.5) (MEROPS ID: S09.003) }\end{array}$ & $\begin{array}{l}\text { dipeptidyl peptidase } \\
\text { IV inhibitor }\end{array}$ & 305.1260 & 305.3180 \\
\hline 11 & 8685 & WT & $(72-73)$ & $\begin{array}{l}\text { dipeptidyl peptidase IV } \\
\text { inhibitor (DPP IV inhibitor) }\end{array}$ & $\begin{array}{l}\text { Inhibitor of Dipeptidyl Peptidase IV } \\
\text { (EC 3.4.14.5) (MEROPS ID: S09.003) }\end{array}$ & $\begin{array}{l}\text { dipeptidyl peptidase } \\
\text { IV inhibitor }\end{array}$ & 305.1260 & 305.3180 \\
\hline 12 & 8769 & DR & $(80-81)$ & $\begin{array}{l}\text { dipeptidyl peptidase IV } \\
\text { inhibitor (DPP IV inhibitor) }\end{array}$ & $\begin{array}{l}\text { Inhibitor of Dipeptidyl Peptidase IV } \\
\text { (EC 3.4.14.5) (MEROPS ID: S09.003) }\end{array}$ & $\begin{array}{l}\text { dipeptidyl peptidase } \\
\text { IV inhibitor }\end{array}$ & 289.1279 & 289.2770 \\
\hline
\end{tabular}


Table A37. Cont

\begin{tabular}{|c|c|c|c|c|c|c|c|c|}
\hline No. & $\begin{array}{l}\text { Peptide } \\
\text { ID }\end{array}$ & Sequence & Location & Name & Function & Activity & $\begin{array}{l}\text { Monoisotopic } \\
\text { Mass }\end{array}$ & $\begin{array}{l}\text { Chemical } \\
\text { Mass }\end{array}$ \\
\hline 13 & 8769 & DR & $(164-165)$ & $\begin{array}{l}\text { dipeptidyl peptidase IV } \\
\text { inhibitor (DPP IV inhibitor) }\end{array}$ & $\begin{array}{l}\text { Inhibitor of Dipeptidyl Peptidase IV } \\
\text { (EC 3.4.14.5) (MEROPS ID: S09.003) }\end{array}$ & $\begin{array}{l}\text { dipeptidyl peptidase } \\
\text { IV inhibitor }\end{array}$ & 289.1279 & 289.2770 \\
\hline 14 & 8774 & ET & $(6-7)$ & $\begin{array}{l}\text { dipeptidyl peptidase IV } \\
\text { inhibitor (DPP IV inhibitor) }\end{array}$ & $\begin{array}{l}\text { Inhibitor of Dipeptidyl Peptidase IV } \\
\text { (EC 3.4.14.5) (MEROPS ID: S09.003) }\end{array}$ & $\begin{array}{l}\text { dipeptidyl peptidase } \\
\text { IV inhibitor }\end{array}$ & 248.0890 & 248.2210 \\
\hline 15 & 8816 & KT & $(150-151)$ & $\begin{array}{l}\text { dipeptidyl peptidase IV } \\
\text { inhibitor (DPP IV inhibitor) }\end{array}$ & $\begin{array}{l}\text { Inhibitor of Dipeptidyl Peptidase IV } \\
\text { (EC 3.4.14.5) (MEROPS ID: S09.003) }\end{array}$ & $\begin{array}{l}\text { dipeptidyl peptidase } \\
\text { IV inhibitor }\end{array}$ & 247.1410 & 247.2790 \\
\hline 16 & 8851 & NV & $(127-128)$ & $\begin{array}{l}\text { dipeptidyl peptidase IV } \\
\text { inhibitor (DPP IV inhibitor) }\end{array}$ & $\begin{array}{l}\text { Inhibitor of Dipeptidyl Peptidase IV } \\
\text { (EC 3.4.14.5) (MEROPS ID: S09.003) }\end{array}$ & $\begin{array}{l}\text { dipeptidyl peptidase } \\
\text { IV inhibitor }\end{array}$ & 231.1109 & 231.2370 \\
\hline 17 & 8867 & QA & $(14-15)$ & $\begin{array}{l}\text { dipeptidyl peptidase IV } \\
\text { inhibitor (DPP IV inhibitor) }\end{array}$ & $\begin{array}{l}\text { Inhibitor of Dipeptidyl Peptidase IV } \\
\text { (EC 3.4.14.5) (MEROPS ID: S09.003) }\end{array}$ & $\begin{array}{l}\text { dipeptidyl peptidase } \\
\text { IV inhibitor }\end{array}$ & 217.0950 & 217.2100 \\
\hline 18 & 8871 & QG & $(153-154)$ & $\begin{array}{l}\text { dipeptidyl peptidase IV } \\
\text { inhibitor (DPP IV inhibitor) }\end{array}$ & $\begin{array}{l}\text { Inhibitor of Dipeptidyl Peptidase IV } \\
\text { (EC 3.4.14.5) (MEROPS ID: S09.003) }\end{array}$ & $\begin{array}{l}\text { dipeptidyl peptidase } \\
\text { IV inhibitor }\end{array}$ & 203.0790 & 203.1830 \\
\hline 19 & 8945 & YS & $(148-149)$ & $\begin{array}{l}\text { dipeptidyl peptidase IV } \\
\text { inhibitor (DPP IV inhibitor) }\end{array}$ & $\begin{array}{l}\text { Inhibitor of Dipeptidyl Peptidase IV } \\
\text { (EC 3.4.14.5) (MEROPS ID: S09.003) }\end{array}$ & $\begin{array}{l}\text { dipeptidyl peptidase } \\
\text { IV inhibitor }\end{array}$ & 268.0950 & 268.2500 \\
\hline 20 & 8946 & YV & $(102-103)$ & $\begin{array}{l}\text { dipeptidyl peptidase IV } \\
\text { inhibitor (DPP IV inhibitor) }\end{array}$ & $\begin{array}{l}\text { Inhibitor of Dipeptidyl Peptidase IV } \\
\text { (EC 3.4.14.5) (MEROPS ID: S09.003) }\end{array}$ & $\begin{array}{l}\text { dipeptidyl peptidase } \\
\text { IV inhibitor }\end{array}$ & 280.1310 & 280.3030 \\
\hline 21 & 9074 & $\mathrm{DF}$ & $(204-205)$ & ACE inhibitor & $\begin{array}{l}\text { Inhibitor of Angiotensin-Converting } \\
\text { Enzyme (ACE) (EC 3.4.15.1) (MEROPS } \\
\text { ID: XM02-001) }\end{array}$ & ACE inhibitor & 280.0949 & 280.2660 \\
\hline 22 & 9077 & YV & $(102-103)$ & ACE inhibitor & $\begin{array}{l}\text { Inhibitor of Angiotensin-Converting } \\
\text { Enzyme (ACE) (EC 3.4.15.1) (MEROPS } \\
\text { ID: XM02-001) }\end{array}$ & ACE inhibitor & 280.1310 & 280.3030 \\
\hline
\end{tabular}

Table A38. $A_{E}, D H_{t}, W, B_{E}$ and $V$ values from RubisCO of Halophila stipulacea. In silico enzymatic cleavage was carried out by using stem bromelain.

\begin{tabular}{llllll}
\hline $\begin{array}{l}\mathrm{DH}_{t} \mathbf{( \% )} \\
\mathbf{5 4 . 1 4 6 3}\end{array}$ & & & & \\
\hline No. & Activity & $A_{E}$ & $\boldsymbol{W}$ & $\boldsymbol{B}_{\boldsymbol{E}}$ & $\boldsymbol{V}$ \\
\hline 1 & dipeptidyl peptidase IV inhibitor & 0.0680 & 0.1045 & $2.1686874619195 \mathrm{E}-5$ & 0.10053477023254 \\
2 & ACE inhibitor & 0.0340 & 0.0584 & 0.00073973077367093 & 0.027644377422971 \\
3 & antioxidative & 0.0049 & 0.0673 & 0 & 0 \\
\hline
\end{tabular}


Table A39. Bioactive peptides from RubisCO of Halophila stipulacea. In silico enzymatic cleavage was carried out by using oligopeptidase B.

\begin{tabular}{|c|c|c|c|c|c|c|c|c|}
\hline No. & $\begin{array}{l}\text { Peptide } \\
\text { ID }\end{array}$ & Sequence & Location & Name & Function & Activity & $\begin{array}{l}\text { Monoisotopic } \\
\text { Mass }\end{array}$ & $\begin{array}{l}\text { Chemical } \\
\text { Mass }\end{array}$ \\
\hline 1 & 7603 & GR & $(84-85)$ & ACE inhibitor & $\begin{array}{l}\text { Inhibitor of Angiotensin-Converting } \\
\text { Enzyme (ACE) (EC 3.4.15.1) (MEROPS } \\
\text { ID: XM02-001) }\end{array}$ & ACE inhibitor & 231.1220 & 231.2400 \\
\hline 2 & 7697 & YK & $(82-83)$ & ACE inhibitor from wakame & & ACE inhibitor & 309.1570 & 309.3440 \\
\hline 3 & 8769 & $\mathrm{DR}$ & $(164-165)$ & $\begin{array}{l}\text { dipeptidyl peptidase IV } \\
\text { inhibitor (DPP IV inhibitor) }\end{array}$ & $\begin{array}{l}\text { Inhibitor of Dipeptidyl Peptidase IV } \\
\text { (EC 3.4.14.5) (MEROPS ID: S09.003) }\end{array}$ & $\begin{array}{l}\text { dipeptidyl peptidase } \\
\text { IV inhibitor }\end{array}$ & 289.1279 & 289.2770 \\
\hline 4 & 8858 & PK & $(180-181)$ & $\begin{array}{l}\text { dipeptidyl peptidase IV } \\
\text { inhibitor (DPP IV inhibitor) }\end{array}$ & $\begin{array}{l}\text { Inhibitor of Dipeptidyl Peptidase IV } \\
\text { (EC 3.4.14.5) (MEROPS ID: S09.003) }\end{array}$ & $\begin{array}{l}\text { dipeptidyl peptidase } \\
\text { IV inhibitor }\end{array}$ & 243.1460 & 243.2910 \\
\hline 5 & 8939 & YK & $(82-83)$ & $\begin{array}{l}\text { dipeptidyl peptidase IV } \\
\text { inhibitor (DPP IV inhibitor) }\end{array}$ & $\begin{array}{l}\text { Inhibitor of Dipeptidyl Peptidase IV } \\
\text { (EC 3.4.14.5) (MEROPS ID: S09.003) }\end{array}$ & $\begin{array}{l}\text { dipeptidyl peptidase } \\
\text { IV inhibitor }\end{array}$ & 309.1570 & 309.3440 \\
\hline
\end{tabular}

Table A40. $A_{E}, D H_{t}, W, B_{E}$ and $V$ values from RubisCO of Halophila stipulacea. In silico enzymatic cleavage was carried out by using oligopeptidase B.

\begin{tabular}{llllll}
\hline $\begin{array}{l}\mathrm{DH} \\
\mathbf{1 0 . 7 3 1 7}\end{array}$ & & & & \\
\hline No. & Activity & $A_{E}$ & $W$ & $\boldsymbol{B}_{E}$ & $\boldsymbol{V}$ \\
\hline 1 & ACE inhibitor & 0.0097 & 0.0167 & $9.4749721470635 \mathrm{E}-6$ & 0.00035408788633428 \\
2 & dipeptidyl peptidase IV inhibitor & 0.0146 & 0.0224 & 0 & 0 \\
\hline
\end{tabular}


Table A41. Bioactive peptides from RubisCO of Halophila stipulacea. In silico enzymatic cleavage was carried out by using calpain 2.

\begin{tabular}{|c|c|c|c|c|c|c|c|c|}
\hline No. & $\begin{array}{l}\text { Peptide } \\
\text { ID }\end{array}$ & Sequence & Location & Name & Function & Activity & $\begin{array}{l}\text { Monoisotopic } \\
\text { Mass }\end{array}$ & $\begin{array}{l}\text { Chemical } \\
\text { Mass }\end{array}$ \\
\hline 1 & 2754 & PG & $(46-47)$ & $\begin{array}{l}\text { peptide regulating the stomach } \\
\text { mucosal membrane activity }\end{array}$ & $\begin{array}{l}\text { regulating the stomach mucosal } \\
\text { membrane activity }\end{array}$ & regulating & 172.0730 & 172.1690 \\
\hline 2 & 2882 & YG & $(169-170)$ & Immunostimulating peptide & $\begin{array}{l}\text { Enhancing protein biosynthesis in } \\
\text { lymphocytes }\end{array}$ & immunomodulating & 238.0840 & 238.2220 \\
\hline 3 & 3285 & PG & $(46-47)$ & Antithrombotic peptide & Antithrombotic & antithrombotic & 172.0730 & 172.1690 \\
\hline 4 & 3460 & PG & $(46-47)$ & Prolyl endopeptidase inhibitor & $\begin{array}{l}\text { Inhibitor of Prolyl Endopeptidase } \\
\text { (PEP) (EC 3.4.21.26) (MEROPS ID: } \\
\text { S09.001) }\end{array}$ & antiamnestic & 172.0730 & 172.1690 \\
\hline 5 & 3522 & IPP & $(144-146)$ & $\begin{array}{l}\text { ACE inhibitor (from bovine } \\
\text { b-CN) }\end{array}$ & & ACE inhibitor & 325.1880 & 325.3940 \\
\hline 6 & 3553 & YG & $(169-170)$ & ACE inhibitor & $\begin{array}{l}\text { Inhibitor of Angiotensin-Converting } \\
\text { Enzyme (ACE) (EC 3.4.15.1) (MEROPS } \\
\text { ID: XM02-001) }\end{array}$ & ACE inhibitor & 238.0840 & 238.2220 \\
\hline 7 & 3563 & AY & $(147-148)$ & ACE inhibitor & $\begin{array}{l}\text { Inhibitor of Angiotensin-Converting } \\
\text { Enzyme (ACE) (EC 3.4.15.1) (MEROPS } \\
\text { ID: XM02-001) }\end{array}$ & ACE inhibitor & 252.1000 & 252.2490 \\
\hline 8 & 7513 & PL & $(172-173)$ & $\begin{array}{l}\text { ACE inhibitor from Alaskan } \\
\text { pollack skin }\end{array}$ & $\begin{array}{l}\text { Inhibitor of Angiotensin-converting } \\
\text { enzyme (EC 3.4.15.1) (MEROPS ID: } \\
\text { XM02-001) }\end{array}$ & ACE inhibitor & 228.1360 & 228.2770 \\
\hline 9 & 7558 & VK & $(17-18)$ & ACE inhibitor from buckwheat & & ACE inhibitor & 245.1620 & 245.3070 \\
\hline 10 & 7594 & VG & $(11-12)$ & ACE inhibitor & $\begin{array}{l}\text { Inhibitor of Angiotensin-Converting } \\
\text { Enzyme (ACE) (EC 3.4.15.1) (MEROPS } \\
\text { ID: XM02-001) }\end{array}$ & ACE inhibitor & 174.0890 & 174.1850 \\
\hline 11 & 7600 & AG & $(9-10)$ & ACE inhibitor & $\begin{array}{l}\text { Inhibitor of Angiotensin-Converting } \\
\text { Enzyme (ACE) (EC 3.4.15.1) (MEROPS } \\
\text { ID: XM02-001) }\end{array}$ & ACE inhibitor & 146.0580 & 146.1310 \\
\hline 12 & 7600 & AG & $(15-16)$ & ACE inhibitor & $\begin{array}{l}\text { Inhibitor of Angiotensin-Converting } \\
\text { Enzyme (ACE) (EC 3.4.15.1) (MEROPS } \\
\text { ID: XM02-001) }\end{array}$ & ACE inhibitor & 146.0580 & 146.1310 \\
\hline 13 & 7600 & AG & $(53-54)$ & ACE inhibitor & $\begin{array}{l}\text { Inhibitor of Angiotensin-Converting } \\
\text { Enzyme (ACE) (EC 3.4.15.1) (MEROPS } \\
\text { ID: XM02-001) }\end{array}$ & ACE inhibitor & 146.0580 & 146.1310 \\
\hline 14 & 7600 & AG & $(93-94)$ & ACE inhibitor & $\begin{array}{l}\text { Inhibitor of Angiotensin-Converting } \\
\text { Enzyme (ACE) (EC 3.4.15.1) (MEROPS } \\
\text { ID: XM02-001) }\end{array}$ & ACE inhibitor & 146.0580 & 146.1310 \\
\hline
\end{tabular}


Table A41. Cont.

\begin{tabular}{|c|c|c|c|c|c|c|c|c|}
\hline No. & $\begin{array}{l}\text { Peptide } \\
\text { ID }\end{array}$ & Sequence & Location & Name & Function & Activity & $\begin{array}{l}\text { Monoisotopic } \\
\text { Mass }\end{array}$ & $\begin{array}{l}\text { Chemical } \\
\text { Mass }\end{array}$ \\
\hline 15 & 7625 & PG & $(46-47)$ & ACE inhibitor & $\begin{array}{l}\text { Inhibitor of Angiotensin-Converting } \\
\text { Enzyme (ACE) (EC 3.4.15.1) (MEROPS } \\
\text { ID: M02-001) }\end{array}$ & ACE inhibitor & 172.0730 & 172.1690 \\
\hline 16 & 7681 & DG & $(74-75)$ & ACE inhibitor from soy & $\begin{array}{l}\text { Inhibitor of Angiotensin-converting } \\
\text { enzyme (ACE) (EC 3.4.15.1) (MEROPS } \\
\text { ID: XM02-001) }\end{array}$ & ACE inhibitor & 190.0479 & 190.1410 \\
\hline 17 & 7697 & YK & $(82-83)$ & ACE inhibitor from wakame & & ACE inhibitor & 309.1570 & 309.3440 \\
\hline 18 & 7698 & NK & $(167-168)$ & ACE inhibitor from wakame & & ACE inhibitor & 260.1369 & 260.2780 \\
\hline 19 & 7866 & AY & $(147-148)$ & peptide from Okara protein & $\begin{array}{l}\text { Peptide obtained by hydrolysis of } \\
\text { Okara protein by use of enzymatic } \\
\text { preparation Protease N. }\end{array}$ & antioxidative & 252.1000 & 252.2490 \\
\hline 20 & 7951 & YYT & $(24-26)$ & synthetic peptide & & antioxidative & 445.1730 & 445.4450 \\
\hline 21 & 8559 & $\mathrm{AL}$ & $(133-134)$ & $\begin{array}{l}\text { dipeptidyl peptidase IV } \\
\text { inhibitor (DPP IV inhibitor) }\end{array}$ & $\begin{array}{l}\text { Inhibitor of Dipeptidyl Peptidase IV } \\
\text { (EC 3.4.14.5) (MEROPS ID: S09.003) }\end{array}$ & $\begin{array}{l}\text { dipeptidyl peptidase } \\
\text { IV inhibitor }\end{array}$ & 202.1210 & 202.2390 \\
\hline 22 & 8559 & $\mathrm{AL}$ & $(136-137)$ & $\begin{array}{l}\text { dipeptidyl peptidase IV } \\
\text { inhibitor (DPP IV inhibitor) }\end{array}$ & $\begin{array}{l}\text { Inhibitor of Dipeptidyl Peptidase IV } \\
\text { (EC 3.4.14.5) (MEROPS ID: S09.003) }\end{array}$ & $\begin{array}{l}\text { dipeptidyl peptidase } \\
\text { IV inhibitor }\end{array}$ & 202.1210 & 202.2390 \\
\hline 23 & 8560 & SL & $(78-79)$ & $\begin{array}{l}\text { dipeptidyl peptidase IV } \\
\text { inhibitor (DPP IV inhibitor) }\end{array}$ & $\begin{array}{l}\text { Inhibitor of Dipeptidyl Peptidase IV } \\
\text { (EC 3.4.14.5) (MEROPS ID: S09.003) }\end{array}$ & $\begin{array}{l}\text { dipeptidyl peptidase } \\
\text { IV inhibitor }\end{array}$ & 218.1160 & 218.2400 \\
\hline 24 & 8638 & PL & $(172-173)$ & $\begin{array}{l}\text { dipeptidyl peptidase IV } \\
\text { inhibitor (DPP IV inhibitor) }\end{array}$ & $\begin{array}{l}\text { Inhibitor of Dipeptidyl Peptidase IV } \\
\text { (EC 3.4.14.5) (MEROPS ID: S09.003) }\end{array}$ & $\begin{array}{l}\text { dipeptidyl peptidase } \\
\text { IV inhibitor }\end{array}$ & 228.1360 & 228.2770 \\
\hline 25 & 8685 & WT & $(68-69)$ & $\begin{array}{l}\text { dipeptidyl peptidase IV } \\
\text { inhibitor (DPP IV inhibitor) }\end{array}$ & $\begin{array}{l}\text { Inhibitor of Dipeptidyl Peptidase IV } \\
\text { (EC 3.4.14.5) (MEROPS ID: S09.003) }\end{array}$ & $\begin{array}{l}\text { dipeptidyl peptidase } \\
\text { IV inhibitor }\end{array}$ & 305.1260 & 305.3180 \\
\hline 26 & 8760 & AG & $(9-10)$ & $\begin{array}{l}\text { dipeptidyl peptidase IV } \\
\text { inhibitor (DPP IV inhibitor) }\end{array}$ & $\begin{array}{l}\text { Inhibitor of Dipeptidyl Peptidase IV } \\
\text { (EC 3.4.14.5) (MEROPS ID: S09.003) }\end{array}$ & $\begin{array}{l}\text { dipeptidyl peptidase } \\
\text { IV inhibitor }\end{array}$ & 146.0580 & 146.1310 \\
\hline 27 & 8760 & AG & $(15-16)$ & $\begin{array}{l}\text { dipeptidyl peptidase IV } \\
\text { inhibitor (DPP IV inhibitor) }\end{array}$ & $\begin{array}{l}\text { Inhibitor of Dipeptidyl Peptidase IV } \\
\text { (EC 3.4.14.5) (MEROPS ID: S09.003) }\end{array}$ & $\begin{array}{l}\text { dipeptidyl peptidase } \\
\text { IV inhibitor }\end{array}$ & 146.0580 & 146.1310 \\
\hline 28 & 8760 & AG & (53-54) & $\begin{array}{l}\text { dipeptidyl peptidase IV } \\
\text { inhibitor (DPP IV inhibitor) }\end{array}$ & $\begin{array}{l}\text { Inhibitor of Dipeptidyl Peptidase IV } \\
\text { (EC 3.4.14.5) (MEROPS ID: S09.003) }\end{array}$ & $\begin{array}{l}\text { dipeptidyl peptidase } \\
\text { IV inhibitor }\end{array}$ & 146.0580 & 146.1310 \\
\hline 29 & 8760 & AG & (93-94) & $\begin{array}{l}\text { dipeptidyl peptidase IV } \\
\text { inhibitor (DPP IV inhibitor) }\end{array}$ & $\begin{array}{l}\text { Inhibitor of Dipeptidyl Peptidase IV } \\
\text { (EC 3.4.14.5) (MEROPS ID: S09.003) }\end{array}$ & $\begin{array}{l}\text { dipeptidyl peptidase } \\
\text { IV inhibitor }\end{array}$ & 146.0580 & 146.1310 \\
\hline 30 & 8764 & AV & $(56-57)$ & $\begin{array}{l}\text { dipeptidyl peptidase IV } \\
\text { inhibitor (DPP IV inhibitor) }\end{array}$ & $\begin{array}{l}\text { Inhibitor of Dipeptidyl Peptidase IV } \\
\text { (EC 3.4.14.5) (MEROPS ID: S09.003) }\end{array}$ & $\begin{array}{l}\text { dipeptidyl peptidase } \\
\text { IV inhibitor }\end{array}$ & 188.1050 & 188.2120 \\
\hline 31 & 8765 & AY & $(147-148)$ & $\begin{array}{l}\text { dipeptidyl peptidase IV } \\
\text { inhibitor (DPP IV inhibitor) }\end{array}$ & $\begin{array}{l}\text { Inhibitor of Dipeptidyl Peptidase IV } \\
\text { (EC 3.4.14.5) (MEROPS ID: S09.003) }\end{array}$ & $\begin{array}{l}\text { dipeptidyl peptidase } \\
\text { IV inhibitor }\end{array}$ & 252.1000 & 252.2490 \\
\hline 32 & 8769 & DR & $(80-81)$ & $\begin{array}{l}\text { dipeptidyl peptidase IV } \\
\text { inhibitor (DPP IV inhibitor) }\end{array}$ & $\begin{array}{l}\text { Inhibitor of Dipeptidyl Peptidase IV } \\
\text { (EC 3.4.14.5) (MEROPS ID: S09.003) }\end{array}$ & $\begin{array}{l}\text { dipeptidyl peptidase } \\
\text { IV inhibitor }\end{array}$ & 289.1279 & 289.2770 \\
\hline
\end{tabular}


Table A41. Cont.

\begin{tabular}{|c|c|c|c|c|c|c|c|c|}
\hline No. & $\begin{array}{l}\text { Peptide } \\
\text { ID }\end{array}$ & Sequence & Location & Name & Function & Activity & $\begin{array}{l}\text { Monoisotopic } \\
\text { Mass }\end{array}$ & $\begin{array}{l}\text { Chemical } \\
\text { Mass }\end{array}$ \\
\hline 33 & 8769 & DR & $(164-165)$ & $\begin{array}{l}\text { dipeptidyl peptidase IV } \\
\text { inhibitor (DPP IV inhibitor) }\end{array}$ & $\begin{array}{l}\text { Inhibitor of Dipeptidyl Peptidase IV } \\
\text { (EC 3.4.14.5) (MEROPS ID: S09.003) }\end{array}$ & $\begin{array}{l}\text { dipeptidyl peptidase } \\
\text { IV inhibitor }\end{array}$ & 289.1279 & 289.2770 \\
\hline 34 & 8774 & ET & $(6-7)$ & $\begin{array}{l}\text { dipeptidyl peptidase IV } \\
\text { inhibitor (DPP IV inhibitor) }\end{array}$ & $\begin{array}{l}\text { Inhibitor of Dipeptidyl Peptidase IV } \\
\text { (EC 3.4.14.5) (MEROPS ID: S09.003) }\end{array}$ & $\begin{array}{l}\text { dipeptidyl peptidase } \\
\text { IV inhibitor }\end{array}$ & 248.0890 & 248.2210 \\
\hline 35 & 8779 & FQ & $(13-14)$ & $\begin{array}{l}\text { dipeptidyl peptidase IV } \\
\text { inhibitor (DPP IV inhibitor) }\end{array}$ & $\begin{array}{l}\text { Inhibitor of Dipeptidyl Peptidase IV } \\
\text { (EC 3.4.14.5) (MEROPS ID: S09.003) }\end{array}$ & $\begin{array}{l}\text { dipeptidyl peptidase } \\
\text { IV inhibitor }\end{array}$ & 293.1260 & 293.3080 \\
\hline 36 & 8779 & FQ & $(152-153)$ & $\begin{array}{l}\text { dipeptidyl peptidase IV } \\
\text { inhibitor (DPP IV inhibitor) }\end{array}$ & $\begin{array}{l}\text { Inhibitor of Dipeptidyl Peptidase IV } \\
\text { (EC 3.4.14.5) (MEROPS ID: S09.003) }\end{array}$ & $\begin{array}{l}\text { dipeptidyl peptidase } \\
\text { IV inhibitor }\end{array}$ & 293.1260 & 293.3080 \\
\hline 37 & 8805 & IQ & $(159-160)$ & $\begin{array}{l}\text { dipeptidyl peptidase IV } \\
\text { inhibitor (DPP IV inhibitor) }\end{array}$ & $\begin{array}{l}\text { Inhibitor of Dipeptidyl Peptidase IV } \\
\text { (EC 3.4.14.5) (MEROPS ID: S09.003) }\end{array}$ & $\begin{array}{l}\text { dipeptidyl peptidase } \\
\text { IV inhibitor }\end{array}$ & 259.1420 & 259.2910 \\
\hline 38 & 8855 & PG & $(46-47)$ & $\begin{array}{l}\text { dipeptidyl peptidase IV } \\
\text { inhibitor (DPP IV inhibitor) }\end{array}$ & $\begin{array}{l}\text { Inhibitor of Dipeptidyl Peptidase IV } \\
\text { (EC 3.4.14.5) (MEROPS ID: S09.003) }\end{array}$ & $\begin{array}{l}\text { dipeptidyl peptidase } \\
\text { IV inhibitor }\end{array}$ & 172.0730 & 172.1690 \\
\hline 39 & 8858 & PK & $(180-181)$ & $\begin{array}{l}\text { dipeptidyl peptidase IV } \\
\text { inhibitor (DPP IV inhibitor) }\end{array}$ & $\begin{array}{l}\text { Inhibitor of Dipeptidyl Peptidase IV } \\
\text { (EC 3.4.14.5) (MEROPS ID: S09.003) }\end{array}$ & $\begin{array}{l}\text { dipeptidyl peptidase } \\
\text { IV inhibitor }\end{array}$ & 243.1460 & 243.2910 \\
\hline 40 & 8894 & SK & $(149-150)$ & $\begin{array}{l}\text { dipeptidyl peptidase IV } \\
\text { inhibitor (DPP IV inhibitor) }\end{array}$ & $\begin{array}{l}\text { Inhibitor of Dipeptidyl Peptidase IV } \\
\text { (EC 3.4.14.5) (MEROPS ID: S09.003) }\end{array}$ & $\begin{array}{l}\text { dipeptidyl peptidase } \\
\text { IV inhibitor }\end{array}$ & 233.1260 & 233.2540 \\
\hline 41 & 8918 & VG & $(11-12)$ & $\begin{array}{l}\text { dipeptidyl peptidase IV } \\
\text { inhibitor (DPP IV inhibitor) }\end{array}$ & $\begin{array}{l}\text { Inhibitor of Dipeptidyl Peptidase IV } \\
\text { (EC 3.4.14.5) (MEROPS ID: S09.003) }\end{array}$ & $\begin{array}{l}\text { dipeptidyl peptidase } \\
\text { IV inhibitor }\end{array}$ & 174.0890 & 174.1850 \\
\hline 42 & 8921 & VK & $(17-18)$ & $\begin{array}{l}\text { dipeptidyl peptidase IV } \\
\text { inhibitor (DPP IV inhibitor) }\end{array}$ & $\begin{array}{l}\text { Inhibitor of Dipeptidyl Peptidase IV } \\
\text { (EC 3.4.14.5) (MEROPS ID: S09.003) }\end{array}$ & $\begin{array}{l}\text { dipeptidyl peptidase } \\
\text { IV inhibitor }\end{array}$ & 245.1620 & 245.3070 \\
\hline 43 & 8936 & YG & $(169-170)$ & $\begin{array}{l}\text { dipeptidyl peptidase IV } \\
\text { inhibitor (DPP IV inhibitor) }\end{array}$ & $\begin{array}{l}\text { Inhibitor of Dipeptidyl Peptidase IV } \\
\text { (EC 3.4.14.5) (MEROPS ID: S09.003) }\end{array}$ & $\begin{array}{l}\text { dipeptidyl peptidase } \\
\text { IV inhibitor }\end{array}$ & 238.0840 & 238.2220 \\
\hline 44 & 8938 & YI & (99-100) & $\begin{array}{l}\text { dipeptidyl peptidase IV } \\
\text { inhibitor (DPP IV inhibitor) }\end{array}$ & $\begin{array}{l}\text { Inhibitor of Dipeptidyl Peptidase IV } \\
\text { (EC 3.4.14.5) (MEROPS ID: S09.003) }\end{array}$ & $\begin{array}{l}\text { dipeptidyl peptidase } \\
\text { IV inhibitor }\end{array}$ & 294.1470 & 294.3300 \\
\hline 45 & 8939 & YK & $(82-83)$ & $\begin{array}{l}\text { dipeptidyl peptidase IV } \\
\text { inhibitor (DPP IV inhibitor) }\end{array}$ & $\begin{array}{l}\text { Inhibitor of Dipeptidyl Peptidase IV } \\
\text { (EC 3.4.14.5) (MEROPS ID: S09.003) }\end{array}$ & $\begin{array}{l}\text { dipeptidyl peptidase } \\
\text { IV inhibitor }\end{array}$ & 309.1570 & 309.3440 \\
\hline 46 & 8951 & $\mathrm{AV}$ & $(56-57)$ & ACE inhibitor & $\begin{array}{l}\text { Inhibitor of Angiotensin-Converting } \\
\text { Enzyme (ACE) (EC 3.4.15.1) (MEROPS } \\
\text { ID: XM02-001) }\end{array}$ & ACE inhibitor & 188.1050 & 188.2120 \\
\hline 47 & 9076 & FQ & $(13-14)$ & ACE inhibitor & $\begin{array}{l}\text { Inhibitor of Angiotensin-Converting } \\
\text { Enzyme (ACE) (EC 3.4.15.1) (MEROPS } \\
\text { ID: XM02-001) }\end{array}$ & ACE inhibitor & 293.1260 & 293.3080 \\
\hline 48 & 9076 & FQ & $(152-153)$ & ACE inhibitor & $\begin{array}{l}\text { Inhibitor of Angiotensin-Converting } \\
\text { Enzyme (ACE) (EC 3.4.15.1) (MEROPS } \\
\text { ID: XM02-001) }\end{array}$ & ACE inhibitor & 293.1260 & 293.3080 \\
\hline 49 & 9184 & ST & $(64-65)$ & ACE inhibitor & $\begin{array}{l}\text { Inhibitor of Angiotensin-Converting } \\
\text { Enzyme (ACE) (EC 3.4.15.1) (MEROPS } \\
\text { ID: M02-001) }\end{array}$ & ACE inhibitor & 206.0790 & 206.1850 \\
\hline
\end{tabular}


Table A42. $A_{E}, D H_{t}, W, B_{E}$ and $V$ values from RubisCO of Halophila stipulacea. In silico enzymatic cleavage was carried out by using calpain 2.

\begin{tabular}{|c|c|c|c|c|c|}
\hline \multicolumn{6}{|c|}{$\begin{array}{l}\mathrm{DH}_{t}(\%) \\
47.3171\end{array}$} \\
\hline No. & Activity & $A_{E}$ & $W$ & $B_{E}$ & $V$ \\
\hline 1 & regulating & 0.0049 & 0.3356 & 0 & \\
\hline 2 & immunomodulating & 0.0049 & 0.5052 & 0 & \\
\hline 3 & antithrombotic & 0.0049 & 0.5052 & 0 & \\
\hline 4 & antiamnestic & 0.0049 & 0.5052 & 0 & \\
\hline 5 & ACE inhibitor & 0.0874 & 0.1500 & 0.0034373644220009 & 0.12845727500362 \\
\hline 6 & antioxidative & 0.0097 & 0.1332 & 0 & 0 \\
\hline 7 & dipeptidyl peptidase IV inhibitor & 0.1214 & 0.1866 & $2.3003804384162 \mathrm{E}-5$ & 0.10663971774841 \\
\hline
\end{tabular}

Table A43. Bioactive peptides from RubisCO of Halophila stipulacea. In silico enzymatic cleavage was carried out by using glycyl endopeptidase.

\begin{tabular}{|c|c|c|c|c|c|c|c|c|}
\hline No. & $\begin{array}{l}\text { Peptide } \\
\text { ID }\end{array}$ & Sequence & Location & Name & Function & Activity & $\begin{array}{l}\text { Monoisotopic } \\
\text { Mass }\end{array}$ & $\begin{array}{l}\text { Chemical } \\
\text { Mass }\end{array}$ \\
\hline 1 & 7594 & VG & $(11-12)$ & ACE inhibitor & $\begin{array}{l}\text { Inhibitor of Angiotensin-Converting } \\
\text { Enzyme (ACE) (EC 3.4.15.1) (MEROPS } \\
\text { ID: XM02-001) }\end{array}$ & ACE inhibitor & 174.0890 & 174.1850 \\
\hline 2 & 8918 & VG & $(11-12)$ & $\begin{array}{l}\text { dipeptidyl peptidase IV } \\
\text { inhibitor (DPP IV inhibitor) }\end{array}$ & $\begin{array}{l}\text { Inhibitor of Dipeptidyl Peptidase IV } \\
\text { (EC 3.4.14.5) (MEROPS ID: S09.003) }\end{array}$ & $\begin{array}{l}\text { dipeptidyl peptidase } \\
\text { IV inhibitor }\end{array}$ & 174.0890 & 174.1850 \\
\hline
\end{tabular}

Table A44. $A_{E}, D H_{t}, W, B_{E}$ and $V$ values from RubisCO of Halophila stipulacea. In silico enzymatic cleavage was carried out by using glycyl endopeptidase.

\begin{tabular}{llllll}
\hline $\begin{array}{l}\boldsymbol{D} \boldsymbol{H}_{\boldsymbol{t}}(\boldsymbol{\%}) \\
\mathbf{9 . 7 5 6 1}\end{array}$ & & & & \\
\hline No. & Activity & $A_{E}$ & $W$ & $\boldsymbol{B}_{E}$ & $\boldsymbol{V}$ \\
\hline 1 & ACE inhibitor & 0.0049 & 0.0084 & $4.4130626654898 \mathrm{E}-6$ & 0.00016491996042102 \\
2 & dipeptidyl peptidase IV inhibitor & 0.0049 & 0.0075 & 0 & 0 \\
\hline
\end{tabular}


Table A45. Bioactive peptides from RubisCO of Halophila stipulacea. In silico enzymatic cleavage was carried out by using oligopeptidase F.

\begin{tabular}{|c|c|c|c|c|c|c|c|c|}
\hline No. & $\begin{array}{l}\text { Peptide } \\
\text { ID }\end{array}$ & Sequence & Location & Name & Function & Activity & $\begin{array}{l}\text { Monoisotopic } \\
\text { Mass }\end{array}$ & $\begin{array}{l}\text { Chemical } \\
\text { Mass }\end{array}$ \\
\hline 1 & 3257 & RL & $(138-139)$ & beta-lactokinin & $\begin{array}{l}\text { Inhibitor of Angiotensin-Converting } \\
\text { Enzyme (ACE) (EC 3.4.15.1) (MEROPS } \\
\text { ID: XM02-001) }\end{array}$ & ACE inhibitor & 287.1850 & 287.3480 \\
\hline 2 & 7591 & GF & $(130-131)$ & ACE inhibitor & $\begin{array}{l}\text { Inhibitor of Angiotensin-Converting } \\
\text { Enzyme (ACE) (EC 3.4.15.1) (MEROPS } \\
\text { ID: XM02-001) }\end{array}$ & ACE inhibitor & 222.0890 & 222.2290 \\
\hline 3 & 7599 & GL & $(183-184)$ & ACE inhibitor & $\begin{array}{l}\text { Inhibitor of Angiotensin-converting } \\
\text { enzyme (EC 3.4.15.1) (MEROPS ID: } \\
\text { XM02-001) }\end{array}$ & ACE inhibitor & 188.1050 & 188.2120 \\
\hline 4 & 8561 & GL & $(183-184)$ & $\begin{array}{l}\text { dipeptidyl peptidase IV } \\
\text { inhibitor (DPP IV inhibitor) }\end{array}$ & $\begin{array}{l}\text { Inhibitor of Dipeptidyl Peptidase IV } \\
\text { (EC 3.4.14.5) (MEROPS ID: S09.003) }\end{array}$ & $\begin{array}{l}\text { dipeptidyl peptidase } \\
\text { IV inhibitor }\end{array}$ & 188.1050 & 188.2120 \\
\hline 5 & 8782 & GF & $(130-131)$ & $\begin{array}{l}\text { dipeptidyl peptidase IV } \\
\text { inhibitor (DPP IV inhibitor) }\end{array}$ & $\begin{array}{l}\text { Inhibitor of Dipeptidyl Peptidase IV } \\
\text { (EC 3.4.14.5) (MEROPS ID: S09.003) }\end{array}$ & $\begin{array}{l}\text { dipeptidyl peptidase } \\
\text { IV inhibitor }\end{array}$ & 222.0890 & 222.2290 \\
\hline 6 & 8886 & RL & $(138-139)$ & $\begin{array}{l}\text { dipeptidyl peptidase IV } \\
\text { inhibitor (DPP IV inhibitor) }\end{array}$ & $\begin{array}{l}\text { Inhibitor of Dipeptidyl Peptidase IV } \\
\text { (EC 3.4.14.5) (MEROPS ID: S09.003) }\end{array}$ & $\begin{array}{l}\text { dipeptidyl peptidase } \\
\text { IV inhibitor }\end{array}$ & 287.1850 & 287.3480 \\
\hline 7 & 9074 & DF & $(204-205)$ & ACE inhibitor & $\begin{array}{l}\text { Inhibitor of Angiotensin-Converting } \\
\text { Enzyme (ACE) (EC 3.4.15.1) (MEROPS } \\
\text { ID: XM02-001) }\end{array}$ & ACE inhibitor & 280.0949 & 280.2660 \\
\hline
\end{tabular}

Table A46. $A_{E}, D H_{t}, W, B_{E}$ and $V$ values from RubisCO of Halophila stipulacea. In silico enzymatic cleavage was carried out by using oligopeptidase F.

\begin{tabular}{llllll}
\hline $\begin{array}{l}\mathrm{DH} \\
\mathbf{1 2 . 1 9 5 1}\end{array}$ & & & & \\
\hline No. & Activity & $A_{E}$ & $\boldsymbol{W}$ & $\boldsymbol{B}_{\boldsymbol{E}}$ & $\boldsymbol{V}$ \\
\hline 1 & ACE inhibitor & 0.0194 & 0.0333 & $2.5006640432763 \mathrm{E}-5$ & 0.00093451973448837 \\
2 & dipeptidyl peptidase IV inhibitor & 0.0146 & 0.0224 & $1.8563339357632 \mathrm{E}-6$ & 0.0086054864513139 \\
\hline
\end{tabular}


Table A47. Bioactive peptides from RubisCO of Halophila stipulacea. In silico enzymatic cleavage was carried out by using proteinase P1 (lactocepin).

\begin{tabular}{|c|c|c|c|c|c|c|c|c|}
\hline No. & $\begin{array}{l}\text { Peptide } \\
\text { ID }\end{array}$ & Sequence & Location & Name & Function & Activity & $\begin{array}{l}\text { Monoisotopic } \\
\text { Mass }\end{array}$ & $\begin{array}{l}\text { Chemical } \\
\text { Mass }\end{array}$ \\
\hline 1 & 3563 & $\mathrm{AY}$ & $(104-105)$ & ACE inhibitor & $\begin{array}{l}\text { Inhibitor of Angiotensin-Converting Enzyme } \\
\text { (ACE) (EC 3.4.15.1) (MEROPS ID: XM02-001) }\end{array}$ & ACE inhibitor & 252.1000 & 252.2490 \\
\hline 2 & 3563 & $\mathrm{AY}$ & $(147-148)$ & ACE inhibitor & $\begin{array}{l}\text { Inhibitor of Angiotensin-Converting Enzyme } \\
\text { (ACE) (EC 3.4.15.1) (MEROPS ID: XM02-001) }\end{array}$ & ACE inhibitor & 252.1000 & 252.2490 \\
\hline 3 & 4005 & RA & $(135-136)$ & & Activation of ubiquitin-dependent proteolysis & $\begin{array}{l}\text { activating } \\
\text { ubiquitin-mediated } \\
\text { proteolysis }\end{array}$ & 245.1380 & 245.2670 \\
\hline 4 & 7588 & RA & $(135-136)$ & ACE inhibitor & $\begin{array}{l}\text { Inhibitor of Angiotensin-Converting Enzyme } \\
\text { (ACE) (EC 3.4.15.1) (MEROPS ID: XM02-001) }\end{array}$ & ACE inhibitor & 245.1380 & 245.2670 \\
\hline 5 & 7591 & GF & $(12-13)$ & ACE inhibitor & $\begin{array}{l}\text { Inhibitor of Angiotensin-Converting Enzyme } \\
\text { (ACE) (EC 3.4.15.1) (MEROPS ID: XM02-001) }\end{array}$ & ACE inhibitor & 222.0890 & 222.2290 \\
\hline 6 & 7608 & GV & $(47-48)$ & ACE inhibitor & $\begin{array}{l}\text { Inhibitor of Angiotensin-Converting Enzyme } \\
\text { (ACE) (EC 3.4.15.1) (MEROPS ID: XM02-001) }\end{array}$ & ACE inhibitor & 174.0890 & 174.1850 \\
\hline 7 & 7866 & $\mathrm{AY}$ & $(104-105)$ & peptide from Okara protein & $\begin{array}{l}\text { Peptide obtained by hydrolysis of Okara protein } \\
\text { by use of enzymatic preparation Protease N. }\end{array}$ & antioxidative & 252.1000 & 252.2490 \\
\hline 8 & 7866 & $\mathrm{AY}$ & $(147-148)$ & peptide from Okara protein & $\begin{array}{l}\text { Peptide obtained by hydrolysis of Okara protein } \\
\text { by use of enzymatic preparation Protease N. }\end{array}$ & antioxidative & 252.1000 & 252.2490 \\
\hline 9 & 8526 & RA & $(135-136)$ & $\begin{array}{l}\text { dipeptidyl peptidase IV } \\
\text { inhibitor (DPP IV inhibitor) }\end{array}$ & $\begin{array}{l}\text { Inhibitor of Dipeptidyl Peptidase IV (EC 3.4.14.5) } \\
\text { (MEROPS ID: S09.003) }\end{array}$ & $\begin{array}{l}\text { dipeptidyl peptidase } \\
\text { IV inhibitor }\end{array}$ & 245.1380 & 245.2670 \\
\hline 10 & 8765 & $\mathrm{AY}$ & $(104-105)$ & $\begin{array}{l}\text { dipeptidyl peptidase IV } \\
\text { inhibitor (DPP IV inhibitor) }\end{array}$ & $\begin{array}{l}\text { Inhibitor of Dipeptidyl Peptidase IV (EC 3.4.14.5) } \\
\text { (MEROPS ID: S09.003) }\end{array}$ & $\begin{array}{l}\text { dipeptidyl peptidase } \\
\text { IV inhibitor }\end{array}$ & 252.1000 & 252.2490 \\
\hline 11 & 8765 & $\mathrm{AY}$ & $(147-148)$ & $\begin{array}{l}\text { dipeptidyl peptidase IV } \\
\text { inhibitor (DPP IV inhibitor) }\end{array}$ & $\begin{array}{l}\text { Inhibitor of Dipeptidyl Peptidase IV (EC 3.4.14.5) } \\
\text { (MEROPS ID: S09.003) }\end{array}$ & $\begin{array}{l}\text { dipeptidyl peptidase } \\
\text { IV inhibitor }\end{array}$ & 252.1000 & 252.2490 \\
\hline 12 & 8782 & GF & $(12-13)$ & $\begin{array}{l}\text { dipeptidyl peptidase IV } \\
\text { inhibitor (DPP IV inhibitor) }\end{array}$ & $\begin{array}{l}\text { Inhibitor of Dipeptidyl Peptidase IV (EC 3.4.14.5) } \\
\text { (MEROPS ID: S09.003) }\end{array}$ & $\begin{array}{l}\text { dipeptidyl peptidase } \\
\text { IV inhibitor }\end{array}$ & 222.0890 & 222.2290 \\
\hline 13 & 8786 & GV & $(47-48)$ & $\begin{array}{l}\text { dipeptidyl peptidase IV } \\
\text { inhibitor (DPP IV inhibitor) }\end{array}$ & $\begin{array}{l}\text { Inhibitor of Dipeptidyl Peptidase IV (EC 3.4.14.5) } \\
\text { (MEROPS ID: S09.003) }\end{array}$ & $\begin{array}{l}\text { dipeptidyl peptidase } \\
\text { IV inhibitor }\end{array}$ & 174.0890 & 174.1850 \\
\hline 14 & 8884 & RI & $(143-144)$ & $\begin{array}{l}\text { dipeptidyl peptidase IV } \\
\text { inhibitor (DPP IV inhibitor) }\end{array}$ & $\begin{array}{l}\text { Inhibitor of Dipeptidyl Peptidase IV (EC 3.4.14.5) } \\
\text { (MEROPS ID: S09.003) }\end{array}$ & $\begin{array}{l}\text { dipeptidyl peptidase } \\
\text { IV inhibitor }\end{array}$ & 287.1850 & 287.3480 \\
\hline 15 & 8895 & SV & $(114-115)$ & $\begin{array}{l}\text { dipeptidyl peptidase IV } \\
\text { inhibitor (DPP IV inhibitor) }\end{array}$ & $\begin{array}{l}\text { Inhibitor of Dipeptidyl Peptidase IV (EC 3.4.14.5) } \\
\text { (MEROPS ID: S09.003) }\end{array}$ & $\begin{array}{l}\text { dipeptidyl peptidase } \\
\text { IV inhibitor }\end{array}$ & 204.1000 & 204.2130 \\
\hline
\end{tabular}


Table A48. $A_{E}, D H_{t}, W, B_{E}$ and $V$ values from RubisCO of Halophila stipulacea. In silico enzymatic cleavage carried out by using proteinase P1 (lactocepin).

\begin{tabular}{llllll}
\hline $\begin{array}{l}\mathrm{DH}(\%) \\
\mathbf{4 1 . 4 6 3 4}\end{array}$ & \multicolumn{1}{l}{} & & & \\
\hline No. & Activity & $A_{E}$ & $W$ & $\boldsymbol{B}_{E}$ & $\boldsymbol{V}$ \\
\hline 1 & ACE inhibitor & 0.0243 & 0.0417 & 0.00053029982441682 & 0.019817762103858 \\
2 & activating ubiquitin-mediated proteolysis & 0.0049 & 0.3356 & 0 & 0 \\
3 & antioxidative & 0.0097 & 0.1332 & 0 & 0 \\
4 & dipeptidyl peptidase IV inhibitor & 0.0340 & 0.0523 & 0 & \\
\hline
\end{tabular}

Table A49. Bioactive peptides from RubisCO of Halophila stipulacea. In silico enzymatic cleavage was carried out by using pepsin ( $\mathrm{pH}>2$ ).

\begin{tabular}{|c|c|c|c|c|c|c|c|c|}
\hline No. & $\begin{array}{l}\text { Peptide } \\
\text { ID }\end{array}$ & Sequence & Location & Name & Function & Activity & $\begin{array}{l}\text { Monoisotopic } \\
\text { Mass }\end{array}$ & $\begin{array}{l}\text { Chemical } \\
\text { Mass }\end{array}$ \\
\hline 1 & 2754 & PG & $(46-47)$ & $\begin{array}{l}\text { peptide regulating the } \\
\text { stomach mucosal membrane } \\
\text { activity }\end{array}$ & $\begin{array}{l}\text { regulating the stomach mucosal membrane } \\
\text { activity }\end{array}$ & regulating & 172.0730 & 172.1690 \\
\hline 2 & 3172 & VA & $(57-58)$ & $\begin{array}{l}\text { dipeptidyl peptidase IV } \\
\text { inhibitor (DPP IV inhibitor) }\end{array}$ & $\begin{array}{l}\text { Inhibitor of Dipeptidyl Peptidase IV (EC 3.4.14.5) } \\
\text { (MEROPS ID: S09.003) }\end{array}$ & $\begin{array}{l}\text { dipeptidyl peptidase } \\
\text { IV inhibitor }\end{array}$ & 188.1050 & 188.2120 \\
\hline 3 & 3172 & VA & $(92-93)$ & $\begin{array}{l}\text { dipeptidyl peptidase IV } \\
\text { inhibitor (DPP IV inhibitor) }\end{array}$ & $\begin{array}{l}\text { Inhibitor of Dipeptidyl Peptidase IV (EC 3.4.14.5) } \\
\text { (MEROPS ID: S09.003) }\end{array}$ & $\begin{array}{l}\text { dipeptidyl peptidase } \\
\text { IV inhibitor }\end{array}$ & 188.1050 & 188.2120 \\
\hline 4 & 3172 & VA & $(103-104)$ & $\begin{array}{l}\text { dipeptidyl peptidase IV } \\
\text { inhibitor (DPP IV inhibitor) }\end{array}$ & $\begin{array}{l}\text { Inhibitor of Dipeptidyl Peptidase IV (EC 3.4.14.5) } \\
\text { (MEROPS ID: S09.003) }\end{array}$ & $\begin{array}{l}\text { dipeptidyl peptidase } \\
\text { IV inhibitor }\end{array}$ & 188.1050 & 188.2120 \\
\hline 5 & 3257 & RL & $(138-139)$ & beta-lactokinin & $\begin{array}{l}\text { Inhibitor of Angiotensin-Converting Enzyme } \\
\text { (ACE) (EC 3.4.15.1) (MEROPS ID: XM02-001) }\end{array}$ & ACE inhibitor & 287.1850 & 287.3480 \\
\hline 6 & 3257 & RL & $(165-166)$ & beta-lactokinin & $\begin{array}{l}\text { Inhibitor of Angiotensin-Converting Enzyme } \\
\text { (ACE) (EC 3.4.15.1) (MEROPS ID: XM02-001) }\end{array}$ & ACE inhibitor & 287.1850 & 287.3480 \\
\hline 7 & 3285 & PG & $(46-47)$ & Antithrombotic peptide & Antithrombotic & antithrombotic & 172.0730 & 172.1690 \\
\hline 8 & 3380 & $\mathrm{RY}$ & $(81-82)$ & ACE inhibitor & $\begin{array}{l}\text { Inhibitor of Angiotensin-Converting Enzyme } \\
\text { (ACE) (EC 3.4.15.1) (MEROPS ID: XM02-001) }\end{array}$ & ACE inhibitor & 337.1640 & 337.3580 \\
\hline 9 & 3384 & VF & $(128-129)$ & ACE inhibitor & $\begin{array}{l}\text { Inhibitor of Angiotensin-Converting Enzyme } \\
\text { (ACE) (EC 3.4.15.1) (MEROPS ID: XM02-001) }\end{array}$ & ACE inhibitor & 264.1360 & 264.3100 \\
\hline 10 & 3460 & PG & $(46-47)$ & $\begin{array}{l}\text { Prolyl endopeptidase } \\
\text { inhibitor }\end{array}$ & $\begin{array}{l}\text { Inhibitor of Prolyl Endopeptidase (PEP) (EC } \\
\text { 3.4.21.26) (MEROPS ID: S09.001) }\end{array}$ & antiamnestic & 172.0730 & 172.1690 \\
\hline 11 & 3492 & VY & $(195-196)$ & ACE inhibitor from sake & $\begin{array}{l}\text { Inhibitor of Angiotensin-Converting Enzyme } \\
\text { (ACE) (EC 3.4.15.1) (MEROPS ID: XM02-001) }\end{array}$ & ACE inhibitor & 280.1310 & 280.3030 \\
\hline 12 & 4005 & RA & $(135-136)$ & & Activation of ubiquitin-dependent proteolysis & $\begin{array}{l}\text { activating ubiquitin- } \\
\text { mediated proteolysis }\end{array}$ & 245.1380 & 245.2670 \\
\hline
\end{tabular}


Table A49. Cont

\begin{tabular}{|c|c|c|c|c|c|c|c|c|}
\hline No. & $\begin{array}{l}\text { Peptide } \\
\text { ID }\end{array}$ & Sequence & Location & Name & Function & Activity & $\begin{array}{l}\text { Monoisotopic } \\
\text { Mass }\end{array}$ & $\begin{array}{l}\text { Chemica } \\
\text { Mass }\end{array}$ \\
\hline 13 & 4005 & RA & $(193-194)$ & & Activation of ubiquitin-dependent proteolysis & $\begin{array}{l}\text { activating ubiquitin- } \\
\text { mediated proteolysis }\end{array}$ & 245.1380 & 245.2670 \\
\hline 14 & 7513 & PL & $(106-107)$ & $\begin{array}{l}\text { ACE inhibitor from Alaskan } \\
\text { pollack skin }\end{array}$ & $\begin{array}{l}\text { Inhibitor of Angiotensin-converting enzyme (EC } \\
\text { 3.4.15.1) (MEROPS ID: XM02-001) }\end{array}$ & ACE inhibitor & 228.1360 & 228.2770 \\
\hline 15 & 7558 & VK & $(17-18)$ & $\begin{array}{l}\text { ACE inhibitor from } \\
\text { buckwheat }\end{array}$ & & ACE inhibitor & 245.1620 & 245.3070 \\
\hline 16 & 7562 & IA & $(100-101)$ & $\begin{array}{l}\text { ACE inhibitor from soy } \\
\text { hydrolysate }\end{array}$ & & ACE inhibitor & 202.1210 & 202.2390 \\
\hline 17 & 7588 & RA & $(135-136)$ & ACE inhibitor & $\begin{array}{l}\text { Inhibitor of Angiotensin-Converting Enzyme } \\
\text { (ACE) (EC 3.4.15.1) (MEROPS ID: XM02-001) }\end{array}$ & ACE inhibitor & 245.1380 & 245.2670 \\
\hline 18 & 7588 & RA & $(193-194)$ & ACE inhibitor & $\begin{array}{l}\text { Inhibitor of Angiotensin-Converting Enzyme } \\
\text { (ACE) (EC 3.4.15.1) (MEROPS ID: XM02-001) }\end{array}$ & ACE inhibitor & 245.1380 & 245.2670 \\
\hline 19 & 7594 & VG & $(11-12)$ & ACE inhibitor & $\begin{array}{l}\text { Inhibitor of Angiotensin-Converting Enzyme } \\
\text { (ACE) (EC 3.4.15.1) (MEROPS ID: XM02-001) }\end{array}$ & ACE inhibitor & 174.0890 & 174.1850 \\
\hline 20 & 7594 & VG & $(125-126)$ & ACE inhibitor & $\begin{array}{l}\text { Inhibitor of Angiotensin-Converting Enzyme } \\
\text { (ACE) (EC 3.4.15.1) (MEROPS ID: XM02-001) }\end{array}$ & ACE inhibitor & 174.0890 & 174.1850 \\
\hline 21 & 7625 & PG & $(46-47)$ & ACE inhibitor & $\begin{array}{l}\text { Inhibitor of Angiotensin-Converting Enzyme } \\
\text { (ACE) (EC 3.4.15.1) (MEROPS ID: M02-001) }\end{array}$ & ACE inhibitor & 172.0730 & 172.1690 \\
\hline 22 & 7827 & IE & $(89-90)$ & ACE inhibitor & & ACE inhibitor & 260.1260 & 260.2760 \\
\hline 23 & 7829 & VE & $(161-162)$ & ACE inhibitor & $\begin{array}{l}\text { Inhibitor of Angiotensin-Converting Enzyme } \\
\text { (ACE) (EC 3.4.15.1) (MEROPS ID: XM02-001) }\end{array}$ & ACE inhibitor & 246.1100 & 246.2490 \\
\hline 24 & 8224 & VY & $(195-196)$ & antioxidative peptide & free radical scavenging & antioxidative & 280.1310 & 280.3030 \\
\hline 25 & 8323 & IL & $(36-37)$ & $\begin{array}{l}\text { Glucose uptake stimulating } \\
\text { peptide }\end{array}$ & Glucose uptake stimulating & stimulating & 244.1680 & 244.3200 \\
\hline 26 & 8525 & IA & $(100-101)$ & $\begin{array}{l}\text { dipeptidyl peptidase IV } \\
\text { inhibitor (DPP IV inhibitor) }\end{array}$ & $\begin{array}{l}\text { Inhibitor of Dipeptidyl Peptidase IV (EC 3.4.14.5) } \\
\text { (MEROPS ID: S09.003) }\end{array}$ & $\begin{array}{l}\text { dipeptidyl peptidase } \\
\text { IV inhibitor }\end{array}$ & 202.1210 & 202.2390 \\
\hline 27 & 8526 & RA & $(135-136)$ & $\begin{array}{l}\text { dipeptidyl peptidase IV } \\
\text { inhibitor (DPP IV inhibitor) }\end{array}$ & $\begin{array}{l}\text { Inhibitor of Dipeptidyl Peptidase IV (EC 3.4.14.5) } \\
\text { (MEROPS ID: S09.003) }\end{array}$ & $\begin{array}{l}\text { dipeptidyl peptidase } \\
\text { IV inhibitor }\end{array}$ & 245.1380 & 245.2670 \\
\hline 28 & 8526 & RA & (193-194) & $\begin{array}{l}\text { dipeptidyl peptidase IV } \\
\text { inhibitor (DPP IV inhibitor) }\end{array}$ & $\begin{array}{l}\text { Inhibitor of Dipeptidyl Peptidase IV (EC 3.4.14.5) } \\
\text { (MEROPS ID: S09.003) }\end{array}$ & $\begin{array}{l}\text { dipeptidyl peptidase } \\
\text { IV inhibitor }\end{array}$ & 245.1380 & 245.2670 \\
\hline 29 & 8560 & SL & (78-79) & $\begin{array}{l}\text { dipeptidyl peptidase IV } \\
\text { inhibitor (DPP IV inhibitor) }\end{array}$ & $\begin{array}{l}\text { Inhibitor of Dipeptidyl Peptidase IV (EC 3.4.14.5) } \\
\text { (MEROPS ID: S09.003) }\end{array}$ & $\begin{array}{l}\text { dipeptidyl peptidase } \\
\text { IV inhibitor }\end{array}$ & 218.1160 & 218.2400 \\
\hline 30 & 8638 & PL & (106-107) & $\begin{array}{l}\text { dipeptidyl peptidase IV } \\
\text { inhibitor (DPP IV inhibitor) }\end{array}$ & $\begin{array}{l}\text { Inhibitor of Dipeptidyl Peptidase IV (EC 3.4.14.5) } \\
\text { (MEROPS ID: S09.003) }\end{array}$ & $\begin{array}{l}\text { dipeptidyl peptidase } \\
\text { IV inhibitor }\end{array}$ & 228.1360 & 228.2770 \\
\hline 31 & 8685 & WT & (68-69) & $\begin{array}{l}\text { dipeptidyl peptidase IV } \\
\text { inhibitor (DPP IV inhibitor) }\end{array}$ & $\begin{array}{l}\text { Inhibitor of Dipeptidyl Peptidase IV (EC 3.4.14.5) } \\
\text { (MEROPS ID: S09.003) }\end{array}$ & $\begin{array}{l}\text { dipeptidyl peptidase } \\
\text { IV inhibitor }\end{array}$ & 305.1260 & 305.3180 \\
\hline 32 & 8802 & IL & $(36-37)$ & $\begin{array}{l}\text { dipeptidyl peptidase IV } \\
\text { inhibitor (DPP IV inhibitor) }\end{array}$ & $\begin{array}{l}\text { Inhibitor of Dipeptidyl Peptidase IV (EC 3.4.14.5) } \\
\text { (MEROPS ID: S09.003) }\end{array}$ & $\begin{array}{l}\text { dipeptidyl peptidase } \\
\text { IV inhibitor }\end{array}$ & 244.1680 & 244.3200 \\
\hline
\end{tabular}


Table A49. Cont.

\begin{tabular}{|c|c|c|c|c|c|c|c|c|}
\hline No. & $\begin{array}{l}\text { Peptide } \\
\text { ID }\end{array}$ & Sequence & Location & Name & Function & Activity & $\begin{array}{l}\text { Monoisotopic } \\
\text { Mass }\end{array}$ & $\begin{array}{l}\text { Chemical } \\
\text { Mass }\end{array}$ \\
\hline 33 & 8805 & IQ & (159-160) & $\begin{array}{l}\text { dipeptidyl peptidase IV } \\
\text { inhibitor (DPP IV inhibitor) }\end{array}$ & $\begin{array}{l}\text { Inhibitor of Dipeptidyl Peptidase IV (EC 3.4.14.5) } \\
\text { (MEROPS ID: S09.003) }\end{array}$ & $\begin{array}{l}\text { dipeptidyl peptidase } \\
\text { IV inhibitor }\end{array}$ & 259.1420 & 259.2910 \\
\hline 34 & 8855 & PG & $(46-47)$ & $\begin{array}{l}\text { dipeptidyl peptidase IV } \\
\text { inhibitor (DPP IV inhibitor) }\end{array}$ & $\begin{array}{l}\text { Inhibitor of Dipeptidyl Peptidase IV (EC 3.4.14.5) } \\
\text { (MEROPS ID: S09.003) }\end{array}$ & $\begin{array}{l}\text { dipeptidyl peptidase } \\
\text { IV inhibitor }\end{array}$ & 172.0730 & 172.1690 \\
\hline 35 & 8858 & PK & $(180-181)$ & $\begin{array}{l}\text { dipeptidyl peptidase IV } \\
\text { inhibitor (DPP IV inhibitor) }\end{array}$ & $\begin{array}{l}\text { Inhibitor of Dipeptidyl Peptidase IV (EC 3.4.14.5) } \\
\text { (MEROPS ID: S09.003) }\end{array}$ & $\begin{array}{l}\text { dipeptidyl peptidase } \\
\text { IV inhibitor }\end{array}$ & 243.1460 & 243.2910 \\
\hline 36 & 8882 & RG & $(200-201)$ & $\begin{array}{l}\text { dipeptidyl peptidase IV } \\
\text { inhibitor (DPP IV inhibitor) }\end{array}$ & $\begin{array}{l}\text { Inhibitor of Dipeptidyl Peptidase IV (EC 3.4.14.5) } \\
\text { (MEROPS ID: S09.003) }\end{array}$ & $\begin{array}{l}\text { dipeptidyl peptidase } \\
\text { IV inhibitor }\end{array}$ & 231.1220 & 231.2400 \\
\hline 37 & 8886 & RL & $(138-139)$ & $\begin{array}{l}\text { dipeptidyl peptidase IV } \\
\text { inhibitor (DPP IV inhibitor) }\end{array}$ & $\begin{array}{l}\text { Inhibitor of Dipeptidyl Peptidase IV (EC 3.4.14.5) } \\
\text { (MEROPS ID: S09.003) }\end{array}$ & $\begin{array}{l}\text { dipeptidyl peptidase } \\
\text { IV inhibitor }\end{array}$ & 287.1850 & 287.3480 \\
\hline 38 & 8886 & RL & $(165-166)$ & $\begin{array}{l}\text { dipeptidyl peptidase IV } \\
\text { inhibitor (DPP IV inhibitor) }\end{array}$ & $\begin{array}{l}\text { Inhibitor of Dipeptidyl Peptidase IV (EC 3.4.14.5) } \\
\text { (MEROPS ID: S09.003) }\end{array}$ & $\begin{array}{l}\text { dipeptidyl peptidase } \\
\text { IV inhibitor }\end{array}$ & 287.1850 & 287.3480 \\
\hline 39 & 8894 & SK & $(149-150)$ & $\begin{array}{l}\text { dipeptidyl peptidase IV } \\
\text { inhibitor (DPP IV inhibitor) }\end{array}$ & $\begin{array}{l}\text { Inhibitor of Dipeptidyl Peptidase IV (EC 3.4.14.5) } \\
\text { (MEROPS ID: S09.003) }\end{array}$ & $\begin{array}{l}\text { dipeptidyl peptidase } \\
\text { IV inhibitor }\end{array}$ & 233.1260 & 233.2540 \\
\hline 40 & 8916 & VE & $(161-162)$ & $\begin{array}{l}\text { dipeptidyl peptidase IV } \\
\text { inhibitor (DPP IV inhibitor) }\end{array}$ & $\begin{array}{l}\text { Inhibitor of Dipeptidyl Peptidase IV (EC 3.4.14.5) } \\
\text { (MEROPS ID: S09.003) }\end{array}$ & $\begin{array}{l}\text { dipeptidyl peptidase } \\
\text { IV inhibitor }\end{array}$ & 246.1100 & 246.2490 \\
\hline 41 & 8917 & VF & $(128-129)$ & $\begin{array}{l}\text { dipeptidyl peptidase IV } \\
\text { inhibitor (DPP IV inhibitor) }\end{array}$ & $\begin{array}{l}\text { Inhibitor of Dipeptidyl Peptidase IV (EC 3.4.14.5) } \\
\text { (MEROPS ID: S09.003) }\end{array}$ & $\begin{array}{l}\text { dipeptidyl peptidase } \\
\text { IV inhibitor }\end{array}$ & 264.1360 & 264.3100 \\
\hline 42 & 8918 & VG & $(11-12)$ & $\begin{array}{l}\text { dipeptidyl peptidase IV } \\
\text { inhibitor (DPP IV inhibitor) }\end{array}$ & $\begin{array}{l}\text { Inhibitor of Dipeptidyl Peptidase IV (EC 3.4.14.5) } \\
\text { (MEROPS ID: S09.003) }\end{array}$ & $\begin{array}{l}\text { dipeptidyl peptidase } \\
\text { IV inhibitor }\end{array}$ & 174.0890 & 174.1850 \\
\hline 43 & 8918 & VG & $(125-126)$ & $\begin{array}{l}\text { dipeptidyl peptidase IV } \\
\text { inhibitor (DPP IV inhibitor) }\end{array}$ & $\begin{array}{l}\text { Inhibitor of Dipeptidyl Peptidase IV (EC 3.4.14.5) } \\
\text { (MEROPS ID: S09.003) }\end{array}$ & $\begin{array}{l}\text { dipeptidyl peptidase } \\
\text { IV inhibitor }\end{array}$ & 174.0890 & 174.1850 \\
\hline 44 & 8921 & VK & $(17-18)$ & $\begin{array}{l}\text { dipeptidyl peptidase IV } \\
\text { inhibitor (DPP IV inhibitor) }\end{array}$ & $\begin{array}{l}\text { Inhibitor of Dipeptidyl Peptidase IV (EC 3.4.14.5) } \\
\text { (MEROPS ID: S09.003) }\end{array}$ & $\begin{array}{l}\text { dipeptidyl peptidase } \\
\text { IV inhibitor }\end{array}$ & 245.1620 & 245.3070 \\
\hline 45 & 8927 & VT & $(115-116)$ & $\begin{array}{l}\text { dipeptidyl peptidase IV } \\
\text { inhibitor (DPP IV inhibitor) }\end{array}$ & $\begin{array}{l}\text { Inhibitor of Dipeptidyl Peptidase IV (EC 3.4.14.5) } \\
\text { (MEROPS ID: S09.003) }\end{array}$ & $\begin{array}{l}\text { dipeptidyl peptidase } \\
\text { IV inhibitor }\end{array}$ & 218.1150 & 218.2380 \\
\hline 46 & 8929 & VY & $(195-196)$ & $\begin{array}{l}\text { dipeptidyl peptidase IV } \\
\text { inhibitor (DPP IV inhibitor) }\end{array}$ & $\begin{array}{l}\text { Inhibitor of Dipeptidyl Peptidase IV (EC 3.4.14.5) } \\
\text { (MEROPS ID: S09.003) }\end{array}$ & $\begin{array}{l}\text { dipeptidyl peptidase } \\
\text { IV inhibitor }\end{array}$ & 280.1310 & 280.3030 \\
\hline 47 & 9079 & IL & $(36-37)$ & ACE inhibitor & $\begin{array}{l}\text { Inhibitor of Angiotensin-Converting Enzyme } \\
\text { (ACE) (EC 3.4.15.1) (MEROPS ID: XM02-001) }\end{array}$ & ACE inhibitor & 244.1680 & 244.3200 \\
\hline
\end{tabular}


Table A50. $A_{E}, D H_{t}, W, B_{E}$ and $V$ values from RubisCO of Halophila stipulacea. In silico enzymatic cleavage carried out by using pepsin (pH $>2$ ).

\begin{tabular}{llllll}
\hline $\begin{array}{l}\mathbf{D H}(\mathbf{\%}) \\
\mathbf{7 0 . 7 3 1 7}\end{array}$ & & & & & \\
\hline No. & Activity & $A_{\boldsymbol{E}}$ & $\boldsymbol{W}$ & $\boldsymbol{B}_{\boldsymbol{E}}$ & $\boldsymbol{V}$ \\
\hline 1 & regulating & 0.0049 & 0.3356 & 0 & \\
2 & dipeptidyl peptidase IV inhibitor & 0.1165 & 0.1791 & $9.8559287499226 \mathrm{E}-5$ & 0.45689549540936 \\
3 & ACE inhibitor & 0.0777 & 0.1334 & 0.002215755283035 & 0.082804687193409 \\
4 & antithrombotic & 0.0049 & 0.5052 & 0 & \\
5 & antiamnestic & 0.0049 & 0.5052 & 0 & 0 \\
6 & activating ubiquitin-mediated proteolysis & 0.0097 & 0.6644 & 0 & \\
7 & antioxidative & 0.0049 & 0.0673 & 0 & \\
8 & stimulating & 0.0049 & 0.1441 & 0 & \\
\hline
\end{tabular}

Table A51. Bioactive peptides from RubisCO of Halophila stipulacea. In silico enzymatic cleavage was carried out by using cocolysin.

\begin{tabular}{|c|c|c|c|c|c|c|c|c|}
\hline No. & $\begin{array}{l}\text { Peptide } \\
\text { ID }\end{array}$ & Sequence & Location & Name & Function & Activity & $\begin{array}{l}\text { Monoisotopic } \\
\text { Mass }\end{array}$ & $\begin{array}{l}\text { Chemica } \\
\text { Mass }\end{array}$ \\
\hline 1 & 3522 & IPP & $(144-146)$ & $\begin{array}{l}\text { ACE inhibitor (from bovine } \\
\text { b-CN) }\end{array}$ & & ACE inhibitor & 325.1880 & 325.3940 \\
\hline 2 & 3666 & YP & $(105-106)$ & ACE inhibitor & $\begin{array}{l}\text { Inhibitor of Angiotensin-Converting Enzyme } \\
\text { (ACE) (EC 3.4.15.1) (MEROPS ID: XM02-001) }\end{array}$ & ACE inhibitor & 278.1150 & 278.2870 \\
\hline 3 & 7600 & AG & $(53-54)$ & ACE inhibitor & $\begin{array}{l}\text { Inhibitor of Angiotensin-Converting Enzyme } \\
\text { (ACE) (EC 3.4.15.1) (MEROPS ID: XM02-001) }\end{array}$ & ACE inhibitor & 146.0580 & 146.1310 \\
\hline 4 & 7605 & FG & $(129-130)$ & ACE inhibitor & $\begin{array}{l}\text { Inhibitor of Angiotensin-Converting Enzyme } \\
\text { (ACE) (EC 3.4.15.1) (MEROPS ID: XM02-001) }\end{array}$ & ACE inhibitor & 222.0890 & 222.2290 \\
\hline 5 & 7619 & LG & $(182-183)$ & ACE inhibitor & $\begin{array}{l}\text { Inhibitor of Angiotensin-converting enzyme (EC } \\
\text { 3.4.15.1) (MEROPS ID: XM02-001) }\end{array}$ & ACE inhibitor & 188.1050 & 188.2120 \\
\hline 6 & 7697 & YK & $(20-21)$ & ACE inhibitor from wakame & & ACE inhibitor & 309.1570 & 309.3440 \\
\hline 7 & 8521 & YP & $(105-106)$ & $\begin{array}{l}\text { dipeptidyl peptidase IV } \\
\text { inhibitor (DPP IV inhibitor) }\end{array}$ & $\begin{array}{l}\text { Inhibitor of Dipeptidyl Peptidase IV (EC 3.4.14.5) } \\
\text { (MEROPS ID: S09.003) }\end{array}$ & $\begin{array}{l}\text { dipeptidyl peptidase } \\
\text { IV inhibitor }\end{array}$ & 278.1150 & 278.2870 \\
\hline 8 & 8760 & AG & $(53-54)$ & $\begin{array}{l}\text { dipeptidyl peptidase IV } \\
\text { inhibitor (DPP IV inhibitor) }\end{array}$ & $\begin{array}{l}\text { Inhibitor of Dipeptidyl Peptidase IV (EC 3.4.14.5) } \\
\text { (MEROPS ID: S09.003) }\end{array}$ & $\begin{array}{l}\text { dipeptidyl peptidase } \\
\text { IV inhibitor }\end{array}$ & 146.0580 & 146.1310 \\
\hline 9 & 8764 & $\mathrm{AV}$ & $(56-57)$ & $\begin{array}{l}\text { dipeptidyl peptidase IV } \\
\text { inhibitor (DPP IV inhibitor) }\end{array}$ & $\begin{array}{l}\text { Inhibitor of Dipeptidyl Peptidase IV (EC 3.4.14.5) } \\
\text { (MEROPS ID: S09.003) }\end{array}$ & $\begin{array}{l}\text { dipeptidyl peptidase } \\
\text { IV inhibitor }\end{array}$ & 188.1050 & 188.2120 \\
\hline 10 & 8764 & $\mathrm{AV}$ & $(194-195)$ & $\begin{array}{l}\text { dipeptidyl peptidase IV } \\
\text { inhibitor (DPP IV inhibitor) }\end{array}$ & $\begin{array}{l}\text { Inhibitor of Dipeptidyl Peptidase IV (EC 3.4.14.5) } \\
\text { (MEROPS ID: S09.003) }\end{array}$ & $\begin{array}{l}\text { dipeptidyl peptidase } \\
\text { IV inhibitor }\end{array}$ & 188.1050 & 188.2120 \\
\hline 11 & 8779 & FQ & $(13-14)$ & $\begin{array}{l}\text { dipeptidyl peptidase IV } \\
\text { inhibitor (DPP IV inhibitor) }\end{array}$ & $\begin{array}{l}\text { Inhibitor of Dipeptidyl Peptidase IV (EC 3.4.14.5) } \\
\text { (MEROPS ID: S09.003) }\end{array}$ & $\begin{array}{l}\text { dipeptidyl peptidase } \\
\text { IV inhibitor }\end{array}$ & 293.1260 & 293.3080 \\
\hline
\end{tabular}


Table A51. Cont.

\begin{tabular}{|c|c|c|c|c|c|c|c|c|}
\hline No. & $\begin{array}{l}\text { Peptide } \\
\text { ID }\end{array}$ & Sequence & Location & Name & Function & Activity & $\begin{array}{l}\text { Monoisotopic } \\
\text { Mass }\end{array}$ & $\begin{array}{l}\text { Chemical } \\
\text { Mass }\end{array}$ \\
\hline 12 & 8824 & LT & $(22-23)$ & $\begin{array}{l}\text { dipeptidyl peptidase IV } \\
\text { inhibitor (DPP IV inhibitor) }\end{array}$ & $\begin{array}{l}\text { Inhibitor of Dipeptidyl Peptidase IV (EC 3.4.14.5) } \\
\text { (MEROPS ID: S09.003) }\end{array}$ & $\begin{array}{l}\text { dipeptidyl peptidase } \\
\text { IV inhibitor }\end{array}$ & 232.1310 & 232.2650 \\
\hline 13 & 8937 & $\mathrm{YH}$ & $(87-88)$ & $\begin{array}{l}\text { dipeptidyl peptidase IV } \\
\text { inhibitor (DPP IV inhibitor) }\end{array}$ & $\begin{array}{l}\text { Inhibitor of Dipeptidyl Peptidase IV (EC 3.4.14.5) } \\
\text { (MEROPS ID: S09.003) }\end{array}$ & $\begin{array}{l}\text { dipeptidyl peptidase } \\
\text { IV inhibitor }\end{array}$ & 318.1210 & 318.3120 \\
\hline 14 & 8939 & YK & $(20-21)$ & $\begin{array}{l}\text { dipeptidyl peptidase IV } \\
\text { inhibitor (DPP IV inhibitor) }\end{array}$ & $\begin{array}{l}\text { Inhibitor of Dipeptidyl Peptidase IV (EC 3.4.14.5) } \\
\text { (MEROPS ID: S09.003) }\end{array}$ & $\begin{array}{l}\text { dipeptidyl peptidase } \\
\text { IV inhibitor }\end{array}$ & 309.1570 & 309.3440 \\
\hline 15 & 8946 & YV & $(102-103)$ & $\begin{array}{l}\text { dipeptidyl peptidase IV } \\
\text { inhibitor (DPP IV inhibitor) }\end{array}$ & $\begin{array}{l}\text { Inhibitor of Dipeptidyl Peptidase IV (EC 3.4.14.5) } \\
\text { (MEROPS ID: S09.003) }\end{array}$ & $\begin{array}{l}\text { dipeptidyl peptidase } \\
\text { IV inhibitor }\end{array}$ & 280.1310 & 280.3030 \\
\hline 16 & 8951 & $\mathrm{AV}$ & $(56-57)$ & ACE inhibitor & $\begin{array}{l}\text { Inhibitor of Angiotensin-Converting Enzyme } \\
\text { (ACE) (EC 3.4.15.1) (MEROPS ID: XM02-001) }\end{array}$ & ACE inhibitor & 188.1050 & 188.2120 \\
\hline 17 & 8951 & AV & $(194-195)$ & ACE inhibitor & $\begin{array}{l}\text { Inhibitor of Angiotensin-Converting Enzyme } \\
\text { (ACE) (EC 3.4.15.1) (MEROPS ID: XM02-001) }\end{array}$ & ACE inhibitor & 188.1050 & 188.2120 \\
\hline 18 & 9076 & FQ & $(13-14)$ & ACE inhibitor & $\begin{array}{l}\text { Inhibitor of Angiotensin-Converting Enzyme } \\
\text { (ACE) (EC 3.4.15.1) (MEROPS ID: XM02-001) }\end{array}$ & ACE inhibitor & 293.1260 & 293.3080 \\
\hline 19 & 9077 & YV & $(102-103)$ & ACE inhibitor & $\begin{array}{l}\text { Inhibitor of Angiotensin-Converting Enzyme } \\
\text { (ACE) (EC 3.4.15.1) (MEROPS ID: XM02-001) }\end{array}$ & ACE inhibitor & 280.1310 & 280.3030 \\
\hline 20 & 9087 & YH & $(87-88)$ & ACE inhibitor & $\begin{array}{l}\text { Inhibitor of Angiotensin-Converting Enzyme } \\
\text { (ACE) (EC 3.4.15.1) (MEROPS ID: XM02-001) }\end{array}$ & ACE inhibitor & 318.1210 & 318.3120 \\
\hline 21 & 9213 & LR & $(134-135)$ & ACE inhibitor & $\begin{array}{l}\text { Inhibitor of Angiotensin-Converting Enzyme } \\
\text { (ACE) (EC 3.4.15.1) (MEROPS ID: M02-001) }\end{array}$ & ACE inhibitor & 287.1850 & 287.3480 \\
\hline 22 & 9213 & LR & $(137-138)$ & ACE inhibitor & $\begin{array}{l}\text { Inhibitor of Angiotensin-Converting Enzyme } \\
\text { (ACE) (EC 3.4.15.1) (MEROPS ID: M02-001) }\end{array}$ & ACE inhibitor & 287.1850 & 287.3480 \\
\hline 23 & 9213 & LR & $(142-143)$ & ACE inhibitor & $\begin{array}{l}\text { Inhibitor of Angiotensin-Converting Enzyme } \\
\text { (ACE) (EC 3.4.15.1) (MEROPS ID: M02-001) }\end{array}$ & ACE inhibitor & 287.1850 & 287.3480 \\
\hline
\end{tabular}

Table A52. $A_{E}, D H_{t}, W, B_{E}$ and $V$ values from RubisCO of Halophila stipulacea. In silico enzymatic cleavage was carried out by using cocolysin.

\begin{tabular}{llllll}
\hline $\begin{array}{l}\mathrm{DH} \\
\mathbf{3 0 . 2 4 3 9} \mathbf{( \% )}\end{array}$ & & & & & \\
\hline No. & Activity & $A_{E}$ & $W$ & $\boldsymbol{B}_{E}$ & $\boldsymbol{V}$ \\
\hline 1 & ACE inhibitor & 0.0680 & 0.1167 & 0.0021410562742961 & 0.080013120769247 \\
2 & dipeptidyl peptidase IV inhibitor & 0.0437 & 0.0672 & $1.5313466662583 \mathrm{E}-6$ & 0.0070989290961449 \\
\hline
\end{tabular}


Table A53. Bioactive peptides from RubisCO of Halophila stipulacea. In silico enzymatic cleavage was carried out by using subtilisin

\begin{tabular}{|c|c|c|c|c|c|c|c|c|}
\hline No. & $\begin{array}{l}\text { Peptide } \\
\text { ID }\end{array}$ & Sequence & Location & Name & Function & Activity & $\begin{array}{l}\text { Monoisotopic } \\
\text { Mass }\end{array}$ & $\begin{array}{l}\text { Chemical } \\
\text { Mass }\end{array}$ \\
\hline 1 & 3257 & RL & $(138-139)$ & beta-lactokinin & $\begin{array}{l}\text { Inhibitor of Angiotensin-Converting } \\
\text { Enzyme (ACE) (EC 3.4.15.1) (MEROPS } \\
\text { ID: XM02-001) }\end{array}$ & ACE inhibitor & 287.1850 & 287.3480 \\
\hline 2 & 3384 & VF & $(128-129)$ & ACE inhibitor & $\begin{array}{l}\text { Inhibitor of Angiotensin-Converting } \\
\text { Enzyme (ACE) (EC 3.4.15.1) (MEROPS } \\
\text { ID: XM02-001) }\end{array}$ & ACE inhibitor & 264.1360 & 264.3100 \\
\hline 3 & 3486 & VW & $(71-72)$ & ACE inhibitor from sake lees & $\begin{array}{l}\text { Inhibitor of Angiotensin-Converting } \\
\text { Enzyme (ACE) (EC 3.4.15.1) (MEROPS } \\
\text { ID: XM02-001) }\end{array}$ & ACE inhibitor & 303.1470 & 303.3460 \\
\hline 4 & 3492 & VY & $(195-196)$ & ACE inhibitor from sake & $\begin{array}{l}\text { Inhibitor of Angiotensin-Converting } \\
\text { Enzyme (ACE) (EC 3.4.15.1) (MEROPS } \\
\text { ID: XM02-001) }\end{array}$ & ACE inhibitor & 280.1310 & 280.3030 \\
\hline 5 & 3546 & VAY & $(103-105)$ & ACE inhibitor & $\begin{array}{l}\text { Inhibitor of Angiotensin-Converting } \\
\text { Enzyme (ACE) (EC 3.4.15.1) (MEROPS } \\
\text { ID: XM02-001) }\end{array}$ & ACE inhibitor & 351.1680 & 351.3820 \\
\hline 6 & 7513 & PL & $(106-107)$ & $\begin{array}{l}\text { ACE inhibitor from Alaskan } \\
\text { pollack skin }\end{array}$ & $\begin{array}{l}\text { Inhibitor of Angiotensin-converting } \\
\text { enzyme (EC 3.4.15.1) (MEROPS ID: } \\
\text { XM02-001) }\end{array}$ & ACE inhibitor & 228.1360 & 228.2770 \\
\hline 7 & 7591 & GF & $(130-131)$ & ACE inhibitor & $\begin{array}{l}\text { Inhibitor of Angiotensin-Converting } \\
\text { Enzyme (ACE) (EC 3.4.15.1) (MEROPS } \\
\text { ID: XM02-001) }\end{array}$ & ACE inhibitor & 222.0890 & 222.2290 \\
\hline 8 & 7599 & GL & $(183-184)$ & ACE inhibitor & $\begin{array}{l}\text { Inhibitor of Angiotensin-converting } \\
\text { enzyme (EC 3.4.15.1) (MEROPS ID: } \\
\text { XM02-001) }\end{array}$ & ACE inhibitor & 188.1050 & 188.2120 \\
\hline 9 & 7693 & KL & $(21-22)$ & ACE inhibitor from wakame & & ACE inhibitor & 259.1780 & 259.3340 \\
\hline 10 & 8219 & TY & $(23-24)$ & antioxidative peptide & & antioxidative & 282.1100 & 282.2750 \\
\hline 11 & 8224 & VY & $(195-196)$ & antioxidative peptide & free radical scavenging & antioxidative & 280.1310 & 280.3030 \\
\hline 12 & 8461 & VW & $(71-72)$ & $\begin{array}{l}\text { Antioxidant peptide from } \\
\text { marine bivalve (Mactra } \\
\text { veneriformis) }\end{array}$ & Antioxidant & antioxidative & 303.1470 & 303.3460 \\
\hline 13 & 8561 & GL & $(183-184)$ & $\begin{array}{l}\text { dipeptidyl peptidase IV } \\
\text { inhibitor (DPP IV inhibitor) }\end{array}$ & $\begin{array}{l}\text { Inhibitor of Dipeptidyl Peptidase IV } \\
\text { (EC 3.4.14.5) (MEROPS ID: S09.003) }\end{array}$ & $\begin{array}{l}\text { dipeptidyl peptidase } \\
\text { IV inhibitor }\end{array}$ & 188.1050 & 188.2120 \\
\hline 14 & 8638 & PL & $(106-107)$ & $\begin{array}{l}\text { dipeptidyl peptidase IV } \\
\text { inhibitor (DPP IV inhibitor) }\end{array}$ & $\begin{array}{l}\text { Inhibitor of Dipeptidyl Peptidase IV } \\
\text { (EC 3.4.14.5) (MEROPS ID: S09.003) }\end{array}$ & $\begin{array}{l}\text { dipeptidyl peptidase } \\
\text { IV inhibitor }\end{array}$ & 228.1360 & 228.2770 \\
\hline 15 & 8782 & GF & $(130-131)$ & $\begin{array}{l}\text { dipeptidyl peptidase IV } \\
\text { inhibitor (DPP IV inhibitor) }\end{array}$ & $\begin{array}{l}\text { Inhibitor of Dipeptidyl Peptidase IV } \\
\text { (EC 3.4.14.5) (MEROPS ID: S09.003) }\end{array}$ & $\begin{array}{l}\text { dipeptidyl peptidase } \\
\text { IV inhibitor }\end{array}$ & 222.0890 & 222.2290 \\
\hline
\end{tabular}


Table A53. Cont.

\begin{tabular}{|c|c|c|c|c|c|c|c|c|}
\hline No. & $\begin{array}{l}\text { Peptide } \\
\text { ID }\end{array}$ & Sequence & Location & Name & Function & Activity & $\begin{array}{l}\text { Monoisotopic } \\
\text { Mass }\end{array}$ & $\begin{array}{l}\text { Chemical } \\
\text { Mass }\end{array}$ \\
\hline 16 & 8886 & RL & $(138-139)$ & $\begin{array}{l}\text { dipeptidyl peptidase IV } \\
\text { inhibitor (DPP IV inhibitor) }\end{array}$ & $\begin{array}{l}\text { Inhibitor of Dipeptidyl Peptidase IV } \\
\text { (EC 3.4.14.5) (MEROPS ID: S09.003) }\end{array}$ & $\begin{array}{l}\text { dipeptidyl peptidase } \\
\text { IV inhibitor }\end{array}$ & 287.1850 & 287.3480 \\
\hline 17 & 8910 & TS & $(77-78)$ & $\begin{array}{l}\text { dipeptidyl peptidase IV } \\
\text { inhibitor (DPP IV inhibitor) }\end{array}$ & $\begin{array}{l}\text { Inhibitor of Dipeptidyl Peptidase IV } \\
\text { (EC 3.4.14.5) (MEROPS ID: S09.003) }\end{array}$ & $\begin{array}{l}\text { dipeptidyl peptidase } \\
\text { IV inhibitor }\end{array}$ & 206.0790 & 206.1850 \\
\hline 18 & 8910 & TS & $(120-121)$ & $\begin{array}{l}\text { dipeptidyl peptidase IV } \\
\text { inhibitor (DPP IV inhibitor) }\end{array}$ & $\begin{array}{l}\text { Inhibitor of Dipeptidyl Peptidase IV } \\
\text { (EC 3.4.14.5) (MEROPS ID: S09.003) }\end{array}$ & $\begin{array}{l}\text { dipeptidyl peptidase } \\
\text { IV inhibitor }\end{array}$ & 206.0790 & 206.1850 \\
\hline 19 & 8911 & $\mathrm{TT}$ & $(69-70)$ & $\begin{array}{l}\text { dipeptidyl peptidase IV } \\
\text { inhibitor (DPP IV inhibitor) }\end{array}$ & $\begin{array}{l}\text { Inhibitor of Dipeptidyl Peptidase IV } \\
\text { (EC 3.4.14.5) (MEROPS ID: S09.003) }\end{array}$ & $\begin{array}{l}\text { dipeptidyl peptidase } \\
\text { IV inhibitor }\end{array}$ & 220.0940 & 220.2100 \\
\hline 20 & 8914 & TY & $(23-24)$ & $\begin{array}{l}\text { dipeptidyl peptidase IV } \\
\text { inhibitor (DPP IV inhibitor) }\end{array}$ & $\begin{array}{l}\text { Inhibitor of Dipeptidyl Peptidase IV } \\
\text { (EC 3.4.14.5) (MEROPS ID: S09.003) }\end{array}$ & $\begin{array}{l}\text { dipeptidyl peptidase } \\
\text { IV inhibitor }\end{array}$ & 282.1100 & 282.2750 \\
\hline 21 & 8917 & VF & $(128-129)$ & $\begin{array}{l}\text { dipeptidyl peptidase IV } \\
\text { inhibitor (DPP IV inhibitor) }\end{array}$ & $\begin{array}{l}\text { Inhibitor of Dipeptidyl Peptidase IV } \\
\text { (EC 3.4.14.5) (MEROPS ID: S09.003) }\end{array}$ & $\begin{array}{l}\text { dipeptidyl peptidase } \\
\text { IV inhibitor }\end{array}$ & 264.1360 & 264.3100 \\
\hline 22 & 8926 & VS & $(42-43)$ & $\begin{array}{l}\text { dipeptidyl peptidase IV } \\
\text { inhibitor (DPP IV inhibitor) }\end{array}$ & $\begin{array}{l}\text { Inhibitor of Dipeptidyl Peptidase IV } \\
\text { (EC 3.4.14.5) (MEROPS ID: S09.003) }\end{array}$ & $\begin{array}{l}\text { dipeptidyl peptidase } \\
\text { IV inhibitor }\end{array}$ & 204.1000 & 204.2130 \\
\hline 23 & 8928 & VW & $(71-72)$ & $\begin{array}{l}\text { dipeptidyl peptidase IV } \\
\text { inhibitor (DPP IV inhibitor) }\end{array}$ & $\begin{array}{l}\text { Inhibitor of Dipeptidyl Peptidase IV } \\
\text { (EC 3.4.14.5) (MEROPS ID: S09.003) }\end{array}$ & $\begin{array}{l}\text { dipeptidyl peptidase } \\
\text { IV inhibitor }\end{array}$ & 303.1470 & 303.3460 \\
\hline 24 & 8929 & VY & $(195-196)$ & $\begin{array}{l}\text { dipeptidyl peptidase IV } \\
\text { inhibitor (DPP IV inhibitor) }\end{array}$ & $\begin{array}{l}\text { Inhibitor of Dipeptidyl Peptidase IV } \\
\text { (EC 3.4.14.5) (MEROPS ID: S09.003) }\end{array}$ & $\begin{array}{l}\text { dipeptidyl peptidase } \\
\text { IV inhibitor }\end{array}$ & 280.1310 & 280.3030 \\
\hline 25 & 9071 & IAY & $(100-102)$ & ACE inhibitor & $\begin{array}{l}\text { Inhibitor of Angiotensin-Converting } \\
\text { Enzyme (ACE) (EC 3.4.15.1) (MEROPS } \\
\text { ID: M02-001) }\end{array}$ & ACE inhibitor & 365.1840 & 365.4090 \\
\hline 26 & 9074 & DF & $(204-205)$ & ACE inhibitor & $\begin{array}{l}\text { Inhibitor of Angiotensin-Converting } \\
\text { Enzyme (ACE) (EC 3.4.15.1) (MEROPS } \\
\text { ID: XM02-001) }\end{array}$ & ACE inhibitor & 280.0949 & 280.2660 \\
\hline
\end{tabular}

Table A54. $A_{E}, D H_{t}, W, B_{E}$ and $V$ values from RubisCO of Halophila stipulacea. In silico enzymatic cleavage was carried out by using subtilisin.

\begin{tabular}{llllll}
\hline $\begin{array}{l}\mathrm{DH} \\
\mathbf{2 9} \mathbf{( \% )}\end{array}$ & & & & \\
\hline No. & Activity & $A_{E}$ & $W$ & $\boldsymbol{B}_{E}$ & $\boldsymbol{V}$ \\
\hline 1 & ACE inhibitor & 0.0534 & 0.0917 & 0.0055038387628308 & 0.20568320455268 \\
2 & antioxidative & 0.0146 & 0.2005 & 0 & 0 \\
3 & dipeptidyl peptidase IV inhibitor & 0.0583 & 0.0896 & $1.8563339357632 \mathrm{E}-6$ & 0.0086054864513139 \\
\hline
\end{tabular}


Table A55. Bioactive peptides from RubisCO of Halophila stipulacea. In silico enzymatic cleavage was carried out by using V-8 protease (Glutamyl endopeptidase).

\begin{tabular}{|c|c|c|c|c|c|c|c|c|}
\hline No. & $\begin{array}{l}\text { Peptide } \\
\text { ID }\end{array}$ & Sequence & Location & Name & Function & Activity & $\begin{array}{l}\text { Monoisotopic } \\
\text { Mass }\end{array}$ & $\begin{array}{l}\text { Chemical } \\
\text { Mass }\end{array}$ \\
\hline 1 & 8898 & TD & $(34-35)$ & $\begin{array}{l}\text { dipeptidyl peptidase IV } \\
\text { inhibitor (DPP IV inhibitor) }\end{array}$ & $\begin{array}{l}\text { Inhibitor of Dipeptidyl Peptidase IV } \\
\text { (EC 3.4.14.5) (MEROPS ID: S09.003) }\end{array}$ & $\begin{array}{l}\text { dipeptidyl peptidase } \\
\text { IV inhibitor }\end{array}$ & 234.0739 & 234.1940 \\
\hline 2 & 8934 & $\mathrm{YE}$ & $(29-30)$ & $\begin{array}{l}\text { dipeptidyl peptidase IV } \\
\text { inhibitor (DPP IV inhibitor) }\end{array}$ & $\begin{array}{l}\text { Inhibitor of Dipeptidyl Peptidase IV } \\
\text { (EC 3.4.14.5) (MEROPS ID: S09.003) }\end{array}$ & $\begin{array}{l}\text { dipeptidyl peptidase } \\
\text { IV inhibitor }\end{array}$ & 310.1050 & 310.2860 \\
\hline 3 & 9078 & YE & $(29-30)$ & ACE inhibitor & $\begin{array}{l}\text { Inhibitor of Angiotensin-Converting } \\
\text { Enzyme (ACE) (EC 3.4.15.1) (MEROPS } \\
\text { ID: XM02-001) }\end{array}$ & ACE inhibitor & 310.1050 & 310.2860 \\
\hline
\end{tabular}

Table A56. $A_{E}, D H_{t}, W, B_{E}$ and $V$ values from RubisCO of Halophila stipulacea. In silico enzymatic cleavage was carried out by using V-8 protease (Glutamyl endopeptidase).

\begin{tabular}{llllll}
\hline $\begin{array}{l}\mathrm{DH}(\%) \\
\mathbf{1 1 . 7 0 7 3}\end{array}$ & & & & \\
\hline No. & Activity & $\boldsymbol{A}_{\boldsymbol{E}}$ & $\boldsymbol{W}$ & $\boldsymbol{B}_{\boldsymbol{E}}$ & $\boldsymbol{V}$ \\
\hline 1 & dipeptidyl peptidase IV inhibitor & 0.0097 & 0.0149 & 0 & 0 \\
2 & ACE inhibitor & 0.0049 & 0.0084 & $7.6943555746376 \mathrm{E}-6$ & 0.0002875447082947 \\
\hline
\end{tabular}




\section{References}

1. Lipkin, Y. Halophila stipulacea, a review of a successful immigration. Aquat. Bot. 1975, 1, 203-215. [CrossRef]

2. Fritsch, C. Uber die Auffindung einer marinen Hydrocharidee im Mittelmeer. Verh. Zool. Bot. Ges. Wien 1895, 45, 104-106.

3. Guiry, M.D.; Guiry, G.M. AlgaeBase. World-wide electronic publication, National University of Ireland, Galway. Available online: http://www.algaebase.org (accessed on 3 February 2018).

4. Duarte, C. The future of seagrass meadows. Environ. Conserv. 2002, 29, 129-206. [CrossRef]

5. Willette, D.A.; Ambrose, R.F. Effects of the invasive seagrass Halophila stipulacea on the native seagrass, Syringodium filiforme, and associated fish and epibiota communities in the Eastern Caribbean. Aquat. Bot. 2012, 103, 74-82. [CrossRef]

6. Van Tussenbroek, B.I.; Van Katwijk, M.M.; Bouma, T.J.; Van der Heide, T.; Govers, L.L.; Leuven, R.S.E.W. Non-native seagrass Halophila stipulacea forms dense mats under eutrophic conditions in the Caribbean. J. Sea Res. 2016, 115, 1-5. [CrossRef]

7. Cavas, L.; Pohnert, G. The potential of Caulerpa spp. for biotechnological and pharmacological applications. In Seaweeds and Their Role in Globally Changing Environments; Seckbach, J., Einav, R., Israel, A., Eds.; Springer: Berlin, Germany, 2010; pp. 385-397. ISBN 978-90-481-8568-9.

8. Mollo, E.; Cimino, G.; Ghiselin, M.T. Alien biomolecules: A new challenge for natural product chemists. Biol. Invasions 2015, 17, 941-950. [CrossRef]

9. Hartmann, E.M.; Durighello, E.; Pible, O.; Nogales, B.; Beltrametti, F.; Bosch, R.; Christie-Oleza, J.A.; Armengaud, J. Proteomics meets blue biotechnology: A wealth of novelties and opportunities. Mar. Genom. 2014, 17, 35-42. [CrossRef]

10. Tu, M.; Cheng, S.; Lu, W.; Du, M. Advancement and prospects of bioinformatics analysis for studying bioactive peptides from food-derived protein: Sequence, structure, and functions. TrAC Trends Anal. Chem. 2018, 105, 7-17. [CrossRef]

11. Sánchez, A.; Vázquez, A. Bioactive peptides: A review. Food Qual. Saf. 2017, 1, 29-46. [CrossRef]

12. Minkiewicz, P.; Dziuba, J.; Iwaniak, A.; Dziuba, M.; Darewicz, M. BIOPEP database and other programs for processing bioactive peptide sequences. J. AOAC Int. 2008, 91, 965-980.

13. Agirbasli, Z.; Cavas, L. In silico evaluation of bioactive peptides from the green algae Caulerpa. J. Appl. Phycol. 2017, 29, 1635-1646. [CrossRef]

14. Admassu, H.; Gasmalla, M.A.; Yang, R.; Zhao, W. Bioactive Peptides Derived from Seaweed Protein and Their Health Benefits: Antihypertensive, Antioxidant, and Antidiabetic Properties. J. Food Sci. 2018, 83, 6-16. [CrossRef] [PubMed]

15. Barbosa, E.A.; Oliveira, A.; Plácido, A.; Socodato, R.; Portugal, C.C.; Mafud, A.C.; Ombredane, A.S.; Moreira, D.C.; Vale, N.; Bessa, L.J.; et al. Structure and function of a novel antioxidant peptide from the skin of tropical frogs. Free Radic. Biol. Med. 2018, 115, 68-79. [CrossRef] [PubMed]

16. Ji, C.; Han, J.; Zhang, J.; Hu, J.; Fu, Y.; Qi, H.; Yu, C. Omics-prediction of bioactive peptides from the edible cyanobacterium Arthrospira platensis proteome. J. Sci. Food Agric. 2018, 98, 984-990. [CrossRef] [PubMed]

17. Wang, Z.; Cui, Y.; Liu, P.; Zhao, Y.; Wang, L.; Liu, Y.; Xie, J. Small Peptides Isolated from Enzymatic Hydrolyzate of Fermented Soybean Meal Promote Endothelium-Independent Vasorelaxation and ACE Inhibition. J. Agric. Food Chem. 2017, 65, 10844-10850. [CrossRef] [PubMed]

18. Zhao, Y.; Li, B.; Dong, S.; Liu, Z.; Zhao, X.; Wang, J.; Zeng, M. A novel ACE inhibitory peptide isolated from Acaudina molpadioidea hydrolysate. Peptides 2009, 30, 1028-1033. [CrossRef]

19. Udenigwe, C.C.; Gong, M.; Wu, S. In silico analysis of the large and small subunits of cereal RubisCO as precursors of cryptic bioactive peptides. Process Biochem. 2013, 48, 1794-1799. [CrossRef]

20. Nielsen, S.D.; Beverly, R.L.; Qu, Y.; Dallas, D.C. Milk bioactive peptide database: A comprehensive database of milk protein-derived bioactive peptides and novel visualization. Food Chem. 2017, 232, 673-682. [CrossRef]

21. Daliry, E.B.M.; Oh, D.H.; Lee, B.H. Bioactive peptides. Foods 2017, 6, 32. [CrossRef]

22. Guan, H.; Diao, X.; Jiang, F.; Han, J.; Kong, B. The enzymatic hydrolysis of soy protein isolate by Corolase PP under high hydrostatic pressure and its effect on bioactivity and characteristics of hydrolysates. Food Chem. 2018, 245, 89-96. [CrossRef]

23. Borgia, J.A.; Fields, G.B. Chemical synthesis of proteins. Trends Biotechnol. 2000, 18, 243-251. [CrossRef] 
24. Brown, L.; Pingitore, E.V.; Mozzi, F.; Saavedra, L.M.; Villegas, J.; Hebert, E. Lactic acid bacteria as cell factories for the generation of bioactive peptides. Protein Pept. Lett. 2017, 24, 146-155. [CrossRef] [PubMed]

25. Agrawal, H.; Joshi, R.; Gupta, M. Isolation and characterisation of enzymatic hydrolysed peptides with antioxidant activities from green tender sorghum. LWT Food Sci. Technol. 2017, 84, 608-616. [CrossRef]

26. Wang, Z.; Zhang, X. Isolation and identification of anti-proliferative peptides from Spirulina platensis using three-step hydrolysis. J. Sci. Food Agric. 2017, 97, 918-922. [CrossRef] [PubMed]

27. Connolly, A.; O’keeffe, M.B.; Nongonierma, A.B.; Piggott, C.O.; FitzGerald, R.J. Isolation of peptides from a novel brewers spent grain protein isolate with potential to modulate glycaemic response. Int. J. Food Sci. Technol. 2017, 52, 146-153. [CrossRef]

28. Wang, G.; Li, X.; Wang, Z. APD3: The antimicrobial peptide database as a tool for research and education. Nucleic Acids Res. 2016, 44, D1087-D1093. [CrossRef]

29. Shtatland, T.; Guettler, D.; Kossodo, M.; Pivovarov, M.; Weissleder, R. PepBank-a database of peptides based on sequence text mining and public peptide data sources. BMC Bioinform. 2007, 8, 280. [CrossRef]

30. Udenigwe, C.C.; Okolie, C.L.; Qian, H.; Ohanenye, I.C.; Agyei, D.; Aluko, R.E. Ribulose-1, 5-bisphosphate carboxylase as a sustainable and promising plant source of bioactive peptides for food applications. Trends Food Sci. Tech. 2017, 69, 74-82. [CrossRef]

31. Trovaslet, M.; Kapel, R.; Ravallec-Plé, R.; Mouni, F.; Clarisse, M.; Faille, C.; Dhulster, P.; Guillochon, D.; Vercaigne-Marko, D. Secretagogue and bacteriostatic active fractions derived from a peptic hydro-lysate of alfalfa RubisCO small purified subunit. J. Sci. Food Agric. 2007, 87, 534-540. [CrossRef]

32. Je, J.Y.; Cho, Y.S.; Gong, M.; Udenigwe, C.C. Dipeptide Phe-Cys derived from in silico thermolysin-hydrolysed RubisCO large subunit suppresses oxidative stress in cultured human hepatocytes. Food Chem. 2015, 171, 287-291. [CrossRef]

33. Bitam, F.; Ciavatta, M.L.; Carbone, M.; Manzo, E.; Mollo, E.; Gavagnin, M. Chemical analysis of flavonoid constituents of the seagrass Halophila stipulacea: First finding of malonylated derivatives in marine phanerogams. Biochem. Syst. Ecol. 2010, 38, 686-690. [CrossRef]

34. Artimo, P.; Jonnalagedda, M.; Arnold, K.; Baratin, D.; Csardi, G.; de Castro, E.; Duvaud, S.; Flegel, V.; Fortier, A.; Gasteiger, E.; et al. ExPASy: SIB bioinformatics resource portal. Nucleic Acids Res. 2012, 40, W597-W603. [CrossRef] [PubMed]

35. Dziuba, J.; Iwaniak, A.; Minkiewicz, P. Computer-aided characteristics of proteins as potential precursors of bioactive peptides. Polimery 2003, 48, 50-53. [CrossRef]

36. Minkiewicz, P.; Dziuba, J.; Michalska, J. Bovine meat proteins as potential precursors of biologically active peptides-a computational study based on the BIOPEP database. Food Sci. Technol. Int. 2011, 17, $39-45$. [CrossRef] [PubMed]

37. Gasteiger, E.; Hoogland, C.; Gattiker, A.; Duvaud, S.; Wilkins, M.R.; Appel, R.D.; Bairoch, A. Protein identification and analysis tools on the ExPASy server. In the Proteomics Protocols Handbook; Walker, J.M., Ed.; Humana Press Inc.: Totowa, NJ, USA, 2005; pp. 571-607.

38. Expasy. Available online: https://web.expasy.org/protparam/ (accessed on 8 January 2018).

39. Verdecchia, P.; Angeli, F.; Mazzotta, G.; Gentile, G.; Reboldi, G. The renin angiotensin system in the development of cardiovascular disease: Role of aliskiren in risk reduction. Vasc. Health Risk Manag. 2008, 4, 971. [CrossRef] [PubMed]

40. Lin, H.C.; Chou, S.T.; Chuang, M.Y.; Liao, T.Y.; Tsai, W.S.; Chiu, T.H. The effects of Caulerpa microphysa enzyme-digested extracts on ACE-inhibitory activity and in vitro anti-tumour properties. Food Chem. 2012, 134, 2235-2241. [CrossRef] [PubMed]

41. Sarmadi, B.H.; Ismail, A. Antioxidative peptides from food proteins: A review. Peptides 2010, 31, $1949-1956$. [CrossRef] [PubMed]

42. Barnett, A. DPP-4 inhibitors and their potential role in the management of type 2 diabetes. Int. J. Clin. Pract. 2006, 60, 1454-1470. [CrossRef]

43. Cheon, S.; Dean, M.; Chahrour, M. The ubiquitin proteasome pathway in neuropsychiatric disorders. Neurobiol. Learn. Mem. 2018. [CrossRef]

44. Layfield, R.; Cavey, J.R.; Lowe, J. Role of ubiquitin-mediated proteolysis in the pathogenesis of neurodegenerative disorders. Ageing Res. Rev. 2003, 2, 343-356. [CrossRef] 
45. Zenezini Chiozzi, R.; Capriotti, A.L.; Cavaliere, C.; La Barbera, G.; Piovesana, S.; Samperi, R.; Lagana, A. Purification and identification of endogenous antioxidant and ACE-inhibitory peptides from donkey milk by multidimentional liquid chromatography and nano HPLC-high resolution mass spectrometry. Anal. Bioanal. Chem. 2016, 408, 5657-5666. [CrossRef] [PubMed]

46. Tu, M.; Feng, L.; Wang, Z.; Qiao, M.; Shahidi, F.; Lu, W.; Du, M. Sequence analysis and molecular docking of antithrombotic peptides from casein hydrolysate by trypsin digestion. J. Funct. Foods 2017, 32, 313-323. [CrossRef]

47. Tu, M.; Wang, C.; Chen, C.; Zhang, R.; Liu, H.; Lu, W.; Jiang, L.; Du, M. Identification of a novel ACE-inhibitory peptide from casein and evaluation of the inhibitory mechanisms. Food Chem. 2018, 256, 98-104. [CrossRef] [PubMed]

48. Lafarga, T.; O'Connor, P.; Hayes, M. Identification of novel dipeptidyl peptidase-IV and angiotensin-Iconverting enzyme inhibitory peptides from meat proteins using in silico analysis. Peptides 2014, 59, $53-62$. [CrossRef] [PubMed]

49. Sayd, T.; Dufour, C.; Chambon, C.; Buffière, C.; Remond, D.; Santé-Lhoutellier, V. Combined in vivo and in silico approaches for predicting the release of bioactive peptides from meat digestion. Food Chem. 2018, 249, 111-118. [CrossRef] [PubMed]

50. Stephany, R.W. Hormones in meat: Different approaches in the EU and in the USA. Apmis 2001, 109, S357-S363. [CrossRef]

(C) 2019 by the authors. Licensee MDPI, Basel, Switzerland. This article is an open access article distributed under the terms and conditions of the Creative Commons Attribution (CC BY) license (http://creativecommons.org/licenses/by/4.0/). 